NBER WORKING PAPER SERIES

\title{
SPILLOVERS AT THE EXTREMES: \\ THE MACROPRUDENTIAL STANCE AND VULNERABILITY TO \\ THE GLOBAL FINANCIAL CYCLE
}

\author{
Anusha Chari \\ Karlye Dilts Stedman \\ Kristin Forbes \\ Working Paper 29670 \\ http://www.nber.org/papers/w29670 \\ NATIONAL BUREAU OF ECONOMIC RESEARCH \\ 1050 Massachusetts Avenue \\ Cambridge, MA 02138 \\ January 2022
}

Thanks to Chaitri Gulati for excellent research assistance and special thanks to Catherine Casanova, Ambrosio Cesa-Bianchi, Linda Goldberg, Luc Laeven, and two anonymous referees for detailed comments on the paper. Further thanks to seminar participants at the IMF and Federal Reserve Bank of Kansas City, and conference participants at the NBER-ISOM conference, the Barcelona GSE Summer Forum on Financial Shocks, Channels, and Macro Outcomes, and BIS/ BoE/ECB/IMF Spillovers conference for helpful comments and suggestions. This paper reflects the views and analysis of the authors and not any institutions with which they are affiliated. Author contact emails: Anusha_Chari@kenan-flagler.unc.edu, Karlye.Stedman@kc.frb.org, and kjforbes@mit.edu. The views expressed herein are those of the authors and do not necessarily reflect the views of the National Bureau of Economic Research.

NBER working papers are circulated for discussion and comment purposes. They have not been peer-reviewed or been subject to the review by the NBER Board of Directors that accompanies official NBER publications.

(C) 2022 by Anusha Chari, Karlye Dilts Stedman, and Kristin Forbes. All rights reserved. Short sections of text, not to exceed two paragraphs, may be quoted without explicit permission provided that full credit, including ( $)$ notice, is given to the source. 
Spillovers at the Extremes: The Macroprudential Stance and Vulnerability to the Global Financial Cycle

Anusha Chari, Karlye Dilts Stedman, and Kristin Forbes

NBER Working Paper No. 29670

January 2022

JEL No. E58,F3,G15,G28

\begin{abstract}
$\underline{\text { ABSTRACT }}$
The effects of macroprudential policy on portfolio flows vary considerably across the global financial cycle. A tighter ex-ante macroprudential stance amplifies the impact of global risk shocks on bond and equity flows, increasing outflows significantly more during risk-off episodes and increasing inflows significantly more during risk-on episodes. These amplification effects are more prominent at the "extremes," especially for extreme risk-off periods and for regulations that target specific risks instead of generalized cyclical buffers. This paper estimates these relationships using a policy-shocks approach that corrects for reverse causality by combining high-frequency risk measures with weekly data on portfolio investment and a new measure of macroprudential regulations that captures the intensity of policy stances. Overall, the results support a growing body of evidence that macroprudential regulation can reduce the volume and volatility of bank flows but shift risks in ways that aggravate vulnerabilities in other parts of the financial system.

Anusha Chari

Department of Economics, CB \#3305

University of North Carolina at Chapel Hill

Chapel Hill, NC 27599

and NBER

achari@unc.edu

Karlye Dilts Stedman

Federal Reserve Bank of Kansas City

1 Memorial Dr.

Kansas City, MO 64108

karlye.stedman@kc.frb.org

Kristin Forbes

MIT Sloan School of Management

100 Main Street, E62-416

Cambridge, MA 02142

and CEPR

and also NBER

kjforbes@mit.edu
\end{abstract}




\section{Introduction}

Countries around the world have used macroprudential policies more actively over the last decade to reduce the build-up of risks during good times and mitigate the amplification of shocks during bad times. A growing body of literature assesses these policies and finds some success in accomplishing specific domestic goals (such as moderating credit growth or foreign currency-denominated borrowing). However, they are less effective by other metrics (such as stabilizing cross-border capital flows). There is also growing evidence that macroprudential policies generate spillovers and leakages that shift risks outside the regulated banking sector-particularly to corporate bond markets and the broader "shadow" financial system (Ahnert et al., 2021; Avdjiev et al., 2020; Forbes, 2019). If the magnitude of these spillovers and leakages is large enough, and the corresponding risk exposure shifts to financial intermediaries that are more vulnerable to shocks, macroprudential regulations could undermine, rather than mitigate, financial sector vulnerabilities during certain periods. There is little systematic analysis, however, of what these spillovers and leakages imply over different phases of the global financial cycle.

Another rapidly growing body of literature examines extreme events in capital flows, returns, and global risk shocks, with a focus on the entire distribution of outcomes rather than average relationships that may pertain only to "normal" times (Bergant et al., 2020; Chari et al., 2020; Eguren-Martin et al., 2020; and Gelos et al., 2019). Some policies may have minimal impact during stable periods but are highly effective at mitigating vulnerabilities during extreme events (or just extreme adverse events). Macroprudential regulations could be one example; they could reduce extreme tail events but have little measurable impact during stable periods. The spillovers and leakages from tighter macroprudential policies may also be more critical during certain phases of the financial cycle if they shift financial intermediation to entities more vulnerable to extreme events. Therefore, assessing the effectiveness of macroprudential policies may require focusing on the distribution of outcomes - and not just on average effects or during stable periods.

This paper links these two recent bodies of literature and tests if a country's macroprudential stance affects the sensitivity of portfolio investment flows over the global financial cycle-which we characterize as shifts in global investor risk sentiment, broadly defined. It finds that tighter macroprudential regulations (adopted ex-ante) amplify the impact of risk shocks on bond and equity portfolio investment - increasing outflows during "risk-off" episodes and increasing inflows during "riskon" episodes. These amplification effects are usually moderate in magnitude and often insignificant at the mean of the risk distribution but increase at the extremes, especially for extreme risk-off periods. These effects are also larger and more significant for bond than equity flows and macroprudential tools targeting FX exposures and bank credit supply, but weaker for countercyclical policies (such as the Countercyclical Capital Buffer or CCyB). These results support evidence that some macroprudential regulations shift financial intermediation outside the regulated financial sector to portfolio investors more vulnerable to the global financial cycle. The findings do not imply that macroprudential regulations should be diluted or rolled back, as they may still provide significant benefits by improving the resilience of the domestic banking system. Instead, it is vital to consider the precise macroprudential tools, spillovers, leakages, and corresponding vulnerabilities when designing an optimal policy package.

This paper reaches these conclusions based on several related innovations in methodology and data not yet applied to this literature. First, we analyze the marginal effects of policy choices at different 
points in the risk distribution to test how relationships change across the global financial cycle. This methodology highlights how the standard practice of focusing on averages across the cycle can overlook highly consequential relationships that prevail during "extreme" periods. Second, we use high-frequency data to capture the sharp (and often short-lived) events targeted by macroprudential policy that are challenging to identify using standard data available at a quarterly (or annual) frequency; this is particularly important to study "extreme" movements. Third, we construct several new measures of macroprudential policy to capture the intensity of existing regulations. This measure of the macroprudential stance improves most work focusing on dummy variables of recent policy changes. Finally, we use a policy-shocks estimation approach to address concerns with reverse causality-a challenge for any study assessing the impact of macroprudential policy. This methodology can successfully identify and estimate the exogenous component of the macroprudential stance because of the other innovations in the paper: the higher frequency of the data and the more accurate measure of the intensity of the macroprudential stance.

The paper begins with a summary of related literature, focusing on recent theoretical and empirical work showing how macroprudential regulations can increase the resilience of banks to adverse shocks but shift financial intermediation to other segments of financial markets that are more sensitive to the global financial cycle. We also develop a simple example using bank and firm balance sheets to illustrate a potential channel through which tighter regulations could have minimal impact during small risk shocks. While rendering banks more resilient, however, other investors could become more vulnerable to significant risk-off events. This simple example shows how formal regression analysis focusing on mean outcomes could find statistically insignificant effects of macroprudential regulations on capital flows and fail to capture significant effects during extreme risk episodes. The thought experiment also shows how macroprudential regulations that target specific risks, rather than building generalized buffers, could generate more "risk shifting" to other financial intermediaries.

To test if a country's macroprudential stance affects its sensitivity to the global financial cycle, we create several new metrics and draw on alternative data sources less common in this literature. First, to measure a country's macroprudential stance, we construct new indices capturing the intensity of the country's existing regulations. These indices address two important shortcomings in much of the literature on macroprudential policy: ignoring the intensity of regulations and capturing recent policy changes (instead of the overall stance). Our measure combines different data sources, including two that capture the exact levels at which regulations are set. Second, to measure risk shocks, we focus on the Risk-on-Risk-off (RORO) measure of the global financial cycle developed in Chari, Dilts-Stedman, and Lundblad (2020). This measure captures variation in investor risk appetite by calculating the first principal component of the daily variation in advanced economy credit risk, equity market volatility, funding conditions, currencies, and gold. Finally, we use weekly EPFR data to measure portfolio flows, which captures how investors allocate funds (domestically and internationally) and separates flows into bonds and equities and the flow's currency denomination. This high-frequency data is vital to capture the relationship between high-frequency risk shocks and portfolio flows.

To analyze how macroprudential regulations affect portfolio flows' sensitivity to the global financial cycle, we begin by addressing an identification challenge in this literature: reverse causality. Reverse causality can arise if adjustments in the macroprudential stance occur in response to financial and 
macroeconomic developments linked to capital flows. To account for these endogenous forces, our baseline analysis builds on the literature on policy shocks to extract a measure of the macroprudential policy stance orthogonal to observables (as in Ahnert et al., 2021). This new measure of the macroprudential stance, estimated with a high degree of explanatory power, is critical to our identification strategy.

Next, we use this policy-shocks approach to confirm two earlier findings in the literature: risk-off (risk-on) shocks correspond to large and significant portfolio outflows (inflows), and tighter macroprudential regulations have small and insignificant effects on portfolio flows. When we interact the macroprudential stance and risk shocks, we find that the negative impact of risk shocks on portfolio flows is larger in countries with a tighter macroprudential stance. This suggests that macroprudential regulation in place at the time of a high-risk event could aggravate the impact of the shock, contrary to what we might have expected if tighter regulation moderates the build-up of risks during booms and moderates the unwinding of risk exposures during risk-off episodes. The magnitude of this estimated interaction effect, however, is small on average relative to the unconditional impact of the risk shock.

Therefore, we turn to the paper's primary focus: how the relationships between risk, the macroprudential stance, and portfolio allocation change across the global financial cycle. To capture these relationships, we focus on the marginal effects of a tighter ex-ante macroprudential stance at different points in the risk distribution. The results suggest that these relationships vary significantly across this distribution. Specifically, more stringent regulation increases bond and equity inflows during risk-on periods and increases bond and equity outflows during risk-off episodes. These amplification effects are substantial at the distribution extremes, particularly for risk-off shocks and bond flows. For example, a one standard deviation tighter (ex-ante) regulatory stance increases bond outflows during $99 \%$ risk-off events by $30 \%-96 \%$ relative to countries that initially had weaker macroprudential regulations (with the range reflecting different macroprudential measures). The effects during risk-on events are also meaningful, albeit about half as large (and of opposite sign) at the outer $1 \%$ of the risk distribution.

Do alternative macroprudential regulations generate these strong amplification effects at the extremes of the global financial cycle? To answer this, we repeat the analysis using five granular measures of the macroprudential stance: two specific tools that we can measure in magnitudes and are reasonably comparable across countries (the CCyB and LTV ratio) ${ }^{1}$ and three narrower groups of tools (for FX exposures, the demand for bank loans, and the supply of bank loans). The results show that LTV ratios and measures targeting FX and the supply of bank loans are more important drivers of the amplification effects of risk on bond flows than other measures (such as the CCyB). Sverges Riksbank (2012) explains the potency of LTV ratios by showing how tighter LTV ratios cause borrowers to shift from housing-backed loans to unsecured debt. Ahnert et al. (2021) demonstrate the power of FX-related measures, showing how these regulations can lead riskier borrowers to shift from obtaining FX loans from banks to selling FX bonds to non-bank financial intermediaries. In each case, the macroprudential regulations shift financial intermediation in ways that could increase sensitivity to risk shocks outside the banking sector. This series of results comparing the effects of different types of macroprudential

\footnotetext{
${ }^{1} \mathrm{CCyB}$ is the Countercyclical Capital Buffer, and LTV is Loan-to-Value.
} 
regulation also highlights the importance of including the intensity of the policies and not relying on dummy variables to capture policy changes. ${ }^{2}$

This paper also estimates several extensions to understand these relationships for different types of investment flows and countries. The main results and amplification effects are similar for equity and bond flows, albeit somewhat larger for bonds, especially at the extremes of the distribution. The main results, however, do not appear to be significantly different for advanced economies relative to emerging markets or US dollar investment flows relative to non-US dollar flows. The main results are also unchanged if we adjust for capital controls or drop the period of heightened volatility around the COVID19 pandemic.

Although this paper focuses on the bond and equity allocations of institutional investors, it is also helpful to understand whether these relationships between macroprudential regulation and risk shocks are similar for cross-border bond and equity flows and other types of international capital flows (such as bank flows). This extension is also helpful to place this paper's results in the context of the international economics literature on the drivers of capital flows. Therefore, the final section of this paper repeats the main analysis using IMF data on international capital flows. This international capital flow data captures a different aspect of investment than the EPFR data; it includes cross-border transactions (rather than investor portfolio allocation) and consists of a larger universe of investors (rather than just institutional investors). The international capital flow data also is only available at a quarterly frequency (compared to the weekly frequency in the main analysis) and covers additional types of capital flows than just equity and debt. Although the coefficient estimates are rarely significant, the key patterns using this alternative data generally support the main results despite these differences. Most significant are how the interactions between risk and macroprudential regulation change for banks relative to other types of international capital flows. A tighter macroprudential stance appears to amplify the impact of risk shocks on international bond and equity flows (as found for portfolio flows) but dampen the effect on bank flows, with both sets of relationships larger at the extremes. These results support arguments that macroprudential regulations may improve the resilience of bank flows to the global financial cycle but shift risks to other types of capital flows.

The remainder of the paper is as follows. Section 2 puts this analysis in the context of related literature and develops a simple example showing the channels by which certain regulations can shift vulnerability to risk shocks from banks to other financial intermediaries. Section 3 describes the key data used in the analysis, including several new measures of the macroprudential stance, the RORO measure of risk, and the portfolio investment data. Section 4 develops the policy shock methodology and then performs the principal analysis of the impact of risk, the macroprudential stance, and their interaction on bond flows on average and at different stages of the global financial cycle. This section also reports results using other estimation methodologies and more granular measures of the macroprudential stance. Section 5 reports several extensions: for equity flows, advanced versus emerging economies, portfolio

${ }^{2}$ For example, when LTV ratios are measured using the magnitude of the ratio, estimates of the interaction effects between risk and the macroprudential stance are significant, but when LTV ratios are measured based on dummy variables, the interaction effects become insignificant. 
flows in different currencies, capital controls, and additional sensitivity tests. Section 6 repeats the baseline analysis for lower-frequency international capital flows (including bank flows). Section 7 concludes.

\section{Previous Literature, Initial Evidence, and an Illustrative Example}

This section places the analysis in this paper in the broader literature, building on it to develop a simple example to illustrate the channels through which macroprudential regulation can have minimal impact during relatively stable periods but "shift risks" away from banks during extreme shocks.

\subsection{Previous Literature}

This paper builds on several areas of academic research: the use and effectiveness of macroprudential regulations, the spillovers, leakages, and unintended consequences of policy choices, and the distribution of outcomes.

After the 2008 Global Financial Crisis highlighted the importance of policies focused on the resilience of the broader financial system, and especially of mitigating the amplification of shocks across the economy, new literature began to explore the use and effectiveness of macroprudential regulations. ${ }^{3}$ This literature includes theoretical models of the optimal use of macroprudential policy (i.e., Bianchi and Mendoza, 2018; Brunnermeier et al., 2013; Claessens, 2015; and Engel, 2016) and empirical assessments of the effectiveness of various tools. This empirical literature (summarized in Araujo et al., 2020 and Forbes, 2021) generally finds that macroprudential policy can address specific vulnerabilities (such as reducing credit growth or FX exposures), provide somewhat more independence for monetary policy (i.e., Bergant et al., 2020), and possibly reduce the variance of growth (although at the expense of slightly slower short-term growth). The papers that assess whether macroprudential regulations affect capital flows generally find insignificant effects on the volume of flows but more robust evidence that they can affect the composition of flows (i.e., duration and type of capital flow). ${ }^{4}$

A more recent branch of this literature is beginning to examine the direct effects of macroprudential policies on their targets and the leakages to non-bank financial intermediation and spillovers to other countries (Agénor and da Silva, 2018; Avdjiev et al., 2016). ${ }^{5}$ For example, Ahnert et al. (2021) model how tighter FX regulations reduce cross-border bank flows and bank vulnerability to exchange rate movements (which correlate to risk shocks) but shift these vulnerabilities to investors as firms shift to non-bank sources of finance, such as issuing bonds. Similarly, Shin (2013) discusses how tighter macroprudential regulations increased corporate dollar-denominated debt financing. Sverges

\footnotetext{
${ }^{3}$ Macroprudential regulations (which cover the overall financial system) are distinct but closely related to microprudential regulations (which focus on the resilience of individual financial institutions) and capital controls (which focus on cross-border transactions).

${ }^{4}$ For example, see Ostry et al. (2012) and Forbes et al. (2015).

${ }^{5}$ Related work explores interactions between global risk perceptions and the spillovers from US monetary policy on credit conditions (Kalemli-Ozcan, 2020) and on international portfolio flows (Chari, Dilts-Stedman and Lundblad, 2021). Also see CGFS (2021) for a recent and thorough analysis of changes in international capital flows since the GFC, including the direct and spillover effects of macroprudential policy.
} 
Riksbank (2012) shows how tighter LTV ratios cause borrowers to shift from housing-backed loans to unsecured debt. Bengui and Bianchi (2018) model how tighter regulations reduce risk-taking in regulated sectors (i.e., banks), which leads investors to perceive the overall environment as safer and, in turn, resort to riskier activities and exposures. These papers suggest that although macroprudential regulations may yield an important benefit of increasing bank resilience, they may shift risky financial exposures to other types of investors or exposures that may be more sensitive to risk shocks. If these non-bank investors have high leverage, lower reserves, and/or less liquidity, they may be more likely to sell investments after adverse risk shocks and increase positions during risk-on shocks, thereby aggravating the effects of the global financial cycle. Similarly, if these non-bank investors are more likely to be forced to sell and unwind positions during risk-off shocks due to funding shocks from their investor base, this would further amplify the initial impact of the risk-off shock.

One limitation of most of this empirical work assessing the impact of macroprudential regulations, however, is that it assesses the average effects over the financial cycle using a linear framework. Macroprudential regulation might have minimal effects during "normal" periods but more potent effects "at the extremes," especially for portfolio allocation decisions and capital flows. For example, during risk-on episodes when borrowing costs are low, and leverage is high, macroprudential regulations may be more likely to bind by triggering limits (such as on high LTV mortgages) or increasing capital requirements (such as through a CCyB). These regulations could dampen the increase in leverage that traditionally builds during risk-on episodes and boosts asset prices (Bruno and Shin, 2015). The impact could be even more substantial during risk-off episodes, albeit in the opposite direction. Risk-off shocks, which cause asset price declines, can act as funding shocks and cause investors to reduce portfolio allocations, especially for riskier investments (Jotikasthira et al., 2012). Tighter regulations (stricter leverage and reserve requirements) could magnify these effects and generate a more abrupt sell-off that aggravates the price declines. Tighter regulations could magnify these effects if they shift more financial intermediation outside the banking system to entities with more leverage or otherwise more sensitive to these types of funding shocks. On the other hand, countries with tighter macroprudential regulations should have better-capitalized banks with stronger buffers to withstand risk-off shocks, especially if buffers are cyclically adjusted, reducing the amplification effects of risk-off shocks on bank lending. These relationships were difficult to test before the pandemic, however, as macroprudential tools had not been widely utilized across an entire financial cycle.

Although the academic literature has not yet addressed the potential interactions between risk and macroprudential regulations at different phases of the global financial cycle, there is a recent focus on the distribution of outcomes and how relationships may differ at the tails of the risk distribution. Earlier work focused on "disaster risk" and extreme negative tail events (such as Barro, 2009; Gabaix, 2012; Wachter, 2013; and Gourio, 2012), and more recent work has built on the "growth at risk" framework developed in Adrian et al. (2019). Gelos et al. (2019), Eguren-Martin et al. (2020), and Mano and Sgherri (2020) adopt the quantile regression framework used in this literature to estimate the impact of push and pull shocks (including risk shocks) on future quarterly capital flows in emerging markets. These papers find significant effects of these shocks on different parts of the capital flow distribution, especially on the tails. These papers also include some analysis of how various policies can moderate the impact of these shocks, but most find little impact of macroprudential regulations on the future distribution of capital flows. The one exception is Eguren-Martin et al. (2020), which finds evidence that tightening macroprudential policy 
can reduce the impact of push factors on capital flows-at-risk at the extremes. The proxies for macroprudential regulations in these papers are blunt, however, with dummy variables capturing any recent changes in any type of macroprudential policy. ${ }^{6}$ The two papers that go beyond dummy variables when assessing how macroprudential regulations may interact with risk are Bergant et al. (2020) and Eguren-Martin et al. (2020), although compared to our work, their measures are only rough proxies of intensity. ${ }^{7}$ They find that macroprudential regulations can significantly dampen GDP growth sensitivity to movements in the VIX and capital flow shocks, mainly by allowing countries more freedom to pursue countercyclical monetary policy.

A potentially more significant challenge in these papers examining the impact of different shocks across the risk distribution is that they use quarterly data, which may miss important relationships between risk shocks and portfolio allocations that occur at a higher frequency. Chari et al. (2020) is one exception that analyzes the relationship between risk shocks and capital flows across the distribution at a higher frequency, using weekly EPFR data on portfolio allocation for a subset of equity and bond investors. Although this data has some important differences to the international capital flow data used in the papers discussed above (differences discussed in more detail in Section 6), the results also suggest that risk shocks have very different effects on the distribution of future flows and returns. The focus in Chari et al. (2020) is not, however, on how these effects could be amplified or dampened by macroprudential regulations or any other policy tools.

Our analysis builds on this earlier work to assess how macroprudential regulation can interact with risk shocks to affect portfolio flows across the risk distribution. Using the higher frequency and more detailed EPFR data allows us to capture any effects of high-frequency risk shocks and investigate aspects of these relationships beyond the volume of flows (such as on flows in different currencies). By focusing on new and more disaggregated measures of the macroprudential stance, we can improve on past approaches by using a two-stage methodology that better adjusts for reverse causality. We can also delve deeper into how specific macroprudential tools affect investment flows. Finally, to better highlight the impact of macroprudential policy at different stages of the financial cycle, we focus on the marginal effects of different macroprudential stances on portfolio flows at different points in the risk distributionrather than on the average effects or quantile regressions that are the focus of most related work on risk shocks and the distribution of outcomes.

\footnotetext{
${ }^{6}$ For example, Gelos et al. (2019) and Mano and Sgherri (2020) measure macroprudential policy as a dummy indicating any net tightening or loosening in macroprudential tools in the Alam et al. (2020) database over the last quarter. Neither paper considers the underlying macroprudential stance.

${ }^{7}$ Eguren-Martin et al. (2020) measure the stance by accumulating dummies of any changes in macroprudential policy in the Cerutti et al. (2017) database, which includes a more limited set of tools, and Bergant et al. (2020) accumulate dummies of changes using the Alam et al. (2020) data. These approaches are closer to a macroprudential stance but suffer from the challenge discussed in Section 3.1. More specifically, some countries adjust policies more often, but by small amounts, such that they appear to have much tighter policy by this type of measure than an index that incorporates some measure of intensity instead of just the number of times a policy changed.
} 


\subsection{Potential Channels}

This literature review suggests several different channels through which tighter macroprudential regulations can make banks more resilient across the global financial cycle but shift risk in ways that increase the vulnerability of other segments of financial markets. This literature also highlights, however, the complexity of modeling these channels - especially given the multiple potential direct effects, leakages, and spillovers from different types of macroprudential regulations. For example, Breckenfelder and Ivashina (2021) show how tighter regulations on banks' leverage ratios made it more difficult for banks trading securities to support market liquidity during March 2020, thereby putting more pressure on mutual funds and aggravating the price effects of fire sales during this "risk-off" episode. Aramonte et al. (2021) take an even broader view on several ways in which non-bank financial intermediation can aggravate liquidity imbalances and generate larger price movements, especially in money market and bond funds. In contrast, Esrel (2021) focuses on the risks as intermediation shifts from banks to leveraged and syndicated loans from other sources, showing that more highly leveraged (and therefore riskier) borrowers are more likely to shift to these nonbank sources of financing.

A full model of these various channels is beyond the scope of this paper, but Appendix 1 sketches a simple partial-equilibrium example to motivate the key results found in the empirical analysis. This example shows how macroprudential regulations as tighter FX capital requirements or stricter CCyB regulations, have minimal effects on banks, firms, and investors in modest risk-off states but can have significant effects in extreme risk-off states. During these extreme risk-off states, macroprudential regulations can achieve the desired outcome of meaningfully increasing bank resilience (by allowing banks to avoid bankruptcy) but simultaneously make bond investors less resilient as firms shift their borrowing from banks to bond markets. Furthermore, this simple example shows how certain types of targeted regulations (such as on FX exposures) can lead bond investors to incur more significant losses if they create incentives for greater reductions in bank lending and more risk-shifting onto investor balance sheets. It is also straightforward to extend our simple examples to alternative regulations (such as tools targeting mortgage exposures) and markets (such as equity markets) that we consider in our empirical analysis more broadly.

\section{The Data}

This section discusses the primary data used in this paper: the macroprudential policy stance, the RORO measure of risk, the EPFR data on bond and equity flows, other control variables, and the resulting data set.

\subsection{The Macroprudential Policy Stance}

We construct several new measures of a country's macroprudential policy stance, combining updated data on countercyclical capital buffers (CCyBs) with different components of the IMF's Integrated Macroprudential Policy (iMaPP) database. To obtain the CCyB for a large set of countries, we combine information from the Bank of International Settlements (BIS) and the European Systemic Risk 
Board (ESRB). ${ }^{8}$ Both datasets provide details on when the CCyB was changed and the resulting buffer level set. These data have the important advantage of providing a quantitative measure of the stringency of the regulation that is comparable across countries. The data is also available through late 2020 and provides more timely information than other datasets. The disadvantage of this data is that it only incorporates one type of macroprudential regulation (building a cyclical reserve buffer in banks), and therefore does not capture other tools focusing on vulnerabilities in specific sectors (such as the housing market or foreign currency), which are important parts of the macroprudential toolkit in many countries.

The other main source of macroprudential data is the iMaPP database, described in Alam et al. (2019) and recently updated through end-2018. ${ }^{9}$ The iMaPP is the most comprehensive cross-country, time-series data on a broad set of macroprudential regulations available today. This database combines information from several pre-existing surveys with a new IMF annual survey and country-specific data to provide detailed information on a range of macroprudential tools for 134 countries monthly from 19902018. It groups these tools into 17 different types of policy instruments with subcategories. We can use these data to track macroprudential policies that focus on different sectors of the economy, such as the demand for credit, the supply of credit, and international exposures based on the transaction currency (i.e., limits on FX lending and FX positions). ${ }^{10}$ The database tracks when the tools are tightened or loosened using dummy variables for each measure. These dummies have the drawback, however, of only capturing when a regulation was changed, with no information on the overall intensity of the regulation or magnitude of the change. The sole exception is for loan-to-value (LTV) ratios, for which the database provides quantitative measures that allow a comparison of intensity across countries and time. ${ }^{11}$

Although the iMaPP data only report the instance of macroprudential adjustment (except LTV ratios) and not each country's overall macroprudential stance, it is possible to construct a proxy for the stance by aggregating the changes in each country's policies since 2000 - a year when the use of these tools was limited, so each country can be assumed to start from a similar, neutral stance. Adopting this approach (also used in Bergant et al., 2020 and Forbes, 2021), we construct a measure of each country's macroprudential policy stance each month. The resulting stances range from -7 to 72 across 72 countries, with a higher value indicating a tighter stance and a panel median of 0 and a mean of 2.3. Across the entire sample, China has the tightest stance (72), followed by South Korea (41), Russia, and Hong Kong (both at 40). Iceland has the loosest stance (-7), followed by India and Argentina (-6). Advanced Economies (AEs) used macroprudential policy less actively than Emerging Market and Developing

${ }^{8}$ The BIS data is available at: www.bis.org/bcbs/ccyb/ and the ESRB data at: www.esrb.europa.eu/national_policy/ccb/html/index.en.html. Both datasets were accessed as of 11/2020. If a country is not included in either database, we record the CCyB as 0 .

${ }^{9}$ Available at: https://www.elibrary-areaer.imf.org/Macroprudential/Pages/Home.aspx

${ }^{10}$ Policies targeting the demand for credit include limits based on debt-service to income and loan-to-value ratios. Policies targeting the supply of credit include reserve requirements, liquidity requirements, capital requirements, conservation buffers, the leverage ratio, capital surcharges for systemically important financial institutions, CCyBs, limits on credit growth, loan loss provisions, and loan restrictions. Policies targeting international exposures include capital requirements on FX-loans; limits on FX lending or rules or recommendations on FX loans; and limits on net or gross open FX positions, limits on FX exposures and FX funding, and currency mismatch regulations.

${ }^{11}$ Different countries can use different definitions and have different coverage for their LTV ratios, so that they are not directly comparable across countries - albeit still a better measure of relative intensities than dummy variables. 
Economies (EMDEs) and had a looser macroprudential stance on average, although the gap began to close by the end of the sample. The looser stance for AEs reflects their greater tendency to loosen more during recessions rather than a hesitation to tighten during stable times. ${ }^{12}$

Figure 1 (top panel) graphs the sample mean and median for the CCyB and this aggregated measure of each country's macroprudential stance at a quarterly frequency. The early 2000 s saw only a small degree of net tightening and no use of the CCyB so that on the eve of the 2008 Global Financial Crisis, countries had very loose macroprudential stances. Countries began to tighten macroprudential policy more frequently after 2010, and then the CCyB even more quickly after 2014, so that in 2018Q4, the mean stance was 15 tightenings and mean $\mathrm{CCyB}$ was $0.21 \%$. The data for the macroprudential stance ends in 2018, but the sharp decline in the CCyB in early 2020 captures the quick easing in this tool in response to COVID-19. The distribution of both these measures is asymmetric, however, with long right tails corresponding to lower median values (including a median $\mathrm{CCyB}$ of 0 throughout the sample). The difference between the mean and median of the macroprudential stance grows near the end of the sample, capturing a few countries tightening much more frequently.

While the average macroprudential stance has tightened over time, this masks important differences across countries. Forbes (2021) shows that this variation across countries has increased over time, a variation that could help identify any relationships between these policies and country resilience to global shocks. Forbes (2021) also shows, however, that some of these cross-country differences, especially near the end of the sample, reflect different approaches toward adjusting macroprudential policy rather than fundamentally different intensities of their stances. For example, China tends to make frequent but small adjustments to its macroprudential tools, which aggregate to many net tightenings and what appears to be a very tight macroprudential stance by this measure. In contrast, other countries (such as the UK) tend to adjust macroprudential policy less frequently but in larger increments, which results in what seems to be a significantly weaker stance.

Given the advantages and disadvantages of different macroprudential measures, especially the tradeoffs in capturing intensity, timeliness, and a range of tools, our baseline analysis will focus on four different measures of country-level macroprudential policy stances. ${ }^{13}$ Our first - and preferred - measure is an equally-weighted index of the CCyB (from the BIS and ESRB data), LTV ratio (from the iMaPP database), and FX macroprudential stance (calculated based on the iMaPP data using the aggregation procedure above) ${ }^{14}$ We scale all three index components by their standard deviations, and the LTV ratio is expressed as 100-LTV so that a higher value is a tighter stance (to correspond to the other indicators). This index has the important advantages of incorporating the two best intensity measures of

\footnotetext{
${ }^{12}$ For more information on these trends in macroprudential policy, see the updated dataset for Cerutti et al. (2017).

${ }^{13}$ We have also used several other definitions: a dummy equal to one if the country tightened policy at least five times, tightened more than the mean each quarter, or more than the mean/median plus one standard deviation. The key results are similar to the measures in our base case using the closest methodology (i.e., focusing more on the time-series dimension using an absolute cutoff or the cross-section dimension using a relative cutoff).

14 The FX macroprudential stance is the sum of the dummy variables measuring changes in macroprudential tools targeting international exposures, including capital requirements on FX-loans; limits on FX lending or rules or recommendations on FX loans; and limits on net or gross open FX positions, limits on FX exposures and FX funding, and currency mismatch regulations.
} 
macroprudential policy comparable across countries (the CCyB and LTV ratio) and incorporating adjustments to policy in 2020 after the spread of COVID-19 (in the CCyB). It also benefits from incorporating adjustments in three of the most widely used tools that target different risk exposures: countercyclical risk in banks, the housing sector, and foreign currency. The disadvantage is that the measure does not incorporate other tools that could be an important part of the macroprudential framework in certain countries.

Our second measure of the macroprudential stance includes only statistics that incorporate intensity and are most comparable across countries: the first principal component of the CCyB and LTV ratio. This measure has the advantage of "letting the data speak" to extract the macroprudential stance without forcing a weight on the different subcomponents. This measure also can capture changes that occurred after the COVID pandemic (through the CCyB) began. This measure has the disadvantage, however, of reflecting a narrower set of policies, as it does not include changes in FX regulations, which are an important part of the macroprudential toolkit for many emerging markets. ${ }^{15}$

Our final two measures of the macroprudential stance come from the cumulative measure of policy changes discussed above (in the top panel of Figure 1). Our third measure focuses on each country's macroprudential stance relative to other countries, calculated as a dummy equal to one if a country's macroprudential stance is tighter than the sample median. Finally, our fourth measure focuses on each country's stance on an absolute basis (instead of relative to other countries) and is simply a dummy variable equal to 1 if a country has tightened macroprudential policy more than once on net since $2000{ }^{16}$ Therefore, these two measures capture very different approaches to defining a "tight" macroprudential stance. The former defines "tight" relative to other countries and therefore may not capture the general tightening that occurred over time. By contrast, the latter defines "tight" relative to the time series and captures the general tightening later in the sample but misses many cross-country differences within this broader time trend.

The bottom of Figure 1 graphs the resulting four measures of the macroprudential policy stance that will be the baseline throughout this paper: the Broad Intensity Index (the equally weighted index of the CCyB, LTV, and FX measures), the Narrow Intensity Index (the principal component of the CCyB and LTV), the Country Relative Dummy (a dummy if the aggregate index is above the sample median) and the Time Relative Dummy (a dummy if the aggregate index is above one). The figure highlights the different concepts captured by each of these measures. The Intensity indices and Time Relative Dummy capture the general tightening in macroprudential stances over the 2010s. The indices that incorporate the CCyB capture the loosening during 2020. The Country Relative Dummy misses these time trends but has a consistent share of the sample defined as having a "tight" or "loose" macroprudential stance. In contrast,

\footnotetext{
${ }^{15}$ We have calculated a principal component that also includes changes in the macroprudential stance for FX exposure. The main results are basically the same as for the equally weighted index of the three measures. A principal component should not be calculated using two continuous measures and one based on dummy variables, however, so we focus on the equally weighted index when including the three tools.

${ }^{16}$ We use more than one tightening as the cutoff as it is between the sample mean (2) and median tightening (0), but at least requires more than one tightening to qualify as "tighter" policy.
} 
the Time Relative Dummy has most of the sample with a loose macroprudential stance at the start and a tight stance at the end of the sample.

\subsection{The RORO Measure of Risk}

An extensive literature has documented the impact of risk (as measured by the VIX) on capital flows and investment portfolios (i.e., Forbes and Warnock, 2012), and recent work has highlighted the benefits of measuring risk using a broader measure than the VIX (see Miranda-Agrippino and Rey, 2015 and Scheubel et al., 2019). We build on this literature and focus on a broader measure of risk calculated following the method developed in Chari et al. (2020). This method computes a risk-on/risk-off (RORO) index, which captures the realized variation in global investor risk appetite using the first principal component of a multi-faceted set of daily changes in several standardized asset market variables. More specifically, the index's components are normalized such that positive changes in the index imply risk-off behavior, and their respective historical standard deviations scale the normalized changes. Then the first principal component is extracted and used to compute the z-score, which serves as the RORO measure.

The RORO index comprises several series. To capture changes related to credit risk, it uses the change in the ICE BofA BBB Corporate Index Option-Adjusted Spread for the United States and the Euro Area, along with Moody's BAA corporate bond yield relative to that for 10-year Treasuries. To capture changes in risk aversion from advanced economy equity markets, it includes the additive inverse of total daily returns on the S\&P 500, STOXX 50, and MSCI Advanced Economies Index, along with associated changes in option implied volatilities from the VIX and the VSTOXX. To account for changes to funding liquidity, it uses the average daily change in the G-spread on 2-, 5-, and 10-year Treasuries, along with changes in the TED spread, the 3-month LIBOR-OIS spread, and the bid-ask spread on 3month Treasuries. Finally, the index includes the growth in the trade-weighted US Dollar Index against other advanced economies and the spot gold price change.

Figure 2 displays the time series of the resulting RORO index, which shows a sharp increase in the index around the 2008 GFC and 2020 COVID pandemic (as expected) and more moderate swings in risk-on and risk-off in other windows. The distribution is skewed with long tails toward risk-off, indicating that large risk-off events occur more frequently than large risk-on events. Chari et al. (2020) illustrate that adverse RORO shocks reduce median emerging market capital flows and returns and shift their distributions to the left, especially for the left tail (i.e., weaker flows and returns).

\subsection{The Portfolio Flow Data}

We focus on the Country Flows dataset from Emerging Portfolio Fund Research (EPFR) Global to assess the relationships between macroprudential regulations, risk shocks, and portfolio investment. This dataset has high-frequency information on portfolio investment in a large sample of countries. Specifically, EPFR Global publishes weekly portfolio investment flows by more than 14,000 equity funds and over 7,000 bond funds, with more than $\$ 8$ trillion of capital under management. The Country Flows dataset combines EPFR's Fund Flow data (which reports the amount of cash flowing into and out of investment funds) and the Country Weightings data (fund manager allocations to each market they invest 
in). ${ }^{17}$ Combining these two datasets allows us to track a large proportion of money flows into world equity and bond markets by portfolio investors (Jotikasthira, Lundblad, and Ramadorai, 2012). Moreover, because the country flows comprise the sum of fund-level aggregate re-allocations, they come cleansed of valuation effects and represent real quantities. Although this dataset does not focus on cross-border capital flows (as it includes domestically domiciled funds) and does not include all portfolio investors (such as sovereign wealth funds and hedge funds), the flows have significant predictive content for lower frequency, aggregate data on international portfolio flows (Koepke and Paetzold, 2020).

Using this EPFR data, we scale bond and equity flows in a given week $t$ by the holdings in the previous week, $t-1$. We also include the lag of the resulting scaled variable as a control in our benchmark specifications. The scaling and control for lagged flows ensure that larger countries with larger capital flows do not mechanically drive the analysis. The EPFR flows are winsorized at the $0.5 \%$ and $99.5 \%$ levels to prevent several large outliers (that appear to be errors) from driving the results.

\subsection{Policy Shocks, Other Control Variables, and Final Data Set}

In the first stage of our baseline analysis (Section 4.1), we estimate a country's macroprudential stance as a function of a large set of variables capturing the risks and vulnerabilities for financial stability that could cause policymakers to adjust macroprudential regulations. This list of eighteen variables draws from Cerutti et al. (2015, 2017), Cizel et al. (2019), and Ahnert et al. (2021), roughly divided into four groups: "Crisis", "Credit", "Growth", and other macro/institutional characteristics. Details on variable definitions, sources, and frequencies are in Appendix Table A.

The first set of variables, "Crisis" includes whether the country has had a crisis in the last 12 months (from Laeven and Valencia, 2020), a z-score of the distance to default in a country's banking sector (from the Global Financial Development Database), the number of countries in crisis and intensity of the financial crisis index over the last half year (based on Romer and Romer, 2019), and the number of countries in sovereign debt, currency, or banking crises (from Laeven and Valencia, 2020). The second set of variables, "Credit", includes the cross-border borrowing ratio (using IMF data on external claims and claims on public non-financial corporations), domestic credit growth (measured as the percent change in private credit as a share of GDP from the IMF's International Financial Statistics), and the growth in property prices (for real residential property prices from the BIS). The third set of variables, "Growth", includes real exchange rate appreciation (of broad exchange rate indices from Bruegel), forecast GDP growth (from the IMF's World Economic Outlook), inflation expectations as proxied by lagged year-onyear CPI inflation (from Haver), and real GDP growth (from Haver). Finally, the last set of variables includes other macro and institutional characteristics: financial openness (measured by the Chinn-Ito index described in Chinn and Ito, 2008), FX volatility (based on data from Haver), an index of institutional quality (based on the legal environment from the ICRG), the policy interest rate, the policy rate differential vis-à-vis the US federal funds rate, and a fixed exchange rate dummy (based on Ilzetzki et al., 2019).

\footnotetext{
${ }^{17}$ Since all funds do not report their allocations to all countries, the EPFR estimates some allocations. See Koepke
} and Paetzold (2020) for details on the EPFR data and how it compares to data on international capital flows. 
We use these variables to predict the macroprudential "policy shock", i.e., the orthogonal component of each of the four measures of the macroprudential stance developed in Section 3.1. Then, in our baseline analysis (discussed in the next section), we estimate regressions using these macroprudential shocks and a set of standard global/push and domestic/pull variables to understand portfolio flows. We build most closely on the push and pull variables used in Chari et al. (2020), which draws on the extensive literature on the determinants of capital flows. Details on variable definitions, sources, and frequencies are in Appendix Table B.

The push variables reflecting global conditions include the AE Monetary Stance and AE IP Growth, measured by the short-run shadow interest rate and growth in industrial production, respectively, for the four largest advanced economies. ${ }^{18}$ The shadow rate captures monetary policy changes that occur through changes in the policy interest rate and "unconventional" tools, such as quantitative easing. We also include year fixed effects to control for other slow-moving aspects of the business cycle and for changes to the mutual fund and ETF industries over time.

For the pull variables that capture country-specific conditions, we include the Exchange Rate (bilateral exchange rate with the US dollar), $i-i *$ (the interest rate differential with the US), Real Growth (domestic, quarterly, real GDP growth), and $F X$ Volatility (the volatility of the exchange rate over the past thirty days). We also include two slow-moving structural variables: Financial Openness (measured using the Chinn-Ito index) and Institutional Quality (measured using the ICRG index). Except for FX Volatility, all control variables enter as lagged values in the benchmark specification to account for simultaneity. Finally, all specifications include a country fixed effect.

Next, we combine the EPFR data with the macroprudential measures and other controls and exclude the United States, Japan, and Switzerland, as the relationships between risk shocks and capital flows that are the focus of this paper would likely differ for these safe-haven countries. ${ }^{19}$ These adjustments yield a sample of 65 countries, listed in Appendix Table C. Countries with all the data required to estimate our baseline regression with our preferred macroprudential measure (the Broad Intensity Index) are marked with an asterisk. Appendix Table D reports summary statistics for key variables in the baseline regression.

\section{The Macroprudential Stance and Risk: Bond Flows across the Global Financial Cycle}

This section begins by developing the methodology used as the baseline in this paper: a "policyshocks approach" that extracts the portion of the macroprudential stance that remains after accounting for observables. We focus on this methodology to address potential endogeneity between portfolio flows and a country's macroprudential stance. Then it uses the variables discussed in the last section to estimate how investors adjust their portfolios based on a country's macroprudential stance, the risk environment, and their interaction — on average and at different points in the risk distribution. Next, we compare the

${ }^{18}$ Advanced economy push variables are calculated as chained USD denominated GDP-weighted averages for the relevant variable for the US, Japan, UK and Euro area. The shadow rates are from Leo Krippner's website.

${ }^{19}$ A sensitivity test reported in Section 5.5 shows that including these safe havens does not change the key results. 
baseline results to standard OLS estimates that do not use a two-stage policy-shocks approach and then examine the impact of more granular macroprudential tools to understand which policies drive the key results. The section closes by summarizing these results.

\subsection{Empirical Methodology}

Any empirical assessment of the impact of macroprudential policies must address a perennial challenge in this literature; changes in the dependent variables could drive changes in macroprudential policy instead of vice versa. Namely, in the present analysis, a sharp increase in portfolio flows could raise concerns about domestic financial stability risks, leading policymakers to tighten macroprudential regulations. The resulting positive correlation between portfolio flows and the macroprudential stance would be amplified during large risk shocks when policymakers are likely to pay closer attention to large moves in portfolio flows. Most papers address the challenge of reverse causality by lagging their macroprudential policy measures, but this approach is unlikely to address endogeneity concerns fully (Forbes, 2021). To better address any potential issues from reverse causality, we extract exogenous macroprudential shocks as a proxy for the macroprudential policy stance. This approach builds on previous work in the macroeconomics literature assessing the impact of policy shocks, such as papers constructing exogenous fiscal policy shocks (Auerbach and Gorodnichenko, 2013), exogenous monetary policy shocks (Furceri, Lougani, and Zdzienicka, 2016), and exogenous FX regulation shocks (Ahnert et al., 2021).

More specifically, we begin by estimating a first-stage regression of the macroprudential stance (using our four indices from Section 3.2) on the groups of variables that could affect the implementation of macroprudential policies (from Section 3.4):

$$
\begin{gathered}
M P_{i t}=\alpha_{i}+\boldsymbol{\beta}_{\mathbf{1}} \text { Crisis }_{i t-1}+\boldsymbol{\beta}_{\mathbf{2}} \text { Credit }_{i t-1}+\boldsymbol{\beta}_{3} \text { Growth }_{i t-1}+\boldsymbol{\beta}_{\mathbf{4}} \text { Controls }_{i t-1}+\varepsilon_{i, t} \\
\widetilde{M P}_{i t}=M P_{i t}-\widehat{M P}_{i t}
\end{gathered}
$$

Appendix Table A (and the discussion in Section 3) provides more information on these variables. It is worth noting that equation (1) also includes country fixed effects to control for any country-specific, time-invariant factors that may affect a country's macroprudential stance. After estimating equation (1) with the full set of eighteen variables, we then use backward and forward inclusion to narrow down the set of explanatory variables. This process sequentially excludes explanatory variables that do not meet conventional levels of statistical significance (defined as a $10 \%$ threshold in the baseline). Then, the set of excluded variables is reintroduced one at a time to determine whether they meet the threshold when included in the more parsimonious set. This process continues until each excluded variable has been reintroduced for each such significant set of variables. ${ }^{20}$

\footnotetext{
${ }^{20} \mathrm{We}$ have also estimated this first-stage regression using several different approaches. First, we estimated the macroprudential policy shocks with no inclusion procedure (i.e., included the full set of 18 explanatory variables). Second, we used a stricter threshold for inclusion (i.e., using a 5\% threshold that results in a smaller set of explanatory variables). Third, we estimated the regression at a monthly frequency using average monthly values for relevant control variables (instead of using the higher frequency, end-of-period data in our baseline). None of these adjustments has a meaningful effect on the key results reported below.
} 
Next, we use the resulting subset of the variables in equation (1) to predict the macroprudential stance $\left(\widehat{M P}_{i t}\right)$, and then subtract this predicted value from the actual value to calculate the macroprudential policy shock $\left(\widetilde{M P}_{i t}\right)$ for each country (as in equation (2)). Figure 3 (top panel) shows the evolution of these estimated policy shocks averaged over time for the four different measures of the macroprudential stance. The bottom panel of Figure 3 also graphs the resulting mean, median and $90^{\text {th }}$ percentile overtime for this estimated policy shock based on our preferred measure of the macroprudential stance - the Broad Intensity Index. The figure shows the meaningful variation over time and the substantial cross-country variation at each date. This cross-country variation has increased over time, primarily due to countries that actively tighten their macroprudential policies.

This macroprudential policy shock $\left(\widetilde{M P}_{i t}\right)$ provides a more exogenous measure of a country's macroprudential stance in each period and is then used as the explanatory variable in the second stage regression:

$$
P I_{i t}=\alpha_{i}+\beta_{1} \widetilde{M P}_{i, t}+\beta_{2} R I S K_{t}+\beta_{3} \widetilde{M P}_{i, t} * R I S K_{t}+\boldsymbol{\gamma} \boldsymbol{P} \boldsymbol{U S} \boldsymbol{H}_{\boldsymbol{t}}+\boldsymbol{\delta} \boldsymbol{P} \boldsymbol{U} \boldsymbol{L} \boldsymbol{L}_{i, \boldsymbol{t}}+\delta_{t}+\varepsilon_{i, t} .(3)
$$

This baseline regression models portfolio flows as a function of the macroprudential policy shock (which proxies for a country's ex-ante macroprudential stance), global risk, the interaction between the macroprudential policy shock and risk, and other push/global and pull/local factors. ${ }^{21}$ Portfolio Investment $\left(P I_{i t}\right)$ measures portfolio flows into debt or equity for each country $i$ in week $t . R I S K_{t}$ is the risk-on, risk-off (RORO) measure (discussed above), with higher values indicating risk-off states. $\alpha_{i}$ captures country fixed effects and $\delta_{t}$ is year fixed effects, with the latter included to control for slowmoving business cycle effects, slower-moving changes in global financial conditions, and any structural changes (such as in the market for ETFs). We also include a lag of the relevant left-hand side variable to account for the autocorrelation introduced by scaling over lagged positions. The specification also includes additional global/push, and domestic/pull variables (described in Section 3.4) to capture other factors that can affect portfolio flows. Appendix Table B includes additional information on each variable, including definitions, sources, and frequencies. ${ }^{22}$

The key coefficients of interest in equation (3) are the $\beta$ 's, which capture the effects of global risk, the domestic macroprudential stance, and their interaction on portfolio investment. Previous research (Section 2.1) generally finds a negative effect of risk shocks on portfolio flows, so $\beta_{2}$ is expected to be negative (notwithstanding some evidence that the effect has weakened since 2008). The literature is less conclusive on the effect of macroprudential regulation on portfolio flows, although most work finds small

${ }^{21}$ To correct for the estimated regressors, we bootstrap 10,000 replications of the two-step process, clustering by country.

22 It is worth highlighting that equations (1) and (2) are estimated with data of different frequencies. Variables capturing key (and slow-moving) country characteristics are not available at the weekly frequency of the risk and portfolio flow data (for which the high frequency is important to capture key relationships that are the focus of this paper). See Ghysels (2016) for a discussion of the benefits of using different frequency data. For example, analyzing joint processes at a common low frequency would ignore relevant information that may be available at mixed frequencies and lead to model misspecification. 
and insignificant effects, suggesting that $\beta_{1}$ could be of any sign but is likely to be insignificant. ${ }^{23} \beta_{3}$, which measures the interaction between risk shocks and the macroprudential stance, represents a novel contribution of this paper - a negative (positive) coefficient on $\beta_{3}$ would indicate that ex-ante macroprudential regulations aggravate (mitigate) the effects of risk shocks on portfolio flows when risk is near the mean of its distribution. In the discussion below, we will refer to estimates of $\beta_{1}$ as the "conditional" estimates between risk and portfolio flows when controlling for the interaction term in equation (3). We will also compare these results to the "unconditional" estimates for $\beta_{1}$, which do not include the interaction between risk and the macroprudential stance (i.e., the $\beta_{3}$ term), but which are closer to the estimates in the existing literature.

Finally, since equation (3) provides information about the average effects of the macroprudential stance, risk, and their interaction on portfolio allocation, we also calculate a series of marginal effects conditioning on the macroprudential stance for different points of the risk distribution. These calculations examine whether the ex-ante macroprudential stance mitigates or amplifies the impact of risk shocks at different stages of the global financial cycle. More specifically, we compute the first derivative of portfolio investment with respect to our macroprudential measure as follows:

$$
\left.\frac{\partial P I_{i t}}{\partial \widetilde{M P}_{i, t}}\right|_{R I S K_{t}=\bar{r}}=\beta_{1}+\beta_{3} \bar{r}
$$

Next, we evaluate this marginal effect of different macroprudential stances at different points of the risk shock distribution. We compute marginal effects at several points in the distribution of the RISK measure ranging from the $0.5^{\text {th }}$ to the $99.5^{\text {th }}$ percentile. This calculation shows whether a particular macroprudential stance amplifies or mitigates the impact of these different risk shocks on portfolio flows. ${ }^{24}$ If a tighter macroprudential stance amplifies effects, we would expect larger capital inflows at the left of the risk distribution (risk-on shocks) and larger capital outflows at the right of the distribution (risk-off shocks) - and vice versa if macroprudential stance mitigates these effects. Any effects at the extremes could be significant even if the marginal effect of a tighter stance around the mean of the risk distribution is insignificant. By estimating these marginal effects at all points in the risk distribution, the methodology also shows if the effects are larger at the "extreme extremes" $\left(0.5^{\text {th }}\right.$ and $99.5^{\text {th }}$ percentiles $)$, or if they are larger at one end of the distribution (such as risk-off shocks).

\subsection{Baseline Results}

Table 1 presents results from the first-stage regressions extracting the macroprudential policy shocks. The left panel reports all possible variables, and the right shows results after the backward and forward inclusion. The instruments generally have the expected signs, and many are statistically

\footnotetext{
${ }^{23}$ Papers focusing on bank flows (or sometimes aggregate flows, of which bank flows are an important share) often find evidence that tighter regulations reduce flows, while papers focusing on bond and equity flows sometimes find evidence that tighter regulations increase flows. In most cases, any relationships are estimated to be insignificant.

${ }^{24}$ To understand the computation of the marginal effects, start with our benchmark specification in equation 3 and take the first derivative of capital flows with respect to different ex ante macroprudential stances. This calculation shows that $\frac{\partial P I_{i t}}{\partial \widetilde{M P}_{i, t}} @ \widetilde{M P}_{i, t}=0$ is 0 and $\frac{\partial P I_{i t}}{\partial \widetilde{M P}} @ \widetilde{M P}_{i, t}=1$ is $\beta_{1}+\beta_{3} \bar{r}$. The difference between the two derivative values is the marginal effect, which we can evaluate at different values of RISK across the distribution.
} 
significant - especially on the right side of the table (as expected as the narrower set of instruments reduces multicollinearity). The results suggest that a tighter macroprudential policy stance corresponds to: a long time since a domestic banking crisis, fewer countries in crisis (for a range of different crises indicators), more cross-border borrowing, faster domestic credit growth, slower domestic growth, lower domestic policy rates, and a larger interest rate differential with the global rate. For some macroprudential measures, other variables, such as a stronger real exchange rate appreciation, higher inflation, stronger institutions, and a more flexible exchange rate, are also correlated with a tighter macroprudential stance. We have also estimated these models using different combinations of variables in the first stage, with different inclusion criteria, and without using the inclusion/exclusion procedures to narrow down the variable list. These changes have no meaningful impact on our second-stage results below.

The explanatory power of these first-stage regressions is high, with F-statistics around 100 for our preferred Intensity indices. This is an improvement over past work, which has had more limited success in predicting the use of macroprudential regulations, especially given the role of hard-to-measure institutional characteristics. ${ }^{25}$ The greater success of these first-stage estimates in Table 1 likely reflect three innovations in this paper. First, we estimate the macroprudential stance instead of changes in regulations over a quarter or year; attempting to predict the timing of policy changes can be challenging as many hard-to-measure factors can affect the precise timing of policy adjustments (including political events, institutional structure, pre-set meeting dates, and so on). Second, and closely related, we focus on macroprudential measures that capture the intensity of policies rather than using dummies that do not capture magnitudes. Finally, we use higher frequency data to capture changes in financial variables that could affect decisions about the macroprudential stance.

Next, we use the coefficients in Table 1 to estimate the fitted values of the macroprudential stance and calculate our measure of the macroprudential policy shock (the residual from equation (2)) to use in our baseline estimates. Table 2 reports these second-stage estimates of changes in the RORO index and macroprudential policy stance on weekly bond flows (equation 3). Each column reports results using one of the four different measures of the macroprudential stance discussed in Section 3.1: the Broad Intensity Index, the Narrow Intensity Index, the Country Relative Dummy, and the Time Relative Dummy. We cluster robust standard errors by country in all specifications, bootstrapping the standard errors over the two stages with 10,000 replications.

The coefficient estimates show that higher RORO values (i.e., risk-off shocks) are associated with sizable and statistically significant declines in portfolio bond flows across all macroprudential measures. In contrast, tighter macroprudential policy (ignoring the interaction with risk) is not significantly correlated with bond flows. Both results agree with the existing literature, as do the global/push and domestic/pull coefficient estimates. For example, the global variables are more consistently significantwith more robust global growth and looser monetary policy in advanced economies significantly correlated with larger portfolio bond flows. Some domestic variables are also significant, such as a larger interest rate differential (relative to the U.S.) significantly correlated with weaker bond flows.

\footnotetext{
${ }^{25}$ See Aikman et al. (2021), Borio et al. (2021) and Edge and Liang (2017).
} 
More noteworthy are the coefficients on the interaction between the macroprudential stance and risk, not previously included in this literature. This interaction is negative and usually significant (for three of the four macroprudential measures, including the two preferred Intensity indices). These estimates suggest that when the RORO measure of risk is near the mean of its distribution, a tighter macroprudential stance amplifies the impact of the global financial cycle on bond flows (i.e., increases bond outflows when risk increases and increases bond inflows when risk falls).

How large are these magnification effects, especially compared to the unconditional effects of risk shocks and macroprudential policy? It is helpful to compare these estimates with those from the "unconditional" regressions (equation (3)) but exclude the interaction between risk and the macroprudential stance. The top of Table 3 reports key coefficients from this unconditional regression, with the corresponding coefficients for the conditional regression (from Table 2) in the middle of the table. These unconditional estimates suggest that an increase in the RORO index of one unit ${ }^{26}$ corresponds to an $0.09 \%-0.10 \%$ decline in weekly bond flows, equivalent to $-\$ 2.3$ to $-\$ 2.4$ billion (based on AUM at the start of 2020). These estimates agree with the extensive literature documenting a large, adverse effect of risk shocks on portfolio flows. ${ }^{27}$ In contrast, the relationship between portfolio flows and the macroprudential stance is insignificant and weak in magnitude - with an increase in macroprudential regulation of one unit reducing capital flows by about one-tenth of the impact of a one-unit increase in risk.

These unconditional estimates, however, do not capture the interaction effect between risk and the macroprudential stance. The middle of Table 3 suggests that the magnitude of this interaction effect is modest near the mean of the risk distribution, especially compared to the unconditional effects of risk shocks. For example, the results suggest that if a country has a one-unit ${ }^{28}$ tighter ex-ante macroprudential stance and global risk increased by one unit, this correlates to a further decline in bond inflows of about $\$ 151-\$ 543$ million $(0.01 \%$ to $0.02 \%)$ using the AUM at the start of 2020 . These magnitudes suggest a meaningful impact - but moderate when compared to the unconditional impact of a one-unit increase in risk (corresponding to over $-\$ 2$ billion).

These moderate estimates of the impact of a country's macroprudential stance (including its interaction with risk), however, capture the average effects on bond flows across the entire distribution of the risk index. As discussed above, a tighter macroprudential stance could mitigate or amplify the impact

\footnotetext{
${ }^{26}$ This increase of one unit in the RORO measure is a moderate and common increase, as shown in Figure 2. It is equivalent to one standard deviation and close to the $90^{\text {th }}$ percentile of the distribution for the full the sample.

${ }^{27}$ For example, see Chari et al. (2020, 2021) for evidence on portfolio flows, Forbes and Warnock (2012) for evidence for extreme capital flow movements, and Rey (2013) for evidence across a broad set of asset categories. Recent work has suggested that this relationship between risk measures (such as the VIX) and capital flows may have weakened since 2008 (Forbes, 2020), although this evidence is based on quarterly data that may miss the high frequency movements captured in this paper.

${ }^{28}$ An increase of one unit for the Broad or Narrow Intensity Index is close to one standard deviation (see Appendix Table D). An increase of 1 unit for the Country or Time Relative Dummies is equivalent to tightening regulation so that the dummy moves from 0 to 1 , i.e., if a country moves from having aggregate regulation weaker than the median to tighter than the median (the Country Relative Dummy) or moves from one or less net tightenings across measures to more than one (the Time Relative Dummy).
} 
of risk shocks at the extremes of the risk distribution in different ways from around the mean. In other words, relationships estimated at the mean of the RORO distribution may obscure the effect at other points in the global financial cycle, especially at the extremes.

To capture these effects at different stages of the global financial cycle, we calculate the marginal effects on bond investments of adjusting the ex-ante macroprudential stance by one unit at different realizations of the RORO index..$^{29}$ These marginal effects include any direct impact and any impact through the macroprudential stance interacted with the RORO index multiplied by the size of the risk shock. The bottom of Table 3 shows these results, reporting the marginal effects from this tighter macroprudential stance as the RORO index moves from extreme risk-on to extreme risk-off (at the bottom of the table). To help interpret the large number of results at the bottom of this table, Figure 4 shows the coefficients on these key interaction terms graphically for results for each of our measures. ${ }^{30}$ The figure graphs the percent impact on bond portfolio flows (the vertical axis) from having had a tighter ex-ante macroprudential stance at different points in the risk distribution (the horizontal axis).

As we suspected, the table and corresponding figure show that the smaller estimates near the mean obscure larger and usually significant relationships in the tails of the risk distribution. The marginal effects from having a tighter macroprudential stance vary meaningfully across the risk distribution, with positive marginal effects of tighter macroprudential policy for risk-on shocks and negative effects for risk-off shocks. In other words, adopting a tighter macroprudential stance amplifies the subsequent effects of risk shocks at both ends of the distribution by increasing bond inflows during risk-on periods (the top left of Figure 4) and increasing bond outflows during risk-off episodes (the bottom right of the figure). These effects are highly significant across our preferred indices of the macroprudential stance and only insignificant using the time-relative measure of the policy stance. The magnitudes of these amplification effects also increase more at the extremes of the risk distribution, with especially large marginal effects at the $99^{\text {th }}$ and $99.5^{\text {th }}$ percentiles (i.e., for extreme risk-off shocks).

Moreover, the coefficients suggest that the magnitudes of these amplification effects between risk and the macroprudential stance can be large and meaningful at the extremes of the risk distribution-even when compared to the large, unconditional effects of risk shocks. For example, increasing macroprudential regulation by one for the Broad Intensity Index corresponds to bond flows statistically indistinguishable from zero when risk is at the median level, but a decline in flows of - $\$ 636 \mathrm{mn}$, $\$ 1,529 \mathrm{mn}$, and $-\$ 2,076 \mathrm{mn}$ when risk is at the $95^{\text {th }}, 99^{\text {th }}$ and $99.5^{\text {th }}$ percentiles of the distribution, respectively. ${ }^{31}$ This is a significant amplification of risk shocks compared to the unconditional effect of \$2 billion from the same risk-off shock (which does not incorporate this impact of macroprudential policy and its interaction effects). The effects during risk-on episodes tend to be meaningful but smaller at the extremes of the distribution, with the same increase in macroprudential regulations corresponding to bond inflows of $+\$ 631 \mathrm{mn},+\$ 969 \mathrm{mn}$, and $+\$ 1,215 \mathrm{mn}$ during risk-on episodes when the RORO index is at the $5^{\text {th }}, 1^{\text {st }}$ and $0.5^{\text {th }}$ percentiles of the distribution, respectively.

\footnotetext{
${ }^{29}$ This is equivalent to the macroprudential index increasing by 1 when measured by the Broad or Narrow Intensity Index, or moving from 0 to 1 when measured by the Country or Time Relative Dummy Variables.

${ }^{30}$ Thanks to Ambrosio Cesa-Bianchi for inspiring this graph in a discussion of this paper.

${ }^{31}$ Based on AUM at the start of 2020.
} 
Finally, to further put the magnitudes of these risk shocks in context, consider an example of a shock that causes risk to increase to the $99^{\text {th }}$ percentile of the distribution (3.49), which Figure 2 shows occurred during the Global Financial Crisis in 2008 and 2009, the Euro crisis in 2011, and during the COVID pandemic. For countries with the Broad or Narrow macroprudential index set at zero, this corresponds to bond outflows of $\$ 7.9 \mathrm{bn}$. For countries with a macroprudential stance one unit higher, this corresponds to bond outflows of $\$ 11.5-\$ 15.8 \mathrm{bn}$. In other words, this ex-ante tighter macroprudential policy stance would amplify the impact of risk-off shocks on bond outflows by about $22 \%-87 \%$ (based on all four measures of the macroprudential stance, or by $45 \%-67 \%$ for our preferred two intensity indices).

These large movements in capital result from the interaction of macroprudential regulations and risk at different phases of the global financial cycle and could correspond to significant disruptions in financial and economic activity. Analyses focusing on estimates based on risk outcomes at the central tendency of the risk distribution, however, overlook these interactions as it only captures the small and insignificant effects shown around the origin in Figure 4. These results highlight the importance of analyzing these effects across the complete financial cycle and assessing the relationships at the extremes of the distribution.

\subsection{Alternative Methodology: Ignoring Endogeneity}

This paper focuses on the "policy-shocks approach", which estimates an orthogonal measure of the macroprudential stance in a first-stage regression to control for reverse causality between portfolio flows and a country's macroprudential stance. Compared to past work, this section reports key results using a more traditional OLS estimation methodology, which addresses reverse causality simply by lagging measures of the macroprudential stance.

First, we repeat our baseline estimates from equation (3), but instead of using the constructed measure of the macroprudential policy shock, we simply insert a lagged measure of the macroprudential stance. We use the same measures for the macroprudential stance, risk, and the other control variables. Table 4 reports the key coefficients in the unconditional regressions, conditional regressions, and marginal effects that correspond directly to Table 3 (estimated with the policy-shocks methodology).

The coefficient signs and significance patterns in Table 4 are qualitatively similar to those based on the policy shocks approach. The estimated interactions between the macroprudential stance and risk at different points in the risk distribution continue to suggest that a tighter stance amplifies the impact of risk shocks on bond flows. The primary difference, however, is that the policy shocks approach has greater power and usually delivers larger coefficient estimates at both the mean and the margins of the risk distribution.

\subsection{More Granular Measures of the Macroprudential Stance}

The baseline models countries' macroprudential stances using four new measures (discussed in Section 3.1) aggregated across different macroprudential tools. While these aggregate indices help capture a country's general macroprudential stance, they could miss important distinctions in how individual macroprudential tools interact with portfolio flows and risk. These broader measures also do not answer 
key questions for policymakers. What are the effects of adjusting a specific macroprudential tool? Do different types of macroprudential regulations have different effects?

To better understand if specific macroprudential tools, or types of tools, have different effects, we repeat the baseline analysis separately for more granular measures of the macroprudential stance. We focus on five measures (with additional details in Section 3.1). The first two variables can be expressed in comparable magnitudes across countries: the LTV ratio and CCyB. The other three measures aggregate tools that focus on a specific aspect of macroprudential regulation: FX Measures, which target foreigncurrency exposures and transactions (and are part of the Broad Intensity Index); Demand Measures, which focus on the demand for loans from banks, including debt-service-to-income (DSTI) and loan-tovalue limits (LTV); Supply Measures, which are a broad range of tools focusing on banks' ability to supply credit. ${ }^{32}$ These three categories of tools are calculated by summing dummy variables of changes in the relevant tools since 2000 based on the iMaPP data, with each tightening of the relevant tool denoted by $\mathrm{a}+1$ and each loosening by $\mathrm{a}-1$. Although changes in each of these tools are not comparable across countries as for the LTV ratio and $\mathrm{CCyB}$, the cumulative adjustment in each tool should provide a rough measure of the intensity of use. ${ }^{33}$

Next, we estimate our baseline model predicting bond flows using the policy-shock approach for each of these five more granular measures of the macroprudential policy stance. Table 5 reports the results, using the same format as Tables 3 and 4. The top of the table confirms the main results from the more aggregated macroprudential measures: risk shocks are correlated with significantly lower bond flows, and the macroprudential stance has no significant relationship with flows - for any of these more disaggregated measures.

The main differences for these more granular measures of the macroprudential stance are the coefficients on the interaction between risk and the macroprudential stance - at the extremes and the mean of the risk distribution. Adjustments in LTV ratios, FX Measures, and Supply Measures correspond to the results for the aggregate macroprudential measures; they amplify the impact of risk shocks, particularly for extreme "risk-off" shocks. The $C C y B$ and Demand Measures appear to work in the same direction, but the effects are not significant, including at the extremes of the risk distribution.

These varied effects of different macroprudential tools on bond flows suggest that the choice of tools can affect the extent of leakages to portfolio investors. For example, the $C C y B$ is a policy focused on moderating the impact of the financial cycle on banks. It adjusts bank capital buffers across the cycle, such that buffers should be higher during risk-on periods and lower during risk-off periods. Even if the $C C y B$ remains constant, it is more likely to bind and affect lending and credit growth during sharp risk-on and risk-off movements. Given this focus, it is not surprising that the $C C y B$ does not significantly amplify

\footnotetext{
${ }^{32}$ Policies targeting the supply of credit include reserve requirements, liquidity requirements, capital requirements, conservation buffers, the leverage ratio, capital surcharges for systemically-important financial institutions, CCyBs, limits on credit growth, loan loss provisions, and loan restrictions. We exclude measures related to FX.

${ }^{33}$ As discussed in Section 3.1, these cumulative measures may overstate the intensity of the macroprudential stance if a country adjusts the given tool often, but by small increments.
} 
the impact of risk shocks as found for other measures. ${ }^{34}$ This supports evidence in Buch et al. (2019), which finds that macroprudential regulations focused on general capital requirements tend to have smaller spillover effects than those focused on specific sectors. Additional estimates from a more granular breakdown of Supply Measures also support the $C C y B$ result. When we estimate Supply Measures for subcomponents that do not include the $\mathrm{CCyB}$, the macroprudential stance continues to amplify the impact of risk shocks significantly, but when this interaction is estimated for the component including the CCyB, it is insignificant.

In contrast to these results for the CCyB, the results for FX Measures, the LTV ratio, and Supply Measures suggest that these macroprudential tools may have the unintended consequence of shifting risks to portfolio investors. This supports evidence from other research that has examined the impact of these types of regulations in more detail and shows how these leakages can occur. For example, Ahnert et al. (2021) document that tighter FX regulations on banks reduce bank lending and borrowing in FX but then cause companies to shift to other sources of cheaper FX credit, especially through issuing bonds sold to non-bank investors. Their underlying model shows that this shift away from bank loans occurs in riskier firms less well hedged against currency risk - a shift which would make bond flows more sensitive to global financial conditions (on average and particularly at the extremes of the risk distribution). Similarly, Sveriges Riksbank (2012) provides a concrete example of how a tighter LTV ratio could shift vulnerabilities. When Sweden increased LTV limits on secured lending, making it harder for borrowers to purchase homes with mortgages secured by property, there was an increase in unsecured loans. These unsecured loans, which are then often packaged and sold to bond investors, are likely to be more sensitive to risk shocks than those backed by assets, thereby increasing the sensitivity of bond investments.

It is also worth noting that the significant interactions between risk and macroprudential regulations from tighter LTV ratios, but not tighter Demand Measures (which primarily consist of changes in LTV and DSTI ratios) supports our focus of using measures of the macroprudential stance that incorporate intensity, rather than based on dummy variables. More specifically, the difference in results reflects that the $L T V$ measure is a precise magnitude measuring the intensity of the LTV ratio, while Demand Measures is the sum of dummy variables for any past changes in these housing-related ratios. The importance of capturing intensity is confirmed when we repeat the analysis using an LTV statistic based on dummy variables of past changes and ignoring the actual levels at which the ratio is set—in which case the interaction term becomes insignificant (including at the extremes). ${ }^{35}$ Although summing dummy variables of past policy changes may create a better measure of the policy stance than simply focusing on whether a policy was changed recently, it does not fully capture that policy's intensity. This

\footnotetext{
${ }^{34}$ More specifically, Supply Measures can be disaggregated into three components: Capital Measures (which include conservation buffers, capital surcharges for SIFIs and CCyBs); Loan Measures (which focus on limits on credit growth, loan loss provisions, and loan restrictions), and General Measures (such as reserve requirements and liquidity requirements). Although Supply Measures significantly amplifies the impact of risks shocks (as shown in Table 5), when this relationship is estimated for each of the subcomponents, it is not significant for Capital Measures (which are more cyclically focused and include the CCyB), but is significant for the other subcomponents.

${ }^{35}$ More specifically, we aggregate dummy variables indicating any changes in LTV ratios, using the same procedure as for Demand Measures. Results using this rougher measure of the LTV ratio correspond to those for Demand Measures instead of those using the numerical indicator of the LTV ratio.
} 
lack of precision introduces noise, making it more difficult to estimate any relationship between the macroprudential stance and risk. This series of results highlights the importance of incorporating intensity in measures of the macroprudential stance - as in our preferred indices.

\subsection{Summary: Bond Flows, the Macroprudential Stance, and Risk across the Cycle}

This series of results supports earlier evidence that risk-off episodes correspond to large and significant declines in portfolio bond investments and finds new evidence that a country's macroprudential stance can meaningfully amplify these effects. Even though a country's macroprudential stance does not necessarily affect the volume of bond flows directly, its interaction with risk shocks can generate significant effects. A tighter macroprudential stance amplifies the negative impact of risk-off shocks (causing larger bond outflows) and risk-on shocks (causing larger bond inflows). The magnitudes of these amplification effects are larger at the extremes, especially for extreme risk-off episodes.

These results suggest that although macroprudential tools may improve the resilience of financial institutions to a range of shocks, they also correspond to a meaningful increase in the sensitivity of bond flows to the global financial cycle. This could increase a country's vulnerability - especially to extreme risk-off shocks. Although these spillovers from macroprudential regulations on the volume of bond flows are small on average and during more stable periods, they are large during periods of stress. This heightened vulnerability should be an essential consideration when designing a package of macroprudential policies.

\section{Extensions: Equity Flows, Country Groups, Currencies, Capital Controls, and Other Sensitivity Tests}

This section extends the baseline analysis on how investors adjust portfolios based on a country's macroprudential stance, risk shocks, and their interaction at different points in the risk distribution (from Section 4.2) but explores several dimensions in more detail, including for portfolio equity investments, comparing advanced economies to emerging markets, comparing capital flows in different currencies, and for different treatments of capital controls. The section closes by reporting several additional sensitivity tests, such as excluding the COVID period and using different risk measures. For each set of tests, we continue to focus on estimation using the policy-shocks approach (Section 4.1) and with our preferred measure of the macroprudential stance, the Broad Intensity Index (Section 3.1), as the baseline.

\subsection{Equity Portfolio Flows}

This section repeats key parts of the analysis from Section but replaces bond flows with portfolio equity flows. The pattern of results is very similar to those for bond flows, albeit with smaller magnitudes for many of the estimated coefficients.

Table 6 presents the key results for equity flows. The left side of the table reports results using the aggregate measures of the macroprudential stance (comparable to Table 3), and the right side reports results using the five more granular measures (comparable to Table 5). Across each of the measures for the macroprudential stance, the risk-on/risk-off index continues to be negatively and statistically significantly correlated with portfolio flows. The unconditional effect of macroprudential policy is also 
insignificant in most specifications and small in magnitude. Both results agree with prior work that risk shocks have significant adverse effects on equity flows, while macroprudential policy tends to have modest or insignificant effects. More interesting, the interaction between macroprudential policy and risk continues to be negative and is usually significant when the macroprudential stance is measured using one of the indices (as also found for bonds). The magnitude of these coefficient estimates for equity flows, however, are usually smaller in magnitude than those for bond flows. In some respects, this is not surprising given that many macroprudential measures explicitly target excessive leverage in the economy and would therefore be more likely to affect debt than equity investments.

Moving to the bottom of Table 6, the marginal effects from a tighter macroprudential stance vary meaningfully across the risk distribution for most macroprudential measures, including our preferred Broad Intensity Index. Specifically, we find a positive marginal effects of a tighter macroprudential stance for risk-on shocks $(\mathrm{RORO}<0)$ and negative effects for risk-off shocks $(\mathrm{RORO}>0)$. In other words, a tighter macroprudential stance amplifies the effects of risk shocks at both ends of the distribution by increasing equity inflows during risk-on periods and increasing equity outflows during risk-off episodes. The magnitudes of these amplification effects also increase more at the extremes of the risk distribution, and even though the size of the effects is smaller than for bonds, the aggregate effects on capital flows can be larger in our sample as the size of the equity portfolios included in this data is larger than for bonds. For example, increasing ex-ante macroprudential regulation by one for the Broad Intensity Index corresponds to equity outflows which are statistically indistinguishable from zero when risk is at the median, but $\$ 740 \mathrm{mn}, \$ 1,859 \mathrm{mn}$, and $\$ 2,545 \mathrm{mn}$ when risk is at the $95 \%, 99 \%$, and $99.5 \%$ point in the distribution, respectively. ${ }^{36}$ The conditional magnitudes constitute a significant amplification effect compared to the base effect of $-\$ 3.8$ billion from the same risk-off shock. As in the case of bonds, the effects during risk-on episodes tend to be somewhat smaller at the most extreme values, with the same increase in macroprudential regulations corresponding to equity flows of $+\$ 845 \mathrm{mn},+\$ 1,268 \mathrm{mn}$, and $+\$ 1,577 \mathrm{mn}$ during risk-on episodes when the RORO index is at the 5\%,1\% and $0.5 \%$ of the distribution, respectively.

To further put the magnitudes of these risk shocks in context, consider the example of a $99^{\text {th }}$ percentile risk shock (3.49) during the Global Financial Crisis, the Euro crisis, and the COVID crisis. For countries with the Broad or Narrow macroprudential index set at zero, this corresponds to equity outflows of $\$ 13.4$ billion. For countries with a one-unit higher macroprudential index, before the shock occurs, this would instead correspond to equity outflows of $\$ 16.5-\$ 30.4$ billion. In other words, this tighter macroprudential policy stance would amplify the impact of risk-off shocks on equity outflows by about $20 \%-127 \%$ (or $20 \%-48 \%$ for our two intensity indices). These effects provide additional evidence that macroprudential tools can have unintended consequences.

Turning to the more granular measures of macroprudential regulation, the right side of Table 6 shows similar patterns as for bond flows in Table 5. A tighter macroprudential stance as measured by the LTV ratio, FX measures, and Supply measures interact with risk states of the world in a negative and statistically significant way to magnify their impact on investment flows. There is also more difference in

${ }^{36}$ Based on AUM at the start of 2020. 
how these macroprudential policies interact with risk at different points in the risk distribution. The effects of the LTV ratio, FX measures, and Supply measures magnify inflows during risk-on episodes and outflows during risk-off episodes, although the effects of the $F X$ and Supply measures appear to be more potent during risk-off episodes, while the $L T V$ ratio appears to be more potent for risk-on episodes. It is also worth noting that while the mean impact of the $C C y B$ is not significant, the interaction is significant for extreme risk-on and risk-off episodes. This could indicate that the CCyB could modestly amplify equity inflows and outflows during risk on episodes.

Finally, it is worth noting that although the key estimates for bond flows (in the last section) are unchanged when we use an OLS estimation methodology that does not control for reverse causality (as shown in Section 4.3), these results for equity flows can fluctuate across the two estimation methodologies. Some coefficient estimates change meaningfully when we estimate the same model but simply use a lagged measure of the country's macroprudential stance (instead of the residuals from the first-stage regression). For example, the naive estimates (i.e., not adjusted for reverse causality) suggest that a tighter macroprudential stance stabilizes equity flows during extreme risk-off episodes instead of amplifying outflows (as found in Table 6). At first glance, this might suggest that macroprudential regulations have beneficial effects for equity portfolio flows, consistent with evidence that macroprudential tools slow credit creation and, therefore capital flows. However, these unadjusted estimates are also not robust to modest changes in specification. For example, if we repeat the OLS estimates and remove the initial period of the COVID pandemic from the sample, the interaction effects between macroprudential regulation and equity flows shift to insignificant. Given this lack of robustness, we focus on the preferred specification that should control for the critical challenge of reverse causality and is also more robust to these modifications to the sample and period.

In summary, macroprudential regulations appear to amplify the impact of changes in global investor risk on equity portfolio flows. These effects follow similar patterns found for bond flows, including more potent effects at the tails of the risk distribution and being more potent for macroprudential regulations through changes in LTV ratios, FX measures, and Supply measures. The magnitude and statistical significance of the effects of macroprudential regulation interacted with risk on equity flows are, however, generally more moderate than for bond flows.

\subsection{Advanced Economies versus Emerging Markets}

This section repeats the main results (for bond and equity flows) but tests for different effects in advanced economies and emerging markets. We use the baseline model in equation (3) but add interaction terms for our key variables with a dummy equal to one if the country is an emerging market. More specifically, we add two interaction terms: one for the EM dummy and RORO measure of risk, and another for the EM dummy, RORO measure of risk, and the macroprudential stance. Columns 1 and 2 of Table 7 report the bond and equity flows results, respectively, using our preferred measure of the macroprudential stance (the Broad Intensity Index). The bottom of the table continues to report marginal effects across the risk distribution but now reports the marginal effects for EMs relative to AEs (from a one-unit tighter macroprudential stance at different points in the risk distribution).

Focusing first on the coefficient estimates near the mean of the distribution (in the middle of the table), the pattern of coefficients from the baseline analysis is unchanged, and the additional interaction 
terms are generally insignificant at conventional levels. This suggests no significant differences between EMs and AEs near the mean of the distribution for the corresponding measures. The coefficient for the one interaction is negative and marginally significant at the $10 \%$ level for bonds, suggesting a further amplification effect of risk shocks on bond flows for emerging markets relative to advanced economies. This is not even marginally significant for equity flows, and the coefficient for a triple interaction between macroprudential regulation, risk, and a dummy for the country grouping is statistically insignificant for both types of capital flows. Moreover, the marginal effects (reported at the bottom of the table) are now calculated based on the triple interaction between risk, the macroprudential stance, and the EM dummy, and these are not statistically significant at any points in the risk distribution. Together, these results suggest that the effect of macroprudential regulations during periods of extreme risk-on or risk-off sentiment does not differ between emerging markets and advanced economies in a statistically significant manner.

\subsection{Portfolio Flows in Different Currencies}

This section repeats the baseline analysis (for both bond and equity flows), but tests for different effects for portfolio flows in USD relative to other currencies. Most analyses of capital flows and portfolio flows use data aggregating across flows denominated in different currencies. There has recently been increased attention, however, to how the currency denomination of capital flows can influence various relationships (Hofman et al., 2020). The EPFR data used in this paper has a significant advantage over most other data on capital flows as it classifies flows by currency denomination. We take advantage of this feature and examine whether the interactions between the macroprudential stance, risk, and portfolio flows are larger for dollar-denominated flows. Given the dollar's unique role in the global financial cycle, we might expect dollar-denominated, non-US assets to be more sensitive to shifts in global risk aversion. On the other hand, countries with more extensive dollar exposures and/or more sensitive to currency movements might also be more likely to enact macroprudential FX regulations to limit these exposures.

First, we divide our portfolio flows into those in US dollars and those in all other currencies. We do not differentiate between US dollars and local currency flows because many countries in the sample receive trivially small flows in their own currency. The results in columns 3 through 6 in Table 7 confirm that dollar-denominated flows (for both equities and bonds) respond more strongly to risk-on/risk-off shocks. A tighter macroprudential stance continues to significantly amplify the impact of risks shocks, especially at the extremes, for all dollar-denominated flows and non-dollar bond flows. The relationships follow the same patterns for non-dollar equity flows but are insignificant and smaller.

\subsection{Capital Controls}

To test if incorporating capital controls into our analysis can change the results, we consider two extensions - one which uses capital controls instead of macroprudential regulations in our baseline analysis, and the other which adds capital controls to the baseline analysis.

First, we test if the results change if we analyze the direct effects and interactions with risk from prior adjustments to capital controls (instead of macroprudential policy.) This extension builds on recent work (such as Bergant et al., 2020 and Frost, Ito, and Stralen, 2020), suggesting that FX-macroprudential measures can have different effects than capital controls on capital inflows and the resilience of growth to 
VIX and capital flow shocks. ${ }^{37}$ It is worth noting, however, that these papers focus on international capital flows instead of the portfolio flows of domestic and international investors used in this paper (Section 3.3 and Section 6). As a result, capital controls may be less relevant for portfolio allocation in this paper than found in work focusing on international flows. To measure capital controls, we use data from Fernandez et al. (2015, updated through 2017), which allows a detailed disaggregation of different types of capital controls. Like our preferred measure of the macroprudential stance, the Fernandez et al. data provides some information on the regulatory stance (by summing the number of times policy changed in the past), instead of only capturing recent policy changes. The data, however, has three limitations: (1) it does not capture the intensity of the capital controls (thereby missing some of the important advantages of our new macroprudential measures, as discussed in Section 2.1) ${ }^{38}$ (2) the latest date available is 2017 (thereby substantially abbreviating our sample); and (3) it is only available at an annual frequency.

Columns 7 and 8 of Table 7 report the results replacing our measure of the macroprudential stance with this measure of capital controls. ${ }^{39}$ The results are similar to those for macroprudential regulations; capital controls have no independent, significant impact on bond or equity flows (ignoring the interaction with risk), but on average, appear to magnify the impact of risk shocks on portfolio bond and equity flows. The interaction effects for extreme risk shocks follow similar patterns (magnifying capital inflows during risk-on periods and capital outflows during risk-off periods), although they are less often significant, especially for risk-on episodes for bond flows. Columns 9 and 10 repeat the baseline analysis using the macroprudential stance, but with lagged capital controls in the specification as an additional control variable. The central results differ little from the baseline, but the coefficients on capital controls are insignificant.

\subsection{Other Extensions and Sensitivity Tests}

We also performed several additional extensions and sensitivity tests to examine the impact of the time period, sample selection, and variable definitions. Appendix Table E reports a subset of these results.

First, we repeat the baseline analysis but drop the period of the COVID shock. This window was the biggest shock in the sample and coincided with sharp reductions in the CCyB and Broad Intensity Index. Columns 1 and 2 of Appendix Table E show the results from dropping the window from February 15, 2020 through the end of the sample. (Estimates are similar if we only drop March 2020, the month of the sharpest risk-off move.) The key results remain robust and suggest that the sharp movements during the pandemic do not drive the key estimates.

Next, we explore if the key relationships between portfolio flows, risk, and the macroprudential stance have changed since the Global Financial Crisis (GFC). This builds on several papers documenting changes in international capital flows and their reduced correlation with risk since the GFC, changes

\footnotetext{
${ }^{37}$ See Rebucci and Ma (2019) for a recent survey of the literature on capital controls.

${ }^{38}$ The measure uses 0-1 dummies to indicate if there is a control on specific categories of capital flows. When these are averaged across categories, the statistics can capture intensity in the sense that more measures are included, but not the magnitude of each set of controls.

${ }^{39}$ To estimate the first-stage regressions, we repeat the steps from the main analysis, using the same explanatory variables with backward and forward exclusion and inclusion to generate a residual capital controls "shock".
} 
potentially caused by macroprudential regulation. CGFS (2021) provides an excellent summary of this work. Our sample only started in 2004, limiting our ability to test for any changes since the GFC. ${ }^{40}$ With this important caveat, we repeat our baseline estimates for the "early" period from 2004-2009 and the post-GFC period (from 2010-2020) using two approaches. First, we repeat our analysis for the full sample but add a triple interaction of the macroprudential stance, risk, and a dummy variable for the early window. Columns 3 and 4 of Table 8 show that the results for both subsamples agree with our baseline estimates, although the risk and amplification effects are smaller in the pre-crisis period for bonds and larger for equities. Second, we split the sample and estimate the baseline equation separately for the early and post-GFC periods. The interaction terms are insignificant for the earlier window (but the key results are unchanged for the post-GFC window). We are cautious in drawing any firm conclusions from the comparison with the post-GFC window, however, as there is little variation in the macroprudential stance in the earlier window, plus this earlier window is significantly shorter. It only includes an extended "riskon" period plus the sharp "risk-off" episode around the global financial crisis.

As a second set of tests, we explore the impact of sample selection. We repeat the baseline analysis but include safe-haven countries that were previously excluded from our baseline (the United States, Japan, and Switzerland), as the key relationship between risk shocks and portfolio flows is likely to be different for this set of countries. Adding these countries increases the sample size by 5-7\%, but Columns 5 and 6 of Appendix Table E show that the pattern of coefficient signs and significance are largely unchanged.

Finally, we repeat the baseline analysis but use the VIX instead of RORO to measure risk. Columns 7 and 8 of Appendix Table E show that although the main results remain robust for bonds, and the pattern of signs and estimates remain for equities, the interaction effects are no longer significant for equities (at the mean the tails of the distribution). The main factor driving this difference is that the RORO measure includes a broader set of risk-responsive asset prices than the VIX, such as center-country equity returns, corporate spreads, gold prices, other option-implied volatilities, and several different spreads intended to capture liquidity risk. These differences also highlight the benefits of using a broader measure of risk aversion than the VIX (as also argued in Miranda-Agrippino and Rey, 2015 and Scheubel et al., 2019).

\section{Different Forms of International Capital Flows}

This paper focuses on high-frequency EPFR data on portfolio flows to analyze how investors adjust their equity and bond portfolios based on a country's macroprudential stance and its interaction with risk - during normal times and at different phases of the global financial cycle. To understand if the relationships documented above apply to cross-border capital flows and place these results in the context of the international economics literature, this section performs a similar analysis using data on international capital flows. The data on international capital flows captures a different investment aspect (cross-border transactions rather than portfolio allocation by country) and is only available at a lower quarterly frequency, which could miss meaningful relationships between capital flows, risk, and

40 Also see evidence in Goldberg and Krogstrup (2019), Avdjiev et al. (2020), Forbes (2020), Miranda-Agrippino and Rey (2020) and Forbes and Warnock (2021). 
macroprudential policy. This data, however, covers a broader set of portfolio equity and debt investors (such as bank flows and FDI), which may respond differently to changes in risk and macroprudential regulation.

To perform this analysis, we use the same definitions for the macroprudential stance, risk, and other control variables as above, except instead of using the EPFR data on portfolio investment and use data on capital flows from Forbes and Warnock (2021), based on the IMF's International Financial Statistics (IFS). The IMF's IFS data provides quarterly capital flows for a large sample of countries, disaggregated into portfolio debt, portfolio equity, foreign direct investment (FDI), and bank flows (and others). Forbes and Warnock (2021) use this data but fill in several gaps with source-country data and exclude suspect data and gaps to yield a dataset on quarterly capital flows for 59 countries from 1980q1$2020 \mathrm{q} 3 .{ }^{41}$ In this dataset, the portfolio debt and equity categories are the closest to the bond and equity flows captured in the EPFR database, albeit with several important differences. The EPFR data only includes reporting investment funds (primarily mutual funds and exchange-traded funds) and does not include other institutional investors (such as sovereign wealth funds, hedge funds, pension funds, and banks' proprietary trading desks). Also important, the EPFR data reports portfolio investment by domestic and international investors (i.e., includes purchases by residents of the country). In contrast, the IMF data includes cross-border flows calculated on a residency basis (i.e., only including transactions between residents of different countries). ${ }^{42}$ Not surprisingly, and as shown in more detail in Koepke and Paetzold (2020), these differences contribute to a low correlation between the IFS and EPFR data on equity and bond flows. ${ }^{43}$

In order to estimate the relationship between cross-border portfolio flows, the macroprudential stance, risk, and their interactions, we combine the variables and framework used above for bond and equity investment with the standard approach to modeling quarterly international capital flows (i.e., Avdjiev et al., 2020). More specifically, we estimate international capital flows as a function of the country's macroprudential stance, global risk, the interaction between the macroprudential stance and risk, and other push and pull factors:

$$
I C F_{i t}=\alpha_{i}+\beta_{1} \widetilde{M P}_{i t}+\beta_{2} R I S K_{t}+\beta_{3} \widetilde{M P}_{i, t} * R I S K_{t}+\boldsymbol{\gamma} \boldsymbol{P} \boldsymbol{U S} \boldsymbol{H}_{\boldsymbol{t}}+\boldsymbol{\delta} \boldsymbol{P U} \boldsymbol{L} \boldsymbol{L}_{i, t}+\varepsilon_{i, t}
$$

We measure international capital flows $\left(I C F_{i t}\right)$ as the percent change in cross-border inflows (for portfolio debt, portfolio equity, bank or total flows) over the last four quarters for country $i$ in quarter $t$, relative to a year ago (to avoid seasonality). ${ }^{44}$ We continue to measure the macroprudential stance $\left(\widetilde{M P}_{i t}\right)$ using the policy-shock approach to adjust for reverse causality (Section 4.1) and measure most other

\footnotetext{
${ }^{41}$ The Forbes and Warnock (2021) dataset is available at: https://mitmgmtfaculty.mit.edu/kjforbes/research/. We follow standard conventions and use the term "bank flows" to refer to the "Other Investment" category in the BoP statistics. This category is a residual that is dominated by bank flows.

${ }^{42}$ For example, if a resident of India invests in a mutual fund that invests in Indian equities, this would be included in the EPFR data, but not the IMF data.

${ }^{43}$ Another difference, discussed above, is how the EPFR data allocates fund flows by country for funds which do not report specific allocations.

${ }^{44}$ We focus on capital inflows (instead of net flows) as done in Gelos et al. (2019), Eguren-Martin et al. (2020), and Mano and Sgherri (2020). We also winsorize growth in capital flows at the 0.5 and 99.5 level.
} 
variables as in the baseline, including focusing on the Broad Intensity Index for the macroprudential stance. The main change is using two formulations for the PUSH and PULL variables. The first follows Avdjiev et al. (2020), a standard framework modeling capital flows in the international economics literature. In this specification, the two global/push variables are the change in the US shadow interest rate and global GDP growth, and the three domestic/pull variables are: domestic GDP growth, domestic institutions, and financial openness (all lagged). We follow Avdjiev et al. (2020) and estimate the model with country fixed effects, robust standard errors, and most variables estimated as differences or changes to ensure stationarity. The second specification incorporates the variables used above for the EPFR regressions and is more common in the finance literature analyzing portfolio investment, often at a higher frequency. The five PUSH and PULL variables from the first specification continue to be included, as well as three additional PULL variables: the percent change in the bilateral US\$ exchange rate, the change in the interest rate differential versus the US, and the quarterly volatility of the exchange rate (all lagged by one quarter). All sources and variable definitions for both specifications are the same as in Sections 3 and 4 (except at quarterly frequency).

Table 8 follows the same format as Table 3 and reports key coefficients of interest for different types of capital flows: debt, equity, bank, and total (including FDI and other components). The columns labeled "Macro" include the smaller set of control variables that are more standard in the international macro literature, and the columns labeled "Finance" include the more extensive set of controls common in the finance literature. Complete regression results for the full set of control variables are in Appendix Table $\mathrm{F}$ and agree with the general findings in other research. ${ }^{45}$ Regressions predicting quarterly movements in capital flows often have low explanatory power, and coefficient estimates are often insignificant. ${ }^{46}$ This weak explanatory power holds particularly true in the post-2008 period, which is the majority of the sample used in this paper, as the relationship between global risk measures and capital flows (including extreme capital flow episodes) appears to have broken down (as shown in Avdjiev et al., 2020; Forbes and Warnock, 2021; and Forbes, 2020).

Turning to the key coefficients of interest, there is a negative correlation between the macroprudential stance and capital inflows for each capital flow type, but this is never significant. The correlation between risk and capital inflows is negative and significant for bank flows, but not other flows. The interaction between risk and macroprudential regulation is negative for debt and equity flows (as found in the higher frequency analysis, albeit no longer significant) but positive for bank flows.

Next, the bottom of Table 8 shows the effects of a tighter macroprudential stance at different stages of the global financial cycle. The patterns for portfolio debt and equity flows (with either set of control variables) generally agree with the results from the analysis using the higher-frequency portfolio data. A tighter macroprudential stance correlates with larger portfolio inflows at lower risk levels and larger portfolio outflows at higher risk levels, with larger effects at the extremes and especially for riskoff episodes. None of these effects are significant, however, as found for the EPFR data. The lack of

\footnotetext{
${ }^{45}$ Results for the unconditional regressions, which do not include an interaction between risk and the macroprudential stance, are so similar that we do not report them both.

${ }^{46}$ In contrast, regressions predicting "extreme episodes" in capital flows (i.e., Forbes and Warnock, 2012) or using higher frequency data (i.e., Chari et al., 2020) have a higher explanatory power and more significant coefficients.
} 
statistical significance may reflect the data's lower frequency or the different types of investment flows in these two datasets (as explained above). This general insignificance of macroprudential regulations on capital flows at a quarterly frequency also agrees with the results in Gelos et al. (2019) — albeit they use a different measure of macroprudential regulations and different framework (amongst other differences).

Additional sensitivity tests include different measures of the macroprudential stance (all four measures discussed in Section 3.1), different measures of risk (including the VIX), different measures of capital flows (net flows instead of inflows and scaled relative to GDP). The series of estimates generally supports the results discussed above; models explaining quarterly movements in capital flows since 2004 generally have a low degree of explanatory power. Although some coefficients are occasionally significant, most significant estimates are not robust to changes in definitions and control variables.

With these caveats about significance, there is one particularly noteworthy result in Table 8: different patterns for portfolio flows (equity and debt) compared to bank flows in the estimated interaction of risk and macroprudential policy across the risk distribution. A tighter macroprudential stance appears to amplify movements in international portfolio flows, especially at the extremes and for risk-off shocks (as found above for portfolio investment flows). For bank flows, however, a tighter stance appears to work in the opposite direction, especially at the extremes of the distribution. This result that a tighter macroprudential stance dampens (instead of amplifies) the impact of risk shocks on bank flows is not surprising as most macroprudential regulations apply to banks - and therefore, countries with tighter regulations may be less, instead of more, sensitive to changes in the global financial cycle. Nevertheless, these different patterns for different categories of international capital flows suggest that even if macroprudential regulations improve the resilience of bank flows to the global financial cycle, they may simultaneously shift risks to bond and equity markets and increase the sensitivity of these flows.

\section{Conclusion}

Although the academic literature generally finds only modest effects of a country's macroprudential stance on bond and equity flows, this paper suggests that these modest "on average" relationships mask large and significant effects during extreme risk-on risk-off shocks. More specifically, portfolio flows in countries with tighter ex-ante macroprudential regulations are more sensitive to the global financial cycle; portfolio investment flows increase more during good times and fall by more during the bad. Moreover, these amplification effects from a tighter macroprudential stance are meaningful - especially for large risk shocks. These amplification effects also appear to be larger for bond than equity investments but not significantly different for advanced economies relative to emerging markets or for US dollar investment flows relative to non-US dollar flows. The amplification effects are also larger for bond flows when macroprudential regulations are tightened on specific exposures (such as FX and housing) but are usually insignificant for more cyclically-based regulations (such as the CCyB). The series of results highlights the importance of research on macroprudential regulations, carefully examining the impact of different tools (and not just the overall regulatory stance) and incorporating the intensity of various policies (and not just focusing on recent changes or measures based on dummy variables). 
Our results support a growing body of evidence on the importance of examining the impact of different policies at different stages of the financial cycle and incorporating spillovers and leakages. An extensive literature shows that a more stringent macroprudential stance reduces the volume of crossborder bank flows (which tend to be highly sensitive to the global financial cycle) and increases the banking system's resilience to different types of shocks. This literature also finds, however, that borrowers respond by shifting to obtain funding from other sources than banks, such that financial intermediation can shift towards bonds, equities, and other institutions in the "shadow" financial system. This paper suggests that as tighter macroprudential regulation causes this shift in financial intermediation, it can have the unintended consequence of increasing the sensitivity of portfolio flows to risk shocks. It is important to highlight that we do not suggest that macroprudential policies render the broader economy less resilient or more sensitive to risk shocks - as the increased resilience of banks may outweigh the greater sensitivity of non-bank financial intermediation. Our results do, however, suggest that the broader spillovers and interaction effects deserve attention in any discussion of the costs, benefits, and effectiveness of macroprudential regulation. 


\section{References}

Adrian, Tobias, Nina Boyarchenko, and Domenico Giannone. (2019). "Vulnerable Growth." American Economic Review 109(4), pp. 1263-89.

Agénor, Pierre-Richard, and Luiz Pereira da Silva. (2018). Financial Spillovers, Spillbacks, and the Scope for International Macroprudential Policy Coordination. BIS Papers No. 97.

Ahnert, Toni, Kristin Forbes, Christian Friedrich, and Dennis Reinhardt. (2021). "Macroprudential FX Regulations: Shifting the Snowbanks of FX Vulnerability?" Journal of Financial Economics 140:145174.

Aikman, David, Jonathan Bridges, Anil Kashyap and Caspar Siegert. (2021). "Would Is a Macroprudential Reaction Function Emerging and Is It Sensible?" Bank of England, unpublished paper.

Alam, Zohair, Adrian Alter, Jesse Eiseman, Gaston Gelos, Heedon Kan, Machiko Narita, Erlend Nier, and Naixi Wang. (2019). Digging Deeper: Evidence on the Effects of Macroprudential Policies from a New Database. IMF Working Paper WP/19/66.

Aramonte, Sirio, Andreas Schrimpf, and Hyun Song Shin. (2021). "Non-bank Financial Intermediaries and Financial Stability." BIS Working Papers No. 972.

Araujo, Juliana, Manasa Patnam, Adina Popescu, Fabian Valencia, and Weija Yao. (2020). "Effects of Macroprudential Policy: Evidence from over 6,000 Estimates." IMF Working Paper WP/20/67.

Avdjiev, Stefan, Leonardo Gambacorta, Linda Goldberg, and Stefano Schiaffi. (2020). "The Shifting Drivers of Global Liquidity." Journal of International Economics 125(July).

Avdjiev, Stefan, Catherine Koch, Patrick McGuire, and Goetz von Peter. (2016). "International Prudential Policy Spillovers: A Global Perspective." BIS working papers 589 (October).

Barro, Robert. (2009). "Rare Disasters, Asset Prices, and Welfare Costs." American Economic Review 99 (1): 243-64.

Bergant, Katherina, Francesco Grigoli, Niels-Jakob Hansen, and Damiano Sandri. (2020). "Dampening Global Financial Shocks: Can Macroprudential Regulation Help (More than Capital Controls)?" IMF Working Paper 20/106.

Bengui, Julien and Javier Bianchi. (2018). "Macroprudential Policy with Leakages." Federal Reserve Bank of Minneapolis Working Paper 754.

Bianchi, Javier and Enrique Mendoza. (2018). "Optimal time-consistent Macroprudential Policy." Journal of Political Economy 126:588-634.

Borio, Claudio, Ilhyock Shim, and Hyun Song Shin. (2021). "Macro-financial Stability Frameworks: Experience and Challenges." BIS mimeo.

Breckenfelder, Johannes and Victoria Ivashina. (2021). "Bank Balance Sheet Constraints and Bond Liquidity.” ECB Working Paper Series No. 2021/2589. 
Brunnermeier Markus, Thomas Eisenbach, and Yuliy Sannikov. (2013). "Macroeconomics with Financial Frictions: A Survey." In Advances in Economics and Econometrics: Tenth World Congress of the Econometric Society, Vol. III, ed. D Acemoglu, M Arellano, E Dekel, pp. 3-94. Cambridge, UK: Cambridge Univ. Press.

Buch, Claudia, Matthieu Bussière, Linda Goldberg and Robert Hills. (2019). "The International Transmission of Monetary Policy.” Journal of International Money and Finance 91(March): 29-48.

Cerutti, Eugenio, Stijn Claessens, and Luc Laeven. (2017). "The Use and Effectiveness of Macroprudential Policies: New Evidence." Journal of Financial Stability 28: 2013-224.

Chari, Anusha, Karlye Dilts-Stedman, and Christian Lundblad. (2021). "Taper Tantrums: QE, its Aftermath and Emerging Market Capital Flows." Review of Financial Studies, 34 (3):1445-1508.

Chari, Anusha, Karlye Dilts-Stedman, and Christian Lundblad. (2020). "Capital Flows in Risky Times: Risk-on/Risk-off and Emerging Market Tail Risk." NBER Working Paper 27927.

Chari, Anusha, and Peter Henry. (2004). "Risk Sharing and Asset Prices: Evidence from a Natural Experiment." Journal of Finance 59(3): 1295-1324.

Chinn, Menzie, and Hiro Ito. (2008.) "A New Measure of Financial Openness." Journal of Comparative Policy Analysis, 10(3): 309-322.

Cizel, Janko, Jon Frost, Aerdt Houben, and Peter Wierts. (2019). "Effective Macroprudential Policy: Cross-Sector Substitution from Price and Quantity Measures." Journal of Money, Credit and Banking 51: 1209-235.

Claessens, Stijn. (2015). “An Overview of Macroprudential Tools.” Annual Review of Financial Economics 7: 397-422.

Claessens, Stijn and Kristin Forbes. (2001). International Financial Contagion. Kluwer Academic Publishers.

Committee on the Global Financial System (CGFS). (2021). "Changing Patterns of Capital Flows." CGFS Papers \#66.

Committee on the Global Financial System (CGFS). (2010). "Macroprudential Instruments and Frameworks: Stocktaking of Issues and Experiences." CGFS Papers \#38.

ECB (European Central Bank). (2020). "Cross-border Spillover Effects of Macroprudential Policies: A Conceptual Framework. "ECB Working Paper No 242. June

Edge, Rochelle and Nellie Liang. (2017). "Who is in Charge of Financial Stability, Why and What They Can Do." Hutchins Center Working Paper No. 32.

Eguren-Martin, Fernando, Cian O'Neill, Andrej Sokol, and Lukas von dem Berge. (2020). "Capital Flows-at-Risk: Push, Pull and the Role of Policy." Bank of England Staff Working Paper No. 881. 
Engel, Charles. (2016). "Macroprudential Policy in a World of High Capital Mobility: Policy Implications from an Academic Perspective." Journal of the Japanese and International Economies 42(Dec): 162-172.

Esrel, Isil. (2021). "Evolution of Debt Financing Toward Less Regulated Financial Intermediaries.” Paper prepared for Federal Reserve Bank of Boston $65^{\text {th }}$ Economic Conference".

Fernández, Andrés, Michael W. Klein, Alessandro Rebucci, Martin Schindler and Martín Uribe. (2015). "Capital Control Measures: A New Dataset." NBER Working Paper No. 20970.

Forbes, Kristin. (2021). "The International Aspects of Macroprudential Policy." Annual Review of Economics, vol. 13.

Forbes, Kristin (2020). "Do Sounder Banks Make Calmer Waters? The Link Between Bank Regulations and Capital Flow Waves." American Economic Review: Papers and Proceedings 110: 516-522.

Forbes, Kristin. (2013). The "Big C": Identifying and Mitigating Contagion (2013). The Changing Policy Landscape. 2012 Jackson Hole Symposium run by the Federal Reserve Bank of Kansas City, pgs 23-87.

Forbes, Kristin. (2007). "The Microeconomic Evidence on Capital Controls: No Free Lunch." In Sebastian Edwards, ed. Capital Controls and Capital Flows in Emerging Economies: Policies, Practices, and Consequences. Chicago: University of Chicago Press, pgs. 171-199.

Forbes, Kristin, Marcel Fratzscher, and Roland Straub. (2015). "Capital-Flow Management Measures: What are They Good For?" Journal of International Economics 96(S76-S97.

Forbes, Kristin and Michael Klein. (2015). "Pick Your Poison: The Choices and Consequences of Policy Responses to Crises." IMF Economic Review 63 (April): 197-237.

Forbes, Kristin and Francis Warnock. (2021). "Capital Flow Waves—or Ripples? Extreme Capital Flow Movements Since the Crisis." Journal of International Money and Finance 116(Sept).

Forbes, Kristin and Francis Warnock. (2012). "Capital Flow Waves: Surges, Stops, Flight and Retrenchment." Journal of International Economics 88 (2): 235-251.

Frost, Jon, Hiro Ito, and René van Stralen. (2020). "The Effectiveness of Macroprudential Policies and Capital Controls against Volatile Capital Inflows." Unpublished mimeo.

Gabaix, Xavier. (2012). "Variable Rare Disasters: An Exactly Solved Framework for Ten Puzzles in Macro-Finance." Quarterly Journal of Economics 127 (2): 645-700.

Gelos, Gelos, Lucyna Gornicka, Robin Koepke, Ratna Sahay, and Silvia Sgherri. (2019). "Capital Flows at Risk: Taming the Ebbs and Flows." IMF Working Paper WP/19/279.

Ghysels, Eric. (2016). "Macroeconomics and the Reality of Mixed Frequency Data." Journal of Econometrics, 193 (2): 294-314.

Goldberg, Linda and Signe Krogstrup. (2019). "International Capital Flow Pressures.” NBER Working Paper 24286. 
Gourio, François. (2012). "Disaster Risk and Business Cycles." American Economic Review 102 (6): 2734-66.

Hofmann, Boris, Ilhyock Shim, and Hyun Song Shin. (2020). "Emerging market economy exchange rates and local currency bond markets amid the Covid-19 pandemic." BIS Bulletin No. 5.

Ilzetzki, Ethan, Carmen Reinhart, and Kenneth Rogoff. (2019). "Exchange Arrangements Entering the Twenty-first Century: Which Anchor will Hold?" The Quarterly Journal of Economics 134(2): 599-646.

IMF-FSB-BIS. (2016). "Elements of Effective Macroprudential Policies: Lessons from International Experience." Available at: http://www.imf.org/external/np/g20/pdf/2016/083116.pdf.

Kalemli-Ozcan, Sebnem. (2020). "US Monetary Policy and International Risk Spillovers." In Jackson Hole Economic Policy Symposium 2019, organized by the Federal Reserve Bank of Kansas City.

Koepke, Robin and Simon Paetzold. (2020). "Capital Flow Data—A Guide for Empirical Analysis and Real-Time Tracking." IMF Working Paper WP/20/171.

Krippner, Leo. (2015) "Zero Lower Bound Term Structure Modeling: A Practitioner's Guide." PalgraveMacmillan.

Laeven, Luc and Fabian Valencia (2020). "Systemic banking crises database II." IMF Economic Review, 68(2), pp. 307-361,

Mano, Rui and Silvia Sgherri. (2020). "One Shock, Many Policy Responses." IMF Working Paper $W P / 20 / 10$. January.

Miranda-Agrippino, Silvia and Hélène Rey. (2020). "The Global Financial Cycle after Lehman.” American Economic Review: Papers and Proceedings 110: 523-528.

Miranda-Agrippino, Silvia and Hélène Rey. (2015). "US Monetary Policy and the Global Financial Cycle." NBER Working Paper 21722.

Ostry, Jonathan, Atish Ghosh, Marcos Chamon, and Mahvash Qureshi. (2012). "Tools for Managing Financial-Stability Risks from Capital Inflows.” Journal of International Economics 88: 407-421.

Rebucci, Alessandro and Chang Ma. (2019). "Capital Controls: A Survey of the New Literature." NBER Working Paper 26558.

Rey, Hélène. (2013). "Dilemma not Trilemma: The Global Financial Cycle and Monetary Policy Independence." In Proceedings of the 2013 Federal Reserve Bank of Kansas City Economic Symposium at Jackson Hole, pgs. 285-333.

Romer, Christina and David Romer. (2019). Fiscal space and the aftermath of financial crises: how it matters and why. NBER Working Paper 25768.

Scheubel, Beatrice, Livio Stracca, and Cedric Tille. (2019). "The Global Financial Cycle and Capital Flow Episodes: A Wobbly Link?” European Central Bank Working Paper Series 2337

https://ideas.repec.org/p/ecb/ecbwps/20192337.html. 
Shin, Hyun Song. (2013). "The Second Phase of Global Liquidity and Its Impact on Emerging Markets." Speech at the Federal Reserve Bank of San Francisco Asia Economic Policy Conference, San Francisco.

Sveriges Riksbank. (2012). Financial Stability Report 2012:1. Available at:

http://www.riksbank.se/Documents/Rapporter/FSR/2012/FSR 1/rap fsr1 120601 eng.pdf

Wachter, Jessica. (2013). "Can Time-Varying Risk of Rare Disasters Explain Aggregate Stock Market Volatility?" Journal of Finance 68 (3): 987-1035 


\section{Appendix 1: A Sketch of the Potential Impact of Macroprudential Policy on Banks and Firms after Risk Shocks.}

To begin, consider a representative bank and firm, both domiciled locally. ${ }^{47}$ The bank has three funding sources: deposits (in local currency or LC), dollar cross-border loans (from other banks), and capital (retained earnings, shareholder equity, etc.). The bank lends in the form of LC mortgages to households and dollar loans to firms. We make this simple assumption to separate loans to households and firms (which can be subject to different regulations). The balance sheets can be easily modified to include LC loans to the corporate sector. The bank also holds "cash" broadly defined (i.e., any low-risk, highly liquid, LC asset, including US Treasuries) and begins with cash equal to $10 \%$ of the value of its deposits and loans to meet liquidity requirements. To keep the example simple, assume the bank hedges against direct exchange rate risk, i.e., matches dollar lending to dollar funding. The bank must also meet a capital adequacy requirement (CAR) of $8 \% .{ }^{48}$ Initially, let us consider the risk weights as $50 \%$ on all loans and $0 \%$ on cash. The corporate sector setup is even more straightforward; it has one asset (PP\&E). Firms are financed primarily by dollar bank loans, plus a small share of equity investment (in local currency) and the potential to raise additional dollar debt in corporate bond markets. Firms initially obtain all their nonequity financing through bank loans (instead of corporate bonds) as bank loans are cheaper (because they are secured by the firm assets and have seniority over other funding). Scenario A provides a sample balance sheet for the bank and firm, with all values expressed in local currency and round numbers to simplify the calculation.

Scenario A: Starting Point with no macroprudential regulations. BANK

\begin{tabular}{|c|c|c|c|c|c|c|c|}
\hline & \multirow{2}{*}{\multicolumn{3}{|c|}{ Liabilities }} & \multirow{2}{*}{\multicolumn{2}{|c|}{ Assets }} & \multirow{2}{*}{\multicolumn{2}{|c|}{ Liabilities }} \\
\hline Assets & & & & & & & \\
\hline Mortgages & 275 & Deposits & 300 & PP\&E & 110 & \$ Bank loans & 100 \\
\hline$\$$ Corporate loans & 100 & $\$ \mathrm{X}$-border loans & 100 & & & \$ Corp bonds & 0 \\
\hline Cash & 40 & Capital & 15 & & & Equity & 10 \\
\hline & 415 & & 415 & & 110 & & 110 \\
\hline
\end{tabular}

Note: $C A R=8.0 \%$

Next, consider how the balance sheets would change in response to "modest risk-off" and "extreme riskoff" states. To keep it simple, assume changes in risk only affect balance sheets through exchange rate movements, with the modest risk-off state corresponding to a 5\% depreciation (relative to the dollar) and the extreme risk-off state corresponding to a 50\% depreciation. We assume that the dollar loan contracts to firms are such that the LC values on firm and bank balance sheets revalue when the exchange rate changes. The new balance sheet in the modest risk-off state is shown in Scenario B, with changes from the starting point highlighted in grey.

Scenario B: No macroprudential regulations. Modest risk-off (5\% depreciation) BANK

\begin{tabular}{|c|c|c|c|c|c|c|c|}
\hline \multicolumn{2}{|l|}{ Assets } & \multicolumn{2}{|l|}{ Liabilities } & \multicolumn{2}{|c|}{ Assets } & \multicolumn{2}{|c|}{ Liabilities } \\
\hline Mortgages & 275 & Deposits & 300 & PP\&E & 110 & \$ Bank loans & 105 \\
\hline$\$$ Corporate loans & 105 & $\$ X$-border loans & 105 & & & $\$$ Corp bonds & 0 \\
\hline Cash & 40 & Capital & 15 & & & Equity & 5 \\
\hline
\end{tabular}

Note: $C A R=7.9 \%$

${ }^{47}$ We abstract from the nuances associated with the operations of US banks and their branches in foreign countries.

${ }^{48} \mathrm{CAR}$ is calculated as capital divided by the value of each asset multiplied by the asset's respective risk weight. 
In the modest risk-off scenario, the firm's equity value falls from 10 to 5 (and equity investors suffer equivalent losses) due to the negative impact of the depreciation on the dollar loans (with no corresponding boost to assets), but the firm remains solvent and can repay its bank loans. Also, note that a depreciation that impacts the balance sheet will appear on the firm's income statement as a foreign exchange valuation loss, capturing the erosion in the firm's equity value when the exchange rate depreciates. The impact on the bank is minimal - although the small $0.1 \mathrm{pp}$ decline in the CAR ratio will require a modest adjustment, such as raising equity.

In contrast, in the extreme risk-off scenario, when the exchange rate depreciates by $50 \%$, the firm goes bankrupt, equity investors lose their entire investment (of 10), and the firm cannot repay its bank loan. Even if the bank collects the total value of the firm's assets and wipes out the bank's capital, the bank will still require a bailout, regulatory forbearance, or substantial additional capital. Note that in our simple example, if the firm cannot raise alternative funding sources (such as via bond or equity markets) and the bank does not raise additional capital, an exchange rate depreciation exceeding $10 \%$ will make the firm insolvent and constitute a direct hit to bank capital. A depreciation exceeding $15 \%$ will wipe out all bank capital. These large effects on banks occur even though the bank is hedged against direct exchange rate risk because the exchange rate movement affects the solvency of the firms which borrow from the banks.

Now, assume that the country decides to tighten macroprudential regulations to improve the resilience of its banking system to these types of extreme risk-off scenarios. One approach is to adjust regulations to directly address the risks around foreign currency (FX) exposures, such as by increasing the bank's risk weight in the CAR to $100 \%$ for dollar loans (compared to $50 \%$ for LC loans). If this regulation were in place at the start (Scenario A), the bank would no longer satisfy the CAR requirement with the tighter FX regulations. ${ }^{49}$ A simple response would be for banks to reduce dollar-denominated corporate loans (which are now relatively more expensive) to meet the tighter macroprudential requirements, such as in Scenario C. Then, when the firm can no longer obtain as large a dollar loan from the bank, it could shift to issuing corporate dollar bonds to make up for the difference relative to its optimal level of debt in Scenario A.

Scenario C: Tighter regulations on FX capital weights. BANK

\begin{tabular}{|c|c|c|c|c|c|c|}
\hline \multirow{2}{*}{\multicolumn{4}{|c|}{ Liahilities }} & \multirow{2}{*}{\multicolumn{3}{|c|}{ Liabilities }} \\
\hline & & & & & & \\
\hline Mortgages & 275 & Deposits & 300 & PP\&E 110 & \$ Bank loans & 50 \\
\hline$\$$ Corporate loans & 50 & $\$ \mathrm{X}$-border loans & 50 & & \$ Corp bonds & 50 \\
\hline Cash & 40 & Capital & 15 & & Equity & 10 \\
\hline & 365 & & 365 & 110 & & 110 \\
\hline
\end{tabular}

Note: $C A R=8.0 \%$ (with tighter macroprudential regulations on risk weights for FX loans)

Then, it is straightforward to calculate the balance sheets of the bank and the firm with these tighter regulations in the same modest risk-off and extreme risk-off states as above. In the modest risk-off Scenario D, the impact on the bank is similar to that with no macroprudential regulation (a modest increase in the local currency value of both assets and liabilities, leading to a $0.1 \mathrm{pp}$ reduction in the CAR). In the extreme risk-off scenario, however, the bank is more resilient because of the tighter macroprudential regulations. The firm still goes bankrupt, but the bank can now recover the total value of its corporate loans. There would still be an adverse impact on the bank's balance sheet and a need to raise additional equity funding or receive regulatory forbearance to meet the CAR requirement — but the bank would be in a meaningfully stronger position than if it had not reduced its riskier exposures in response to

${ }^{49}$ The calculation in Scenario A for the CAR with the additional FX regulation is: $15 /[(50 \% * 275)+(100 \% * 100)]$ $6.3 \%$, which is less than the required $8 \%$. 
the macroprudential regulations. In sharp contrast, however, bond investors are more negatively affected. Notice that the value of dollar-denominated corporate bonds falls as we move from Scenario D to Scenario $\mathrm{E}$ as the exchange rate exposure rises and the firm defaults on corporate bondholders. In other words, as bond investors stepped in to meet the demand for dollar loans from firms, they became more exposed to corporate FX risks and suffered more significant losses when risk increased. This simple example does not attempt to model hedging by corporate investors against FX risk - but the critical point is that tighter macroprudential regulations caused the risks related to exchange rate movements to shift from banks to bond investors, and this risk-shifting was only significant in the extreme risk scenario.

Scenario D: Tighter regulations on FX capital weights. Modest risk-off (5\% depreciation) BANK

\begin{tabular}{|c|c|c|c|c|c|c|c|}
\hline \multicolumn{2}{|l|}{ Assets } & \multicolumn{2}{|c|}{ Liabilities } & \multicolumn{2}{|c|}{ Assets } & \multicolumn{2}{|c|}{ Liabilities } \\
\hline Mortgages & 275 & Deposits & 300 & PP\&E & 110 & \$ Bank loans & 52.5 \\
\hline$\$$ Corporate loans & 52.5 & $\$ \mathrm{X}$-border loans & 52.5 & & & \$ Corp bonds & 52.5 \\
\hline Cash & 40 & Capital & 15 & & & Equity & 5 \\
\hline & 367.5 & & 367.5 & & 110 & & 110 \\
\hline
\end{tabular}

Note: $C A R=7.9 \%$ (with tighter macroprudential regulations on risk weights for FX loans)

Scenario E: Tighter regulations on FX capital weights. Extreme risk-off (50\% depreciation) BANK

\begin{tabular}{|c|c|c|c|c|c|c|c|}
\hline \multicolumn{2}{|l|}{ Assets } & \multicolumn{2}{|c|}{ Liabilities } & \multicolumn{2}{|c|}{ Assets } & \multicolumn{2}{|c|}{ Liabilities } \\
\hline Mortgages & 275 & Deposits & 300 & PP\&E & 110 & \$ Bank loans & 75 \\
\hline$\$$ Corporate loans & 75 & $\$$ X-border loans & 75 & & & \$ Corp bonds & 35 \\
\hline Cash & 40 & Capital & 15 & & & Equity & 0 \\
\hline & 390 & & 390 & & 110 & & 110 \\
\hline
\end{tabular}

Note: $C A R=7.1 \%$ (with tighter macroprudential regulations on risk weights for FX loans)

As a final extension, consider Scenario $\mathrm{F}$, where the country tightens macroprudential regulations by increasing the $\mathrm{CCyB}$ ratio by $2 \%$ (instead of tightening capital requirements on FX loans). To keep this simple, assume the CCyB regulation translates to a required CAR of 10\% (instead of the initial $8 \%$ with no macroprudential regulation). Returning to the initial Scenario A, banks could adjust by reducing their loans to households and companies by an equal amount and putting the freed-up funds into cash (or any asset with zero risk weights). The bank could invest the funds from the reduced dollar loans in dollardenominated risk-free assets (such as US Treasuries), called "safe assets" below. Scenario F shows a possible adjustment, which corresponds to a reduction in household and corporate loans by $20 \%$ to exactly satisfy the tighter $\mathrm{CCyB}$ requirement. Here we assume that the risk weights attached to both mortgages and dollar corporate loans remain at 50\% (as in the initial Scenario A). The firm could respond to the reduced availability of bank loans by issuing dollar corporate debt (as occurred in response to the tighter regulations in Scenario C).

Scenario F: $\underline{\text { Tighter regulation through } C C y B}$.

\begin{tabular}{|c|c|c|c|c|c|c|}
\hline \multicolumn{4}{|c|}{ BANK } & \multicolumn{3}{|c|}{ FIRM } \\
\hline Assets & & Liabilities & & Assets & Liabiliti & \\
\hline Mortgages & 220 & Deposits & 300 & PP\&E 110 & \$ Bank loans & 80 \\
\hline$\$$ Corporate loans & 80 & $\$ \mathrm{X}$-border loans & 100 & & \$ Corp bonds & 20 \\
\hline Cash & 95 & Capital & 15 & & Equity & 10 \\
\hline \$ Safe asset & 20 & & & & & \\
\hline & 415 & & 415 & 110 & & 110 \\
\hline
\end{tabular}

Note: $C A R=10.0 \%$ (includes additional requirement of $C C y B=2.0 \%$ ) 
Finally, assume the same modest and extreme risk-off scenarios. In the modest risk-off state (Scenario G), the bank and firm continue to be only moderately affected, with both entities remaining solvent and banks requiring a small adjustment to meet the tighter $\mathrm{CCyB}$ regulation. Equity and bond investors suffer identical losses as with no regulations or regulations through tighter FX capital requirements (a loss of 5 to equity investors and no loss to bond investors). In the extreme risk-off state with a $50 \%$ exchange rate depreciation, the firm is again insolvent, and the bank continues to be more resilient than the no macroprudential regulation scenario. The main difference from the other scenarios, however, is the impact on bond investors. Bond investors lose the entire value of their investment and therefore suffer greater losses than in the extreme risk-off scenario with no regulations, but smaller losses than with regulations tightened through FX risk weights. The logic is straightforward; bond investors are more exposed to extreme risk shocks when any macroprudential regulations are in place as investors take on some of the risk previously born by banks. Bond investors, however, are less exposed when the macroprudential regulations generate less shifting of the riskier exposures from banks to investors (as under the more general CCyB that affected all types of loans, rather than the targeted FX requirement).

Scenario G: Tighter regulation through CCyB. Modest risk-off (5\% depreciation) BANK

\begin{tabular}{|c|c|c|c|c|c|c|}
\hline \multicolumn{2}{|l|}{ Assets } & \multicolumn{2}{|l|}{ Liabilities } & Assets & \multicolumn{2}{|c|}{ Liabilities } \\
\hline Mortgages & 220 & Deposits & 300 & $\begin{array}{ll}\text { PP\&E } & 110\end{array}$ & \$ Bank loans & 84 \\
\hline$\$$ Corporate loans & 84 & \$ X-border loans & 105 & & \$ Corp bonds & 21 \\
\hline Cash & 95 & Capital & 15 & & Equity & 5 \\
\hline$\$$ Safe asset & 21 & & & & & \\
\hline & 420 & & 420 & 110 & & 110 \\
\hline
\end{tabular}

To summarize, macroprudential regulations (through either tighter FX capital requirements or a stricter $\mathrm{CCyB}$ ) have a minimal effect on banks, firms, and investors in the modest risk-off state but significant effects in extreme risk-off states. Macroprudential regulations meaningfully increase the resilience of banks to extreme risk-off states (allowing them to avoid bankruptcy) but make bond investors less resilient - as macroprudential regulations cause firms to shift risky exposures from banks to investors. Moreover, bond investors suffer larger losses when the types of macroprudential regulations cause banks to reduce their lending by more and/or cause more of the risk to shift onto investors' balance sheets. These simple examples could also easily be extended to capture other results documented in our empirical analysis, such as for regulations shifting riskier exposures to equity investors or focused on other types of risks (such as mortgage exposures) that shift to other non-bank financial intermediaries. ${ }^{50}$

\footnotetext{
${ }^{50}$ For example, regulations could increase the vulnerability of equity investors to extreme risk-off states if the regulations caused companies to respond to the reduction in bank loans by issuing equity as well as corporate bonds. Or, if regulations increased the risk weights for mortgage lending and caused households to obtain loans through other channels, an extreme risk-off scenario that increases defaults on mortgage debt could generate similar effects as in the scenario with higher risk weights for FX loans.
} 
Table 1

First Stage of Policy Shocks Estimation

\begin{tabular}{|c|c|c|c|c|c|c|c|c|}
\hline \multirow[b]{2}{*}{ MP Stance } & \multicolumn{4}{|c|}{ All Variables } & \multicolumn{4}{|c|}{ After Inclusion Procedures } \\
\hline & $\begin{array}{l}\text { Broad } \\
\text { Index }\end{array}$ & $\begin{array}{l}\text { Narrow } \\
\text { Index }\end{array}$ & $\begin{array}{l}\text { Country- } \\
\text { Relative }\end{array}$ & $\begin{array}{l}\text { Time- } \\
\text { Relative }\end{array}$ & $\begin{array}{l}\text { Broad } \\
\text { Index }\end{array}$ & $\begin{array}{l}\text { Narrow } \\
\text { Index }\end{array}$ & $\begin{array}{l}\text { Country- } \\
\text { Relative }\end{array}$ & $\begin{array}{c}\text { Time- } \\
\text { Relative }\end{array}$ \\
\hline Crisis in last 12 months & $\begin{array}{c}0.0254 \\
(0.0477)\end{array}$ & $\begin{array}{l}0.136 * * \\
(0.0612)\end{array}$ & $\begin{array}{c}0.0158 \\
(0.0250)\end{array}$ & $\begin{array}{c}0.0617^{* *} \\
(0.0250)\end{array}$ & & $\begin{array}{l}0.119 * * \\
(0.0526)\end{array}$ & & \\
\hline Distance to default & $\begin{array}{c}0.0175^{* * *} \\
(0.00267)\end{array}$ & $\begin{array}{c}0.0208^{* * *} \\
(0.00343)\end{array}$ & $\begin{array}{c}0.0134^{* * *} \\
(0.00140)\end{array}$ & $\begin{array}{c}0.00872^{* * *} \\
(0.00140)\end{array}$ & $\begin{array}{l}0.0162^{* * *} \\
(0.00242)\end{array}$ & $\begin{array}{l}0.0231^{* * *} \\
(0.00307)\end{array}$ & $\begin{array}{c}0.00951^{* * *} \\
(0.00126)\end{array}$ & $\begin{array}{c}0.00587^{* * *} \\
(0.00120)\end{array}$ \\
\hline Romer \& Romer count & $\begin{array}{c}-0.0135^{* * *} \\
(0.00242)\end{array}$ & $\begin{array}{c}-0.0168^{* * *} \\
(0.00311)\end{array}$ & $\begin{array}{c}-0.00417^{* * *} \\
(0.00126)\end{array}$ & $\begin{array}{c}-0.00554^{* * *} \\
(0.00126)\end{array}$ & $\begin{array}{l}-0.0121 * * * \\
(0.000455)\end{array}$ & $\begin{array}{l}-0.0132 * * * \\
(0.000572)\end{array}$ & $\begin{array}{l}0.00184^{*} \\
(0.00105)\end{array}$ & $\begin{array}{c}-0.00378^{* * *} \\
(0.00101)\end{array}$ \\
\hline Romer \& Romer intensity & $\begin{array}{c}0.00220 \\
(0.00201)\end{array}$ & $\begin{array}{c}0.00362 \\
(0.00259)\end{array}$ & $\begin{array}{l}0.000545 \\
(0.00105)\end{array}$ & $\begin{array}{l}-0.000774 \\
(0.00105)\end{array}$ & & & $\begin{array}{c}-0.00377^{* * *} \\
(0.000876)\end{array}$ & $\begin{array}{l}-0.00149 * \\
(0.000838)\end{array}$ \\
\hline Sovereign crisis count & $\begin{array}{c}-0.0681 * * * \\
(0.0105)\end{array}$ & $\begin{array}{c}-0.0826^{* * *} \\
(0.0135)\end{array}$ & $\begin{array}{c}-0.0365^{* * *} \\
(0.00547)\end{array}$ & $\begin{array}{c}-0.0700^{* * *} \\
(0.00547)\end{array}$ & $\begin{array}{c}-0.0807^{* * *} \\
(0.00973)\end{array}$ & $\begin{array}{c}-0.0848^{* * *} \\
(0.0123)\end{array}$ & $\begin{array}{l}-0.0261^{* * *} \\
(0.00474)\end{array}$ & $\begin{array}{c}-0.0676^{* * *} \\
(0.00457)\end{array}$ \\
\hline Currency crisis count & $\begin{array}{c}-0.00587^{* *} \\
(0.00265)\end{array}$ & $\begin{array}{l}-0.00626^{*} \\
(0.00341)\end{array}$ & $\begin{array}{l}-0.00202 \\
(0.00137)\end{array}$ & $\begin{array}{c}0.00326 * * \\
(0.00137)\end{array}$ & $\begin{array}{c}-0.00926 * * * \\
(0.00246)\end{array}$ & $\begin{array}{c}-0.0141^{* * *} \\
(0.00314)\end{array}$ & $\begin{array}{l}-0.00227^{*} \\
(0.00118)\end{array}$ & \\
\hline Banking crisis count & $\begin{array}{c}0.00377 \\
(0.00539)\end{array}$ & $\begin{array}{c}0.00654 \\
(0.00692) \\
\end{array}$ & $\begin{array}{c}0.00159 \\
(0.00281) \\
\end{array}$ & $\begin{array}{c}0.0150 * * * \\
(0.00281) \\
\end{array}$ & $\begin{array}{c}0.0127 * * * \\
(0.00225) \\
\end{array}$ & $\begin{array}{c}0.0150 * * * \\
(0.00286) \\
\end{array}$ & $\begin{array}{c}0.0104^{* * *} \\
(0.00234) \\
\end{array}$ & $\begin{array}{l}0.0157^{* * *} \\
(0.00224) \\
\end{array}$ \\
\hline Cross-border ratio & $\begin{array}{l}0.434 * * * \\
(0.0346)\end{array}$ & $\begin{array}{l}0.696 * * * \\
(0.0445)\end{array}$ & $\begin{array}{l}0.123 * * * \\
(0.0182)\end{array}$ & $\begin{array}{c}-0.0927^{* * *} \\
(0.0182)\end{array}$ & $\begin{array}{c}0.389 * * * \\
(0.0336)\end{array}$ & $\begin{array}{l}0.692 * * * \\
(0.0427)\end{array}$ & $\begin{array}{c}0.115^{* * *} \\
(0.0178)\end{array}$ & $\begin{array}{c}-0.0952 * * * \\
(0.0171)\end{array}$ \\
\hline Domestic credit growth & $\begin{array}{c}0.00678^{* * *} \\
(0.00167)\end{array}$ & $\begin{array}{c}0.00926 * * * \\
(0.00215)\end{array}$ & $\begin{array}{l}0.0106 * * * \\
(0.000876)\end{array}$ & $\begin{array}{r}-0.00245^{* * *} \\
(0.000876)\end{array}$ & $\begin{array}{c}0.00500 * * * \\
(0.00132)\end{array}$ & $\begin{array}{c}0.00849 * * * \\
(0.00167)\end{array}$ & $\begin{array}{l}0.00580 * * * \\
(0.000654)\end{array}$ & $\begin{array}{c}-0.00341^{* * *} \\
(0.000666)\end{array}$ \\
\hline Property prices & $\begin{array}{c}-0.00398 * * * \\
(0.00145) \\
\end{array}$ & $\begin{array}{c}-0.00443 * * \\
(0.00186) \\
\end{array}$ & $\begin{array}{c}-0.00415^{* * *} \\
(0.000757) \\
\end{array}$ & $\begin{array}{c}-0.00158^{* *} \\
(0.000757) \\
\end{array}$ & & & & \\
\hline REER growth & $\begin{array}{c}0.366 * * * \\
(0.135)\end{array}$ & $\begin{array}{c}0.418^{* *} \\
(0.173)\end{array}$ & $\begin{array}{c}0.137^{*} \\
(0.0708)\end{array}$ & $\begin{array}{l}0.172 * * \\
(0.0708)\end{array}$ & $\begin{array}{c}0.316 * * * \\
(0.116)\end{array}$ & & $\begin{array}{l}0.0932 * \\
(0.0562)\end{array}$ & $\begin{array}{l}0.151^{* * *} \\
(0.0535)\end{array}$ \\
\hline Growth forecast & $\begin{array}{c}-0.0680 * * * \\
(0.00869)\end{array}$ & $\begin{array}{c}-0.0409 * * * \\
(0.0112)\end{array}$ & $\begin{array}{c}-0.0125^{* * *} \\
(0.00453)\end{array}$ & $\begin{array}{l}-0.00690 \\
(0.00453)\end{array}$ & $\begin{array}{c}-0.0756 * * * \\
(0.00670)\end{array}$ & $\begin{array}{c}-0.0506 * * * \\
(0.00858)\end{array}$ & $\begin{array}{c}-0.0195^{* * *} \\
(0.00317)\end{array}$ & $\begin{array}{c}-0.0186^{* * *} \\
(0.00318)\end{array}$ \\
\hline Inflation & $\begin{array}{c}0.0187^{* * *} \\
(0.00570)\end{array}$ & $\begin{array}{c}0.0613 * * * \\
(0.00732)\end{array}$ & $\begin{array}{c}0.00249 \\
(0.00298)\end{array}$ & $\begin{array}{c}0.0230 * * * \\
(0.00298)\end{array}$ & $\begin{array}{c}0.0136 * * * \\
(0.00351)\end{array}$ & $\begin{array}{c}0.0354 * * * \\
(0.00446)\end{array}$ & & $\begin{array}{c}0.0115^{* * *} \\
(0.00158)\end{array}$ \\
\hline Real GDP growth & $\begin{array}{c}1.136^{* * *} \\
(0.392) \\
\end{array}$ & $\begin{array}{c}1.873 * * * \\
(0.504) \\
\end{array}$ & $\begin{array}{c}1.204^{* * *} \\
(0.205)\end{array}$ & $\begin{array}{c}0.747 * * * \\
(0.205) \\
\end{array}$ & & & & $\begin{array}{c}0.400 * * * \\
(0.146)\end{array}$ \\
\hline Openness & $\begin{array}{c}0.222 * * * \\
(0.0241)\end{array}$ & $\begin{array}{c}-0.0827^{* * *} \\
(0.0309)\end{array}$ & $\begin{array}{c}0.0444^{* * *} \\
(0.0126)\end{array}$ & $\begin{array}{l}0.00176 \\
(0.0127)\end{array}$ & $\begin{array}{c}0.155^{* * *} \\
(0.0220)\end{array}$ & $\begin{array}{c}-0.0841 * * * \\
(0.0275)\end{array}$ & $\begin{array}{c}0.0844^{* * *} \\
(0.0112)\end{array}$ & \\
\hline FX Volatility & $\begin{array}{c}0.000753 \\
(0.000710)\end{array}$ & $\begin{array}{c}-0.000360 \\
(0.000912)\end{array}$ & $\begin{array}{c}-0.000112 \\
(0.000373)\end{array}$ & $\begin{array}{c}0.000104 \\
(0.000373)\end{array}$ & & & & \\
\hline Institutional quality & $\begin{array}{l}0.00748 * \\
(0.00389)\end{array}$ & $\begin{array}{l}0.0120^{* *} \\
(0.00500)\end{array}$ & $\begin{array}{l}-0.000898 \\
(0.00204)\end{array}$ & $\begin{array}{c}-0.00528^{* * *} \\
(0.00204)\end{array}$ & $\begin{array}{l}0.0125^{* * *} \\
(0.00317)\end{array}$ & $\begin{array}{l}0.0105^{* * *} \\
(0.00400)\end{array}$ & & $\begin{array}{c}-0.00375^{* *} \\
(0.00158)\end{array}$ \\
\hline Policy rate & $\begin{array}{l}-0.183^{* * *} \\
(0.00861)\end{array}$ & $\begin{array}{c}-0.226 * * * \\
(0.0111)\end{array}$ & $\begin{array}{c}-0.0865^{* * *} \\
(0.00451)\end{array}$ & $\begin{array}{c}-0.142 * * * \\
(0.00452)\end{array}$ & $\begin{array}{c}-0.198 * * * \\
(0.00754)\end{array}$ & $\begin{array}{l}-0.244 * * * \\
(0.00938)\end{array}$ & $\begin{array}{c}-0.0550 * * * \\
(0.00365)\end{array}$ & $\begin{array}{l}-0.130 * * * \\
(0.00353)\end{array}$ \\
\hline$i-i^{*}$ & $\begin{array}{l}0.132 * * * \\
(0.00966)\end{array}$ & $\begin{array}{c}0.123 * * * \\
(0.0124)\end{array}$ & $\begin{array}{c}0.0553^{* * *} \\
(0.00506)\end{array}$ & $\begin{array}{c}0.0892^{* * *} \\
(0.00506)\end{array}$ & $\begin{array}{l}0.169 * * * \\
(0.00807)\end{array}$ & $\begin{array}{c}0.155^{* * *} \\
(0.0102)\end{array}$ & $\begin{array}{c}0.0306 * * * \\
(0.00387)\end{array}$ & $\begin{array}{c}0.0853^{* * *} \\
(0.00360)\end{array}$ \\
\hline Exchange rate regime & $\begin{array}{r}-0.00250 \\
(0.0744) \\
\end{array}$ & $\begin{array}{l}-0.0618 \\
(0.0955) \\
\end{array}$ & $\begin{array}{c}-0.145^{* * *} \\
(0.0391) \\
\end{array}$ & $\begin{array}{c}-0.290 * * * \\
(0.0391) \\
\end{array}$ & $\begin{array}{c}-0.362 * * * \\
(0.0576) \\
\end{array}$ & & $\begin{array}{c}-0.115^{* * *} \\
(0.0277) \\
\end{array}$ & $\begin{array}{c}-0.274^{* * *} \\
(0.0261) \\
\end{array}$ \\
\hline $\begin{array}{l}\text { Number of countries } \\
\text { F-statistic }\end{array}$ & $\begin{array}{c}41 \\
70.46\end{array}$ & $\begin{array}{c}41 \\
65.36\end{array}$ & $\begin{array}{c}42 \\
46.11\end{array}$ & $\begin{array}{c}42 \\
102.3\end{array}$ & $\begin{array}{c}44 \\
107.6\end{array}$ & $\begin{array}{c}44 \\
110.6\end{array}$ & $\begin{array}{c}55 \\
53.56\end{array}$ & $\begin{array}{c}55 \\
160.2\end{array}$ \\
\hline
\end{tabular}

Notes: Results of first-stage regressions predicting the macroprudential stance listed at the top as a function of the variables listed to the left. The left side of the table reports results when all variables are included, and the right side is after the inclusion/exclusion procedure described in Section 4.1. See Appendix A for details on the definitions and sources for the explanatory variables, and Appendix B for information on the measures of the macroprudential stance. Bootstrapped standard errors clustered by country are in parentheses. ${ }^{*}, * *$, and $* * *$ denote significance at the $10 \%, 5 \%$ and $1 \%$ levels, respectively. 
Table 2

Baseline Results

Bond Flows, the Macroprudential Stance and Risk

\begin{tabular}{|c|c|c|c|c|}
\hline MP Stance Measures & $\begin{array}{l}\text { Broad Intensity } \\
\text { Index } \\
\text { (1) }\end{array}$ & $\begin{array}{l}\text { Narrow Intensity } \\
\text { Index } \\
\text { (2) }\end{array}$ & $\begin{array}{c}\text { Country-Relative } \\
\text { Dummy } \\
\text { (3) }\end{array}$ & $\begin{array}{c}\text { Time-Relative } \\
\text { Dummy } \\
\text { (4) }\end{array}$ \\
\hline \multirow[t]{2}{*}{ MP Stance } & 0.00151 & 0.00221 & -0.00837 & -0.00672 \\
\hline & $(0.00540)$ & $(0.00438)$ & $(0.00972)$ & $(0.0100)$ \\
\hline \multirow[t]{2}{*}{ Risk } & $-0.0920 * * *$ & $-0.0920 * * *$ & $-0.0979 * * *$ & $-0.0976 * * *$ \\
\hline & $(0.00426)$ & $(0.00428)$ & $(0.00390)$ & $(0.00400)$ \\
\hline Interaction of $M P$ & $-0.0182 * * *$ & $-0.0125 * * *$ & $-0.0220 * * *$ & -0.00420 \\
\hline stance and risk & $(0.00444)$ & $(0.00341)$ & $(0.00702)$ & $(0.00820)$ \\
\hline \multicolumn{5}{|l|}{ Pull/Domestic } \\
\hline \multirow[t]{2}{*}{ Exchange Rate (t-1) } & -0.0000136 & -0.0000132 & $-1.52 e-05^{*}$ & -0.000015 \\
\hline & $(-0.00000916)$ & $(-0.00000917)$ & $(-0.00000909)$ & $(-0.00000922)$ \\
\hline \multirow[t]{2}{*}{$i-i^{*}(t-1)$} & $-0.00661 * * *$ & $-0.00664 * * *$ & $-0.00603 * * *$ & $-0.00587^{* * *}$ \\
\hline & $(0.00178)$ & $(0.00179)$ & $(0.00161)$ & $(0.00162)$ \\
\hline \multirow[t]{2}{*}{ Real Growth (t-1) } & -0.153 & -0.158 & -0.106 & -0.100 \\
\hline & $(0.130)$ & $(0.130)$ & $(0.125)$ & $(0.123)$ \\
\hline \multirow[t]{2}{*}{ FX Volatility } & -0.000855 & -0.000855 & -0.000793 & -0.000786 \\
\hline & $(0.000622)$ & $(0.000627)$ & $(0.000606)$ & $(0.000621)$ \\
\hline \multirow[t]{2}{*}{ Openness } & -0.00788 & -0.00760 & -0.00821 & -0.00831 \\
\hline & $(0.00918)$ & $(0.00920)$ & $(0.00850)$ & $(0.00847)$ \\
\hline \multirow[t]{2}{*}{ Inst. Quality } & $-0.00308^{* *}$ & $-0.00308 * *$ & $-0.00240 *$ & $-0.00228^{*}$ \\
\hline & $(0.00144)$ & $(0.00144)$ & $(0.00130)$ & $(0.00130)$ \\
\hline \multicolumn{5}{|l|}{ Push/Global } \\
\hline \multirow{2}{*}{ AE Monetary Stance $(t-1)$} & $-0.0552 * * *$ & $-0.0553 * * *$ & $-0.0542 * * *$ & $-0.0543 * * *$ \\
\hline & $(0.00873)$ & $(0.00874)$ & $(0.00816)$ & $(0.00818)$ \\
\hline \multirow[t]{2}{*}{$A E$ IP Growth (t-1) } & $3.532 * * *$ & $3.530 * * *$ & $3.260 * * *$ & $3.325 * * *$ \\
\hline & $(0.522)$ & $(0.522)$ & $(0.501)$ & $(0.500)$ \\
\hline \multirow[t]{2}{*}{$A R(1)$} & $0.463 * * *$ & $0.463^{* * *}$ & $0.474 * * *$ & $0.474 * * *$ \\
\hline & $(0.0106)$ & $(0.0106)$ & (0.00977) & (0.00958) \\
\hline \multirow[t]{2}{*}{ Constant } & $0.435 * * *$ & $0.434 * * *$ & $0.377 * * *$ & $0.367 * * *$ \\
\hline & $(0.110)$ & $(0.110)$ & $(0.0991)$ & $(0.100)$ \\
\hline \# Observations & 28,070 & 28,070 & 32,742 & 32,573 \\
\hline \# Countries & 44 & 44 & 56 & 55 \\
\hline R-squared & 0.396 & 0.396 & 0.407 & 0.406 \\
\hline \multicolumn{5}{|c|}{$\begin{array}{l}\text { Notes: Full results for equation } 3 \text { regressing portfolio bond flows on Risk, a measure of the MP Stance (listed at the } \\
\text { top), their interaction, and a set of Pull and Push control variables. Portfolio bond flows are the percent change in } \\
\text { weekly flows based on EPFR data. The measure of the MP Stance is estimated using the policy-shocks approach } \\
\text { based on results in Table } 1 \text {. See Appendix Table B for details on variable definitions and sources and Appendix C for } \\
\text { the list of countries. All specifications include country and time fixed effects. Bootstrapped standard errors clustered } \\
\text { by country are reported in parentheses. }{ }^{*}, * * \text {, and } * * * \text { denote significance at the } 10 \%, 5 \% \text { and } 1 \% \text { levels, } \\
\text { respectively. }\end{array}$} \\
\hline
\end{tabular}


Table 3

Key Coefficients and Marginal Effects across the Risk Distribution Bond Flows and the Macroprudential Stance across the Global Financial Cycle

\begin{tabular}{|c|c|c|c|c|}
\hline MP Stance Measures & $\begin{array}{c}\text { Broad Intensity } \\
\text { Index } \\
\text { (1) }\end{array}$ & $\begin{array}{c}\text { Narrow Intensity } \\
\text { Index } \\
(2) \\
\end{array}$ & $\begin{array}{c}\text { Country-Relative } \\
\text { Dummy } \\
\text { (3) }\end{array}$ & $\begin{array}{c}\text { Time-Relative } \\
\text { Dummy } \\
\text { (4) }\end{array}$ \\
\hline \multicolumn{5}{|l|}{ Unconditional Regressions } \\
\hline \multirow[t]{2}{*}{ MP Stance } & 0.00152 & 0.00231 & -0.00935 & -0.00681 \\
\hline & $(0.00538)$ & $(0.00436)$ & $(0.00965)$ & $(0.0101)$ \\
\hline \multirow[t]{2}{*}{ Risk } & $-0.0916 * * *$ & $-0.0916 * * *$ & $-0.0981 * * *$ & $-0.0976 * * *$ \\
\hline & $(0.00423)$ & $(0.00424)$ & $(0.00398)$ & $(0.00398)$ \\
\hline \multicolumn{5}{|c|}{ Regressions with interaction between risk and the macroprudential stance } \\
\hline \multirow[t]{2}{*}{ MP Stance } & 0.00151 & 0.00221 & -0.00837 & -0.00672 \\
\hline & $(0.00540)$ & $(0.00438)$ & $(0.00972)$ & $(0.0100)$ \\
\hline \multirow[t]{2}{*}{ Risk } & $-0.0920 * * *$ & $-0.0920 * * *$ & $-0.0979 * * *$ & $-0.0976 * * *$ \\
\hline & $(0.00426)$ & $(0.00428)$ & $(0.00390)$ & $(0.00400)$ \\
\hline Interaction of $M P$ & $-0.0182 * * *$ & $-0.0125^{* * *}$ & $-0.0220 * * *$ & -0.00420 \\
\hline stance and risk & $(0.00444)$ & $(0.00341)$ & $(0.00702)$ & $(0.00820)$ \\
\hline \multicolumn{5}{|c|}{$\begin{array}{l}\text { Marginal effects of tighter macroprudential policy at different risk levels } \\
\text { (Extreme risk-on) }\end{array}$} \\
\hline \multirow[t]{2}{*}{ Risk@0.5\% } & $0.0493 * * *$ & $0.0348 * * *$ & $0.0494 * * *$ & 0.00428 \\
\hline & $(0.00864)$ & $(0.00652)$ & $(0.0136)$ & $(0.0135)$ \\
\hline \multirow[t]{2}{*}{ Risk@1\% } & $0.0393 * * *$ & $0.0280 * * *$ & $0.0373 * *$ & 0.00198 \\
\hline & (0.0105) & $(0.00814)$ & $(0.0169)$ & $(0.0191)$ \\
\hline \multirow[t]{2}{*}{ Risk @ 5\% } & $0.0256 * * *$ & $0.0187^{* * *}$ & 0.0208 & -0.00116 \\
\hline & $(0.00788)$ & $(0.00620)$ & $(0.0130)$ & $(0.0145)$ \\
\hline \multirow[t]{2}{*}{ Risk@10\% } & $0.0176 * * *$ & $0.0132 * *$ & 0.0111 & -0.00300 \\
\hline & $(0.00661)$ & (0.00528) & $(0.0112)$ & $(0.0122)$ \\
\hline \multirow[t]{2}{*}{ Risk@25\% } & $0.00947^{*}$ & $0.00765^{*}$ & 0.00125 & -0.00488 \\
\hline & $(0.00567)$ & $(0.00461)$ & (0.00995) & $(0.0106)$ \\
\hline \multirow[t]{2}{*}{ Risk@median } & 0.00326 & 0.00340 & -0.00626 & -0.00632 \\
\hline & $(0.00540)$ & $(0.00444)$ & $(0.00963)$ & $(0.0101)$ \\
\hline \multirow[t]{2}{*}{ Risk@75\% } & -0.00512 & -0.00232 & -0.0164 & -0.00825 \\
\hline & $(0.00572)$ & $(0.00469)$ & $(0.0101)$ & $(0.0106)$ \\
\hline \multirow[t]{2}{*}{ Risk@90\% } & $-0.0173 * *$ & $-0.0106^{*}$ & $-0.0311 * *$ & -0.0111 \\
\hline & $(0.00735)$ & $(0.00590)$ & (0.0125) & (0.0134) \\
\hline \multirow[t]{2}{*}{ Risk@95\% } & $-0.0258 * * *$ & $-0.0164 * *$ & $-0.0413 * * *$ & -0.0130 \\
\hline & $(0.00893)$ & $(0.00707)$ & $(0.0148)$ & $(0.0162)$ \\
\hline \multirow[t]{2}{*}{ Risk@99\% } & $-0.0620 * * *$ & $-0.0412 * * *$ & $-0.0852 * * *$ & -0.0214 \\
\hline & (0.0168) & $(0.0130)$ & $(0.0267)$ & $(0.0303)$ \\
\hline Risk@ @9.5\% & $-0.0842 * *$ & $-0.0563 * *$ & $-0.112 * *$ & -0.0265 \\
\hline (Extreme risk-off) & $(0.0394)$ & (0.0269) & $(0.0531)$ & $(0.0346)$ \\
\hline \multicolumn{5}{|c|}{$\begin{array}{l}\text { Notes: Table reports key coefficients from regressions of portfolio bond flows on Risk and different measure of the MP } \\
\text { Stance (listed at the top and estimated using the policy-shocks approach from Table } 1 \text { ). The middle section of the table } \\
\text { reports the main coefficients of interest from the full regression in Table } 2 \text {. The top section of the table reports the } \\
\text { "unconditional" results from the same regression, except excluding the interaction between the MP Stance and Risk. } \\
\text { Each of these regressions includes the full set of controls (not reported) from Table } 2 \text {. The bottom of this table reports } \\
\text { the marginal effects of a } 1 \text { unit increase in the MP Stance when interacted with Risk at different points in the Risk } \\
\text { distribution. See Appendix Table B for details on variable definitions and sources, and Appendix C for a list of countries. } \\
\text { All specifications include country and time fixed effects. Bootstrapped standard errors clustered by country are reported } \\
\text { in parentheses. }{ }^{* * *}, \text { and }{ }^{* * *} \text { denote significance at the } 10 \%, 5 \% \text { and } 1 \% \text { levels, respectively. }\end{array}$} \\
\hline
\end{tabular}


Table 4

Key Coefficients from OLS Estimates

Bond Flows and the Macroprudential Stance across the Global Financial Cycle

\begin{tabular}{|c|c|c|c|c|}
\hline MP Stance Measures & $\begin{array}{l}\text { Broad Intensity Index } \\
\text { (1) }\end{array}$ & $\begin{array}{c}\text { Narrow Intensity } \\
\text { Index } \\
\text { (2) }\end{array}$ & $\begin{array}{c}\text { Country-Relative } \\
\text { Dummy } \\
\text { (3) }\end{array}$ & $\begin{array}{c}\text { Time-Relative } \\
\text { Dummy } \\
\text { (4) }\end{array}$ \\
\hline \multicolumn{5}{|c|}{ Unconditional Regressions } \\
\hline \multirow[t]{2}{*}{ MP Stance } & $-0.00861 * *$ & -0.00536 & -0.0133 & -0.00420 \\
\hline & $(0.00409)$ & $(0.00337)$ & $(0.00871)$ & $(0.0108)$ \\
\hline \multirow[t]{2}{*}{ Risk } & $-0.0933 * * *$ & $-0.0933 * * *$ & $-0.0992 * * *$ & $-0.0993 * * *$ \\
\hline & $(0.00430)$ & $(0.00430)$ & $(0.00417)$ & $(0.00417)$ \\
\hline \multicolumn{5}{|c|}{ Regressions with interaction between risk and the macroprudential stance } \\
\hline \multirow[t]{2}{*}{ MP Stance } & $-0.00734^{*}$ & -0.00453 & -0.0129 & -0.00372 \\
\hline & $(0.00429)$ & $(0.00355)$ & $(0.00869)$ & $(0.0108)$ \\
\hline \multirow[t]{2}{*}{ Risk } & $-0.0902 * * *$ & $-0.0912 * * *$ & $-0.0941 * * *$ & $-0.0818^{* * *}$ \\
\hline & $(0.00433)$ & $(0.00443)$ & $(0.00619)$ & $(0.00713)$ \\
\hline Interaction of $M P$ & $-0.0120 * * *$ & $-0.00699 * * *$ & -0.0101 & $-0.0254 * * *$ \\
\hline stance and risk & $(0.00339)$ & $(0.00254)$ & $(0.00686)$ & $(0.00778)$ \\
\hline \multicolumn{5}{|c|}{$\begin{array}{l}\text { Marginal effects of tighter macroprudential policy at different risk levels } \\
\text { (Extreme risk-on) }\end{array}$} \\
\hline \multirow[t]{2}{*}{ Risk@0.5\% } & $0.0242 * *$ & 0.0138 & 0.0134 & $0.0629 * * *$ \\
\hline & $(0.0114)$ & $(0.00880)$ & $(0.0189)$ & $(0.0221)$ \\
\hline \multirow[t]{2}{*}{ Risk@1\% } & $0.0176^{*}$ & 0.00994 & 0.00789 & $0.0489 * * *$ \\
\hline & $(0.00963)$ & $(0.00752)$ & $(0.0156)$ & $(0.0185)$ \\
\hline \multirow[t]{2}{*}{ Risk@ @\% } & 0.00859 & 0.00472 & 0.000373 & $0.0299 * *$ \\
\hline & $(0.00738)$ & $(0.00586)$ & $(0.0117)$ & $(0.0141)$ \\
\hline \multirow[t]{2}{*}{ Risk@10\% } & 0.00331 & 0.00166 & -0.00404 & 0.0188 \\
\hline & $(0.00617)$ & $(0.00496)$ & (0.00992) & $(0.0122)$ \\
\hline \multirow[t]{2}{*}{ Risk@ 25\% } & -0.00208 & -0.00148 & -0.00855 & 0.00739 \\
\hline & $(0.00508)$ & $(0.00415)$ & $(0.00881)$ & $(0.0110)$ \\
\hline \multirow[t]{2}{*}{ Risk@median } & -0.00618 & -0.00386 & -0.0120 & -0.00128 \\
\hline & $(0.00443)$ & $(0.00366)$ & $(0.00862)$ & $(0.0108)$ \\
\hline \multirow[t]{2}{*}{ Risk@75\% } & $-0.0117 * * *$ & $-0.00708 * *$ & $-0.0166^{*}$ & -0.0130 \\
\hline & $(0.00394)$ & $(0.00325)$ & (0.00935) & $(0.0114)$ \\
\hline \multirow[t]{2}{*}{ Risk@ 90\% } & $-0.0198 * * *$ & $-0.0117 * * *$ & $-0.0233^{*}$ & $-0.0300 * *$ \\
\hline & $(0.00427)$ & $(0.00336)$ & (0.0119) & $(0.0141)$ \\
\hline \multirow[t]{2}{*}{ Risk@ 95\% } & $-0.0253 * * *$ & $-0.0150 * * *$ & $-0.0280 *$ & $-0.0418 * *$ \\
\hline & $(0.00511)$ & $(0.00389)$ & $(0.0143)$ & $(0.0167)$ \\
\hline \multirow[t]{2}{*}{ Risk@ @9\% } & $-0.0493 * * *$ & $-0.0289 * * *$ & $-0.0480 *$ & $-0.0924 * * *$ \\
\hline & $(0.0108)$ & $(0.00795)$ & $(0.0265)$ & $(0.0302)$ \\
\hline Risk@ @9.5\% & $-0.0639 * * *$ & $-0.0374 * * *$ & $-0.0602^{*}$ & $-0.123 * * *$ \\
\hline (Extreme risk-off) & (0.0147) & (0.0108) & $(0.0345)$ & $(0.0392)$ \\
\hline
\end{tabular}

Notes: This table replicates the results from Table 3 of the key coefficients from regressions of portfolio bond flows on Risk and different measure of the MP Stance. The only difference is that the MP Stance is measured using a lag of the measure listed at the top-instead of using the estimated policy shock based on first-stage estimates (as in all other reported regression results). These estimates are therefore closer to the estimation approach in previous literature, but less effective at controlling for endogeneity. See notes to Table 3 for additional details on variables, definitions, and interpreting the coefficients. Bootstrapped standard errors clustered by country are reported in parentheses. $*, * *$, and $* * *$ denote significance at the $10 \%, 5 \%$ and $1 \%$ levels, respectively. 
Table 5

More Granular Measures of the Macroprudential Stance Bond Flows and the Macroprudential Stance across the Global Financial Cycle

\begin{tabular}{|c|c|c|c|c|c|}
\hline MP Stance & $\begin{array}{l}\text { LTV } \\
(1)\end{array}$ & $\begin{array}{c}\text { CCyB } \\
(2)\end{array}$ & $\begin{array}{l}\text { FX Measures } \\
\text { (3) }\end{array}$ & $\begin{array}{l}\text { Demand Measures } \\
\text { (4) }\end{array}$ & $\begin{array}{l}\text { Supply Measures } \\
\text { (5) }\end{array}$ \\
\hline \multicolumn{6}{|c|}{ Unconditional Regressions } \\
\hline \multirow[t]{2}{*}{ MP Stance } & -0.000879 & 0.00158 & -0.000430 & -0.00264 & -0.0121 \\
\hline & $(0.00651)$ & $(0.00251)$ & $(0.00288)$ & $(0.0118)$ & $(0.00913)$ \\
\hline \multirow[t]{2}{*}{ Risk } & $-0.0916 * * *$ & $-0.0977 * * *$ & $-0.0983 * * *$ & $-0.0977 * * *$ & $-0.0976 * * *$ \\
\hline & $(0.00424)$ & $(0.00398)$ & $(0.00385)$ & $(0.00398)$ & $(0.00399)$ \\
\hline \multicolumn{6}{|c|}{ Regressions with interaction between risk and the macroprudential stance } \\
\hline \multirow{2}{*}{ MP Stance } & -0.000698 & 0.00155 & -0.000297 & -0.00256 & -0.0116 \\
\hline & $(0.00640)$ & $(0.00249)$ & $(0.00285)$ & $(0.0119)$ & $(0.00918)$ \\
\hline \multirow[t]{2}{*}{ Risk } & $-0.0915^{* * *}$ & $-0.0977 * * *$ & $-0.0982 * * *$ & $-0.0977 * * *$ & $-0.0970 * * *$ \\
\hline & $(0.00425)$ & $(0.00402)$ & $(0.00383)$ & $(0.00399)$ & $(0.00397)$ \\
\hline \multirow{2}{*}{$\begin{array}{r}\text { Interaction of } M P \\
\text { stance and risk }\end{array}$} & $-0.0129 * * *$ & -0.0026300 & $-0.00616 * *$ & -0.00386 & $-0.0243 * * *$ \\
\hline & $(0.00308)$ & $(0.00345)$ & $(0.00263)$ & $(0.00851)$ & $(0.00702)$ \\
\hline \multicolumn{6}{|c|}{$\begin{array}{l}\text { Marginal effects of tighter macroprudential policy at different risk levels } \\
\text { (Extreme risk-on) }\end{array}$} \\
\hline \multirow[t]{2}{*}{ Risk@ 0.5\% } & $0.0331 * * *$ & $0.00844^{*}$ & $0.0158^{* * *}$ & 0.00756 & $0.0522 * * *$ \\
\hline & $(0.00806)$ & $(0.00451)$ & $(0.00479)$ & $(0.0150)$ & $(0.0132)$ \\
\hline \multirow[t]{2}{*}{ Risk@ 1\% } & $0.0260 * * *$ & 0.00700 & $0.0125^{* *}$ & 0.00544 & $0.0388 * *$ \\
\hline & $(0.00895)$ & $(0.00727)$ & $(0.00611)$ & $(0.0206)$ & $(0.0167)$ \\
\hline \multirow[t]{2}{*}{ Risk@ @\% } & $0.0164 * *$ & 0.00503 & $0.00786^{*}$ & 0.00255 & 0.0206 \\
\hline & $(0.00757)$ & $(0.00501)$ & $(0.00448)$ & $(0.0160)$ & (0.0127) \\
\hline \multirow[t]{2}{*}{ Risk@ 10\% } & 0.0107 & 0.00388 & 0.00516 & 0.000860 & 0.00998 \\
\hline & $(0.00698)$ & $(0.00379)$ & $(0.00367)$ & $(0.0137)$ & $(0.0108)$ \\
\hline \multirow[t]{2}{*}{ Risk@25\% } & 0.00494 & 0.00270 & 0.00240 & -0.000872 & -0.000932 \\
\hline & (0.00659) & $(0.00279)$ & $(0.00303)$ & $(0.0122)$ & $(0.00951)$ \\
\hline \multirow[t]{2}{*}{ Risk@median } & 0.000543 & 0.00180 & 0.000295 & -0.00219 & -0.00922 \\
\hline & $(0.00649)$ & $(0.00248)$ & $(0.00283)$ & $(0.0117)$ & $(0.00917)$ \\
\hline \multirow[t]{2}{*}{ Risk@ 95\% } & -0.00539 & 0.000594 & -0.00254 & -0.00397 & $-0.0204 * *$ \\
\hline & $(0.00664)$ & $(0.00287)$ & $(0.00301)$ & $(0.0123)$ & $(0.00969)$ \\
\hline \multirow[t]{2}{*}{ Risk@ 90\% } & $-0.0140 *$ & -0.00117 & $-0.00666^{*}$ & -0.00655 & $-0.0367 * * *$ \\
\hline & $(0.00740)$ & $(0.00454)$ & $(0.00403)$ & $(0.0150)$ & $(0.0121)$ \\
\hline \multirow[t]{2}{*}{ Risk@ 95\% } & $-0.0200 * *$ & -0.00238 & $-0.00951^{*}$ & -0.00834 & $-0.0480 * * *$ \\
\hline & $(0.00821)$ & $(0.00596)$ & (0.00499) & $(0.0178)$ & $(0.0145)$ \\
\hline \multirow[t]{2}{*}{ Risk@ 99\% } & $-0.0457 * * *$ & -0.00762 & $-0.0218 * *$ & -0.0160 & $-0.0964 * * *$ \\
\hline & $(0.0129)$ & $(0.0124)$ & $(0.00974)$ & $(0.0323)$ & $(0.0267)$ \\
\hline Risk@ @9.5\% & $-0.0614^{* *}$ & -0.0108 & $-0.0293 * *$ & -0.0207 & $-0.126 * *$ \\
\hline (Extreme risk-off) & $(0.0290)$ & $(0.0136)$ & $(0.0135)$ & $(0.0346)$ & $(0.0533)$ \\
\hline No. Countries & 44 & 55 & 55 & 55 & 55 \\
\hline
\end{tabular}

Notes: This table replicates Table 3 with the key coefficients from regressions of portfolio bond flows on Risk and different measure of the MP Stance, except the MP Stance is the more granular measures listed at the top. All of these more granular measures continue to be estimated using the policy-shocks approach discussed in Section 4.1. LTV is the loan-to-value ratio. CCyB is the countercyclical capital buffer. FX Measures is the aggregated changes in any macroprudential measures related to foreign currency exposures, transactions or liquidity. Demand Measures is the aggregated changes in macroprudential tools focused on the demand for loans, including debt-serviceto-income and LTV regulations. Supply Measures is the aggregated changes in a broad range of tools focusing on banks' ability to supply credit, excluding those aimed at FX exposures. The last three measures are the aggregated changes in the relevant tools since 2000 based on dummy variables. All specifications include country and time fixed effects. See notes to Table 3 for details on variables, definitions, and interpreting the coefficients. See Appendix B for details on the definitions of these more granular measures of the MP Stance. Bootstrapped standard errors clustered by country are reported in parentheses. ${ }^{*}, * *$, and ${ }^{* * *}$ denote significance at the $10 \%, 5 \%$ and $1 \%$ levels, respectively. 
Table 6: Equity Portfolio Investment

Portfolio Flows and the Macroprudential Stance across the Global Financial Cycle

\begin{tabular}{|c|c|c|c|c|c|c|c|c|c|}
\hline \multirow[b]{2}{*}{ MP Stance Measures } & \multicolumn{4}{|c|}{ Main indices } & \multicolumn{5}{|c|}{ Alternative measures } \\
\hline & $\begin{array}{c}\text { Broad } \\
\text { Intensity } \\
\text { (1) }\end{array}$ & $\begin{array}{l}\text { Narrow } \\
\text { Intensity } \\
(2)\end{array}$ & $\begin{array}{c}\text { Country- } \\
\text { Relative } \\
\text { (3) }\end{array}$ & $\begin{array}{c}\text { Time-Relative } \\
\text { Dummy } \\
\text { (4) }\end{array}$ & $\begin{array}{r}\text { LTV } \\
(5)\end{array}$ & $\begin{array}{c}\text { ССув } \\
(6)\end{array}$ & $\begin{array}{c}\text { FX Measures } \\
\text { (7) }\end{array}$ & $\begin{array}{c}\text { Demand } \\
\text { Measures } \\
\text { (8) }\end{array}$ & $\begin{array}{c}\text { Supply } \\
\text { Measures } \\
(9) \\
\end{array}$ \\
\hline \multicolumn{10}{|c|}{ Unconditional Regressions } \\
\hline \multirow[t]{2}{*}{ MP Stance } & 0.00223 & $0.00737 * * *$ & -0.0123 & -0.00565 & $0.0166 * * *$ & 0.00148 & -0.00238 & 0.0148 & $-0.0252 * * *$ \\
\hline & $(0.00359)$ & $(0.00274)$ & $(0.00901)$ & $(0.00935)$ & $(0.00542)$ & $(0.00138)$ & $(0.00257)$ & $(0.0102)$ & $(0.00898)$ \\
\hline \multirow[t]{2}{*}{ Risk } & $-0.0842 * * *$ & $-0.0842 * * *$ & $-0.0848 * * *$ & $-0.0849 * * *$ & $-0.0843 * * *$ & $-0.0850 * * *$ & $-0.0870 * * *$ & $-0.0850 * * *$ & $-0.0849 * * *$ \\
\hline & $(0.00300)$ & $(0.00300)$ & $(0.00308)$ & $(0.00310)$ & $(0.00300)$ & $(0.00311)$ & $(0.00306)$ & $(0.00310)$ & $(0.00311)$ \\
\hline \multicolumn{10}{|c|}{ Regressions with interaction between risk and the macroprudential stance } \\
\hline \multirow[t]{2}{*}{ MP Stance } & 0.00224 & $0.00732 * * *$ & -0.0113 & -0.00551 & $0.0167 * * *$ & 0.00145 & -0.00228 & 0.0147 & $-0.0249 * * *$ \\
\hline & $(0.00362)$ & $(0.00276)$ & $(0.00890)$ & $(0.00932)$ & $(0.00537)$ & $(0.00144)$ & $(0.00254)$ & (0.0103) & $(0.00880)$ \\
\hline \multirow[t]{2}{*}{ Risk } & $-0.0844 * * *$ & $-0.0846 * * *$ & $-0.0843 * * *$ & $-0.0849 * * *$ & $-0.0844 * * *$ & $-0.0850 * * *$ & $-0.0868 * * *$ & $-0.0849 * * *$ & $-0.0843 * * *$ \\
\hline & $(0.00307)$ & $(0.00307)$ & $(0.00306)$ & $(0.00308)$ & $(0.00306)$ & $(0.00312)$ & $(0.00301)$ & $(0.00311)$ & $(0.00308)$ \\
\hline \multirow{2}{*}{$\begin{array}{r}\text { Interaction of MP } \\
\text { stance and risk }\end{array}$} & $-0.0124 * * *$ & $-0.00868 * * *$ & $-0.0274 * * *$ & -0.00838 & $-0.00753 * * *$ & -0.00259 & $-0.00430 * *$ & 0.00227 & $-0.0195 * * *$ \\
\hline & $(0.00281)$ & $(0.00213)$ & $(0.00519)$ & $(0.00711)$ & $(0.00212)$ & $(0.00171)$ & $(0.00187)$ & $(0.00568)$ & $(0.00547)$ \\
\hline \multicolumn{10}{|c|}{$\begin{array}{l}\text { Marginal effects of tighter macroprudential policy at different risk levels } \\
\text { (Extreme risk-on) }\end{array}$} \\
\hline \multirow[t]{2}{*}{ Risk @ 0.5\% } & $0.0347 * * *$ & $0.0301 * * *$ & $0.0605^{* * *}$ & 0.0164 & $0.0364 * * *$ & $0.00823^{* * *}$ & $0.00898^{* *}$ & 0.00880 & $0.0261^{*}$ \\
\hline & $(0.00660)$ & $(0.00468)$ & $(0.0137)$ & (0.0147) & $(0.00654)$ & $(0.00314)$ & $(0.00416)$ & $(0.0136)$ & (0.0135) \\
\hline \multirow[t]{2}{*}{ Risk@ 1\% } & $0.0279 * * *$ & $0.0253^{* * *}$ & $0.0454^{* * *}$ & 0.0118 & $0.0322 * * *$ & $0.00681^{*}$ & 0.00662 & 0.0100 & 0.0155 \\
\hline & $(0.00686)$ & $(0.00504)$ & $(0.0133)$ & $(0.0170)$ & $(0.00681)$ & $(0.00373)$ & $(0.00475)$ & $(0.0153)$ & $(0.0142)$ \\
\hline \multirow[t]{2}{*}{ Risk@ @\% } & $0.0186 * * *$ & $0.0188^{* * *}$ & $0.0250 * *$ & 0.00558 & $0.0266 * * *$ & $0.00488^{*}$ & 0.00341 & 0.0117 & 0.000886 \\
\hline & $(0.00522)$ & $(0.00383)$ & (0.0108) & $(0.0130)$ & $(0.00598)$ & $(0.00260)$ & $(0.00364)$ & $(0.0126)$ & $(0.0114)$ \\
\hline \multirow[t]{2}{*}{ Risk@ 10\% } & $0.0132^{* * *}$ & $0.0150^{* * *}$ & 0.0130 & 0.00191 & $0.0233^{* * *}$ & $0.00374 *$ & 0.00153 & 0.0127 & -0.00766 \\
\hline & $(0.00443)$ & $(0.00325)$ & $(0.00966)$ & $(0.0111)$ & $(0.00565)$ & $(0.00201)$ & $(0.00310)$ & $(0.0113)$ & $(0.0101)$ \\
\hline \multirow[t]{2}{*}{ Risk@ 25\% } & $0.00765^{* *}$ & $0.0111^{* * *}$ & 0.000672 & -0.00185 & $0.0200 * * *$ & $0.00258^{*}$ & -0.000402 & 0.0137 & $-0.0164^{*}$ \\
\hline & $(0.00385)$ & $(0.00285)$ & $(0.00897)$ & (0.00969) & $(0.00545)$ & (0.00155) & $(0.00268)$ & $(0.0104)$ & (0.00919) \\
\hline \multirow[t]{2}{*}{ Risk@median } & 0.00343 & $0.00815^{* * *}$ & -0.00866 & -0.00470 & $0.0174 * * *$ & 0.00170 & -0.00187 & 0.0145 & $-0.0230 * * *$ \\
\hline & $(0.00366)$ & $(0.00275)$ & $(0.00884)$ & $(0.00931)$ & $(0.00540)$ & $(0.00142)$ & (0.00252) & $(0.0102)$ & $(0.00894)$ \\
\hline \multirow[t]{2}{*}{ Risk@ 75\% } & -0.00227 & 0.00416 & $-0.0213^{* *}$ & -0.00856 & $0.0139 * *$ & 0.000508 & -0.00384 & 0.0156 & $-0.0320 * * *$ \\
\hline & $(0.00380)$ & $(0.00290)$ & $(0.00922)$ & (0.00978) & $(0.00550)$ & $(0.00160)$ & $(0.00256)$ & $(0.0104)$ & (0.00921) \\
\hline \multirow[t]{2}{*}{ Risk@ 90\% } & $-0.0105^{* *}$ & -0.00165 & $-0.0396 * * *$ & -0.0142 & 0.00889 & -0.00122 & $-0.00671^{* *}$ & 0.0171 & $-0.0450 * * *$ \\
\hline & $(0.00470)$ & $(0.00363)$ & $(0.0107)$ & $(0.0122)$ & (0.00595) & $(0.00239)$ & $(0.00311)$ & $(0.0118)$ & (0.0107) \\
\hline \multirow[t]{2}{*}{ Risk@ 95\% } & $-0.0163 * * *$ & -0.00567 & $-0.0523 * * *$ & -0.0180 & 0.00541 & -0.00242 & $-0.00870 * *$ & 0.0181 & $-0.0541 * * *$ \\
\hline & $(0.00563)$ & $(0.00433)$ & $(0.0123)$ & $(0.0145)$ & $(0.00642)$ & $(0.00306)$ & $(0.00370)$ & $(0.0133)$ & $(0.0123)$ \\
\hline \multirow[t]{2}{*}{ Risk@ 99\% } & $-0.0409 * * *$ & $-0.0230 * * *$ & $-0.107 * * *$ & -0.0347 & -0.00958 & -0.00757 & $-0.0173^{* *}$ & 0.0226 & $-0.0929 * * *$ \\
\hline & $(0.0105)$ & $(0.00800)$ & $(0.0207)$ & (0.0269) & $(0.00935)$ & $(0.00630)$ & (0.00693) & $(0.0221)$ & $(0.0213)$ \\
\hline Risk@ 99.5\% & $-0.0560 * * *$ & $-0.0335^{* *}$ & $-0.140 * * *$ & -0.0449 & -0.0187 & -0.0107 & $-0.0225^{* *}$ & 0.0254 & $-0.117 * * *$ \\
\hline (Extreme risk-off) & $(0.0210)$ & $(0.0139)$ & $(0.0446)$ & $(0.0329)$ & $(0.0145)$ & $(0.00835)$ & $(0.00922)$ & $(0.0249)$ & $(0.0364)$ \\
\hline
\end{tabular}

Notes: Table replicates the results from Tables 3 and 5 , except for portfolio equity flows instead of portfolio bond flows. Portfolio equity flows are the percent change in weekly flows based on EPFR data. See notes to Tables 3 and 5 for details. Bootstrapped standard errors clustered by country are shown in parentheses. $*, * *$, and $* * *$ denote significance at the $10 \%, 5 \%$ and $1 \%$ levels, respectively. 
Table 7

Extensions

Portfolio Flows and the Macroprudential Stance across the Global Financial Cycle

\begin{tabular}{|c|c|c|c|c|c|c|c|c|c|c|}
\hline \multirow{2}{*}{ Unconditional Regressions } & \multicolumn{2}{|c|}{ AE v. EMDE } & \multicolumn{2}{|c|}{ USD } & \multicolumn{2}{|c|}{ Non-USD } & \multicolumn{2}{|c|}{$\begin{array}{c}\text { Capital Controls } \\
\text { instead of MP Stance }\end{array}$} & \multicolumn{2}{|c|}{$\begin{array}{l}\text { Capital Controls } \\
\text { added as control }\end{array}$} \\
\hline & $\begin{array}{c}\text { Bonds } \\
\text { (1) }\end{array}$ & $\begin{array}{c}\text { Equity } \\
\text { (2) }\end{array}$ & $\begin{array}{c}\text { Bonds } \\
\text { (3) }\end{array}$ & $\begin{array}{c}\text { Equity } \\
\text { (4) }\end{array}$ & $\begin{array}{c}\text { Bonds } \\
(5)\end{array}$ & $\begin{array}{c}\text { Equity } \\
\text { (6) }\end{array}$ & $\begin{array}{c}\text { Bonds } \\
(7)\end{array}$ & $\begin{array}{c}\text { Equity } \\
\text { (8) }\end{array}$ & $\begin{array}{l}\text { Bonds } \\
\text { (9) }\end{array}$ & $\begin{array}{c}\text { Equity } \\
\text { (10) }\end{array}$ \\
\hline \multirow[t]{2}{*}{ MP Stance } & 0.00151 & 0.00223 & 0.00721 & 0.00349 & 0.00359 & 0.00219 & -0.0334 & -0.00952 & $-5.73 E-06$ & 0.00207 \\
\hline & $(0.00540)$ & (0.00359) & (0.00789) & $(0.00538)$ & $(0.00890)$ & (0.00749) & $(0.0422)$ & $(0.0458)$ & -0.0052 & -0.00349 \\
\hline \multirow[t]{2}{*}{ Risk } & $-0.0920 * * *$ & $-0.0842 * * *$ & $-0.113 * * *$ & $-0.0910 * * *$ & $-0.0721 * * *$ & $-0.0526 * * *$ & $-0.0771 * * *$ & $-0.0974 * * *$ & $-0.0962 * * *$ & $-0.0804 * * *$ \\
\hline & $(0.00426)$ & $(0.00300)$ & $(0.00530)$ & $(0.00613)$ & (0.0110) & $(0.00510)$ & (0.00396) & (0.00479) & -0.00424 & -0.00295 \\
\hline \multicolumn{11}{|c|}{ Regressions with interaction between risk and the macroprudential stance } \\
\hline \multirow[t]{2}{*}{ MP Stance } & -0.00829 & -0.000496 & 0.00724 & 0.00353 & 0.00362 & 0.00221 & -0.0365 & -0.0138 & 0.000256 & 0.00221 \\
\hline & $(0.00654)$ & $(0.00504)$ & $(0.00788)$ & (0.00539) & $(0.00889)$ & $(0.00750)$ & $(0.0423)$ & $(0.0455)$ & -0.00522 & -0.0035 \\
\hline \multirow[t]{2}{*}{ Risk } & $-0.0784 * * *$ & $-0.0588 * * *$ & $-0.113 * * *$ & $-0.0909 * * *$ & $-0.0719 * * *$ & $-0.0525 * * *$ & $-0.0762 * * *$ & $-0.0956 * * *$ & $-0.0968 * * *$ & $-0.0808 * * *$ \\
\hline & $(0.00431)$ & $(0.00330)$ & $(0.00448)$ & $(0.00538)$ & $(0.00964)$ & $(0.00485)$ & $(0.00372)$ & $(0.00430)$ & -0.00418 & -0.00294 \\
\hline \multirow{4}{*}{$\begin{array}{l}\text { Interaction of MP stance } \\
\text { and risk } \\
\text { Interaction of EM dummy } \\
\text { and Risk }\end{array}$} & $-0.0563 * * *$ & $-0.0565^{* * *}$ & $-0.0212 * * *$ & $-0.0159 * * *$ & $-0.0343 * * *$ & -0.00879 & $-0.0401 * * *$ & $-0.0653 * * *$ & $-0.0169 * * *$ & $0.00989 * * *$ \\
\hline & $(0.00657)$ & $(0.00510)$ & $(0.00551)$ & $(0.00536)$ & $(0.00806)$ & (0.00619) & $(0.0118)$ & $(0.0173)$ & -0.00451 & -0.00288 \\
\hline & $-0.00832^{*}$ & 0.000811 & & & & & & & & \\
\hline & $(0.00437)$ & $(0.00342)$ & & & & & & & & \\
\hline \multirow{2}{*}{$\begin{array}{l}\text { Interaction of EM dummy, } \\
\text { MP Stance and Risk }\end{array}$} & 0.00612 & 0.000519 & & & & & & & & \\
\hline & (0.00748) & (0.00589) & & & & & & & & \\
\hline \multicolumn{11}{|l|}{ (Extreme risk-on) } \\
\hline \multirow[t]{2}{*}{ Risk@ 0.5\% } & 0.0138 & 0.00457 & $0.0629 * * *$ & $0.0450 * * *$ & $0.0934 * * *$ & 0.0252 & 0.0687 & $0.157^{* * *}$ & $0.0446 * * *$ & $0.0281^{* * *}$ \\
\hline & $(0.0182)$ & $(0.0144)$ & $(0.0191)$ & $(0.0148)$ & $(0.0224)$ & $(0.0181)$ & $(0.0477)$ & $(0.0598)$ & -0.0151 & -0.00928 \\
\hline \multirow[t]{2}{*}{ Risk@1\% } & 0.0126 & 0.00530 & $0.0512 * * *$ & $0.0363 * * *$ & $0.0746 * * *$ & 0.0204 & 0.0466 & $0.121 * *$ & $0.0353 * * *$ & $0.0227 * * *$ \\
\hline & (0.0154) & $(0.0121)$ & $(0.0164)$ & $(0.0121)$ & $(0.0184)$ & $(0.0151)$ & (0.0449) & $(0.0540)$ & -0.0104 & -0.00682 \\
\hline \multirow[t]{2}{*}{ Risk@5\% } & 0.0110 & 0.00629 & $0.0354 * * *$ & $0.0245^{* * *}$ & $0.0490 * * *$ & 0.0138 & 0.0166 & 0.0725 & $0.0227^{* * *}$ & $0.0153^{* *}$ \\
\hline & (0.0119) & (0.00940) & $(0.0128)$ & $(0.00868)$ & $(0.0135)$ & $(0.0113)$ & $(0.0424)$ & $(0.0481)$ & -0.00775 & -0.00511 \\
\hline \multirow[t]{2}{*}{ Risk@10\% } & 0.0100 & 0.00687 & $0.0260 * *$ & $0.0176 * *$ & $0.0340 * * *$ & 0.00999 & -0.000953 & 0.0439 & $0.0153^{* *}$ & $0.0110 * *$ \\
\hline & (0.0103) & $(0.00810)$ & (0.0109) & $(0.00700)$ & $(0.0111)$ & $(0.00946)$ & $(0.0417)$ & $(0.0460)$ & -0.00644 & -0.00429 \\
\hline \multirow[t]{2}{*}{ Risk@25\% } & 0.00904 & 0.00747 & $0.0165^{*}$ & $0.0104^{*}$ & $0.0186 * *$ & 0.00605 & -0.0189 & 0.0147 & 0.00766 & $0.00653^{*}$ \\
\hline & (0.00911) & $(0.00718)$ & (0.00916) & $(0.00577)$ & $(0.00937)$ & (0.00807) & $(0.0417)$ & $(0.0451)$ & -0.00549 & -0.0037 \\
\hline \multirow[t]{2}{*}{ Risk@median } & 0.00829 & 0.00792 & 0.00928 & 0.00505 & 0.00691 & 0.00306 & -0.0326 & -0.00756 & 0.00189 & 0.00316 \\
\hline & $(0.00871)$ & $(0.00686)$ & $(0.00812)$ & (0.00539) & (0.00888) & $(0.00755)$ & $(0.0421)$ & $(0.0453)$ & -0.0052 & -0.00351 \\
\hline \multirow[t]{2}{*}{ Risk@75\% } & 0.00728 & 0.00853 & -0.000489 & -0.00224 & -0.00885 & -0.000984 & -0.0511 & -0.0376 & -0.00591 & -0.00138 \\
\hline & (0.00893) & (0.00703) & $(0.00727)$ & $(0.00582)$ & $(0.00952)$ & $(0.00775)$ & $(0.0433)$ & $(0.0468)$ & -0.00551 & -0.00368 \\
\hline \multirow[t]{2}{*}{ Risk@ @0\% } & 0.00581 & 0.00942 & $-0.0147^{*}$ & -0.0128 & $-0.0318 * *$ & -0.00686 & $-0.0779 *$ & -0.0812 & $-0.0172 * *$ & $-0.00799 *$ \\
\hline & $(0.0106)$ & (0.00839) & $(0.00753)$ & $(0.00792)$ & (0.0125) & $(0.00966)$ & $(0.0461)$ & (0.0511) & -0.00718 & -0.00464 \\
\hline \multirow[t]{2}{*}{ Risk@ @5\% } & 0.00480 & 0.0100 & $-0.0245 * * *$ & $-0.0202 * *$ & $-0.0476 * * *$ & -0.0109 & $-0.0965^{* *}$ & $-0.111 * *$ & $-0.0251^{* * *}$ & $-0.0126^{* *}$ \\
\hline & $(0.0125)$ & (0.00985) & $(0.00867)$ & $(0.00988)$ & $(0.0154)$ & $(0.0117)$ & $(0.0487)$ & $(0.0554)$ & -0.00884 & -0.00566 \\
\hline \multirow[t]{2}{*}{ Risk@99\% } & 0.000422 & 0.0127 & $-0.0668 * * *$ & $-0.0517 * * *$ & $-0.116^{* * *}$ & -0.0284 & $-0.176 * * *$ & $-0.241 * * *$ & $-0.0588 * * *$ & $-0.0323 * * *$ \\
\hline & $(0.0227)$ & $(0.0180)$ & $(0.0174)$ & (0.0197) & $(0.0300)$ & $(0.0226)$ & $(0.0641)$ & (0.0804) & -0.0172 & -0.0107 \\
\hline Risk@ 99.5\% & -0.00225 & 0.0143 & $-0.0926 * * *$ & $-0.0710 * * *$ & $-0.157 * * *$ & -0.0391 & $-0.225^{* * *}$ & $-0.321 * * *$ & $-0.0794 * * *$ & $-0.0443 * *$ \\
\hline (Extreme risk-off) & $(0.0297)$ & $(0.0235)$ & $(0.0237)$ & $(0.0260)$ & $(0.0394)$ & $(0.0298)$ & $(0.0756)$ & $(0.0986)$ & -0.00857 & -0.0225 \\
\hline
\end{tabular}

Notes: Table replicates the results from Tables 3, 5 and 6 for portfolio bond and equity flows, except performs the extension listed at the top. Each regression measures the MP Stance using the Broad Intensity Index (our preferred measure). Columns 1 and 2 include additional interactions with an EM dummy variable, so that the marginal effects at the bottom of the table reflect the triple interaction between the MP Stance, Risk, and the EM dummy at each level of Risk, thereby capturing any difference in these marginal effects for EMs relative to AEs. Appendix Table $\mathrm{C}$ lists the countries in each group. Columns 3 and 4 report results for investment flows in USD, and columns 5 and 6 in non-USD. Columns 7 and 8 replace the MP Stance with a measure of the Capital Controls Stance (based on Fernandez et al., 2015, and discussed in Section 5.4). Columns 9 and 10 add a lagged control for the Capital Controls Stance to the baseline analysis (which includes the MP Stance). See Tables 3, 5 and 6 for additional details. All specifications include country and time fixed effects. Robust standard errors clustered by country are reported in parentheses. ${ }^{*}, * *$, and $* * *$ denote significance at the $10 \%, 5 \%$ and $1 \%$ levels, respectively. 
Table 8: International Capital Flows Capital Flows and the Macroprudential Stance across the Global Financial Cycle

\begin{tabular}{|c|c|c|c|c|c|c|c|c|}
\hline \multirow{2}{*}{$\begin{array}{r}\text { Intl Capital Flow } \\
\text { Controls }\end{array}$} & \multicolumn{2}{|c|}{ Debt } & \multicolumn{2}{|c|}{ Equity } & \multicolumn{2}{|c|}{ Bank } & \multicolumn{2}{|c|}{ Total } \\
\hline & $\begin{array}{l}\text { Macro } \\
\text { (1) }\end{array}$ & $\begin{array}{c}\text { Finance } \\
\text { (2) }\end{array}$ & $\begin{array}{c}\text { Macro } \\
\text { (3) }\end{array}$ & $\begin{array}{c}\text { Finance } \\
\text { (4) }\end{array}$ & $\begin{array}{c}\text { Macro } \\
\text { (5) }\end{array}$ & $\begin{array}{c}\text { Finance } \\
(6)\end{array}$ & $\begin{array}{c}\text { Macro } \\
\text { (7) }\end{array}$ & $\begin{array}{c}\text { Finance } \\
\text { (8) }\end{array}$ \\
\hline \multicolumn{9}{|l|}{ Unconditional Regressions } \\
\hline \multirow[t]{2}{*}{ MP Stance } & -0.017 & -0.026 & -0.044 & -0.082 & -0.014 & -0.011 & -0.041 & -0.076 \\
\hline & $(0.137)$ & $(0.130)$ & $(0.158)$ & $(0.168)$ & $(0.092)$ & $(0.095)$ & $(0.108)$ & $(0.113)$ \\
\hline \multirow[t]{2}{*}{ Risk } & 0.445 & $0.643^{* * *}$ & 0.512 & 0.465 & $-0.512^{* *}$ & $-0.562^{* *}$ & -0.006 & -0.071 \\
\hline & $(0.308)$ & $(0.236)$ & $(0.460)$ & $(0.477)$ & $(0.251)$ & $(0.257)$ & $(0.143)$ & $(0.138)$ \\
\hline \multicolumn{9}{|c|}{ Regressions with interaction between risk and the macroprudential stance } \\
\hline \multirow[t]{2}{*}{ MP Stance } & -0.012 & -0.023 & -0.037 & -0.077 & -0.015 & -0.012 & -0.040 & -0.076 \\
\hline & $(0.135)$ & $(0.128)$ & $(0.158)$ & (0.169) & $(0.092)$ & $(0.095)$ & (0.109) & (0.114) \\
\hline \multirow[t]{2}{*}{ Risk } & 0.449 & $0.644 * * *$ & 0.519 & 0.467 & $-0.513^{* *}$ & $-0.562 * *$ & -0.005 & -0.071 \\
\hline & (0.306) & $(0.233)$ & $(0.461)$ & $(0.477)$ & $(0.252)$ & (0.259) & $(0.142)$ & $(0.138)$ \\
\hline Interaction of $M P$ & -0.294 & -0.285 & -0.430 & -0.493 & 0.068 & 0.087 & -0.038 & -0.012 \\
\hline stance and risk & $(0.189)$ & $(0.180)$ & $(0.374)$ & $(0.388)$ & $(0.176)$ & $(0.187)$ & $(0.129)$ & $(0.130)$ \\
\hline \multicolumn{9}{|c|}{$\begin{array}{l}\text { Marginal effects of tighter macroprudential policy at different risk levels } \\
\text { (Extreme risk-on) }\end{array}$} \\
\hline \multirow[t]{2}{*}{ Risk@1\% } & 0.299 & 0.279 & 0.418 & 0.445 & -0.087 & -0.104 & 0.001 & -0.064 \\
\hline & $(0.244)$ & $(0.211)$ & $(0.413)$ & $(0.432)$ & (0.196) & $(0.209)$ & $(0.218)$ & $(0.222)$ \\
\hline \multirow[t]{2}{*}{ Risk@5\% } & 0.083 & 0.070 & 0.102 & 0.083 & -0.037 & -0.040 & -0.027 & -0.072 \\
\hline & (0.149) & $(0.131)$ & (0.191) & $(0.203)$ & $(0.102)$ & $(0.106)$ & $(0.137)$ & $(0.142)$ \\
\hline \multirow[t]{2}{*}{ Risk@ @ 10\% } & 0.047 & 0.035 & 0.049 & 0.023 & -0.029 & -0.030 & -0.032 & -0.074 \\
\hline & $(0.141)$ & $(0.127)$ & $(0.169)$ & $(0.180)$ & $(0.094)$ & $(0.098)$ & $(0.126)$ & $(0.130)$ \\
\hline \multirow[t]{2}{*}{ Risk@ 25\% } & 0.027 & 0.015 & 0.020 & -0.011 & -0.024 & -0.024 & -0.035 & -0.075 \\
\hline & $(0.138)$ & $(0.126)$ & $(0.162)$ & (0.173) & $(0.092)$ & $(0.095)$ & $(0.120)$ & $(0.124)$ \\
\hline \multirow[t]{2}{*}{ Risk@median } & -0.002 & -0.012 & -0.022 & -0.059 & -0.017 & -0.015 & -0.038 & -0.076 \\
\hline & $(0.135)$ & $(0.127)$ & $(0.158)$ & $(0.168)$ & $(0.091)$ & $(0.095)$ & $(0.112)$ & $(0.117)$ \\
\hline \multirow[t]{2}{*}{ Risk@ @5\% } & -0.029 & -0.039 & -0.062 & -0.105 & -0.011 & -0.007 & -0.042 & -0.077 \\
\hline & $(0.135)$ & $(0.130)$ & $(0.162)$ & $(0.172)$ & (0.094) & $(0.097)$ & $(0.105)$ & $(0.110)$ \\
\hline \multirow[t]{2}{*}{ Risk@ @0\% } & -0.147 & -0.154 & -0.235 & -0.303 & 0.016 & 0.028 & -0.058 & -0.082 \\
\hline & (0.159) & $(0.163)$ & $(0.244)$ & $(0.254)$ & $(0.130)$ & $(0.136)$ & $(0.090)$ & (0.095) \\
\hline \multirow[t]{2}{*}{ Risk@ 95\% } & -0.230 & -0.234 & -0.356 & -0.442 & 0.035 & 0.052 & -0.068 & -0.085 \\
\hline & $(0.192)$ & (0.199) & $(0.332)$ & $(0.344)$ & (0.169) & $(0.178)$ & $(0.095)$ & $(0.100)$ \\
\hline Risk@ 99\% & -0.347 & -0.347 & -0.527 & -0.638 & 0.062 & 0.086 & -0.084 & -0.089 \\
\hline (Extreme risk-off) & $(0.251)$ & (0.259) & $(0.468)$ & $(0.485)$ & $(0.231)$ & $(0.244)$ & $(0.123)$ & $(0.127)$ \\
\hline
\end{tabular}

Notes: Table replicates the results from Tables 3 and 6, except for the international capital flows listed at the top (instead of the portfolio investor flows from the EPFR). International capital flows are the percent change in the relevant quarterly flows based on data from Forbes and Warnock (2020) and the MP Stance is measured using the Broad Intensity Index. In the row at the top for Controls, "Macro" indicates the regression includes standard macro controls in capital flow regressions: AE monetary stance, global growth, domestic growth, financial openness and institutional quality, and "Finance " indicates the controls also include the US interest rate differential, the US\$ exchange rate and FX volatility (as in Table 2). See Appendix Table B for definitions and sources. Each equation estimated with fixed effects and robust standard errors, clustered by country. 


\section{Appendix Table A \\ Variables for First-stage of Policy Shock Regressions}

\begin{tabular}{|c|c|c|c|}
\hline Variable & Description & Source & Frequency \\
\hline \multicolumn{4}{|l|}{ CRISIS VARIABLES } \\
\hline Crisis in last 12 months & $\begin{array}{l}\text { Dummy equal to one if the country experienced a banking, } \\
\text { currency, or sovereign debt crisis in the previous } 12 \text { months }\end{array}$ & Laeven and Valencia (2020) & Monthly \\
\hline Distance to default of banking system & Average Z-score of individual banks in a country & Global Financial Development Database & Annual \\
\hline Romer and Romer crisis count & In a given half-year, the count of countries in crisis & Romer and Romer (2019) & Bi-annual \\
\hline Romer and Romer crisis intensity & $\begin{array}{l}\text { In a given half-year, the cross-country sum of a financial } \\
\text { crisis index }\end{array}$ & & Bi-annual \\
\hline Sovereign crisis count & Count of countries in a sovereign debt crisis in a given year & Laeven and Valencia (2020) & Annual \\
\hline Currency crisis count & Count of countries in a currency crisis in a given year & Laeven and Valencia (2020) & Annual \\
\hline Banking crisis count & Count of countries in a banking crisis in a given year & Laeven and Valencia (2020) & Annual \\
\hline \multicolumn{4}{|l|}{ CREDIT VARIABLES } \\
\hline Cross border borrowing ratio & $\begin{array}{l}\text { External claims on nonbank sector of banks as a percentage } \\
\text { of total claims on public non-financial corporations }\end{array}$ & BIS & Annual \\
\hline Domestic credit growth & Annual growth of private sector credit to GDP & IMF International Financial Statistics & Annual \\
\hline Property prices & Real residential property prices, $\mathrm{Y} / \mathrm{Y}$ percent change & BIS & Quarterly \\
\hline \multicolumn{4}{|l|}{ GROWTH VARIABLES } \\
\hline REER growth & Real exchange rate appreciation, $\mathrm{M} / \mathrm{M}$ & Bruegel Broad Datasets & Monthly \\
\hline Growth forecast & 5 quarter ahead forecast annual GDP growth rate, October W & IMF World Economic Outlook & Annual \\
\hline Inflation & Lagged $\mathrm{Y} / \mathrm{Y}$ CPI inflation & Haver & Quarterly \\
\hline Real GDP growth & Quarterly real GDP growth & Haver & Quarterly \\
\hline \multicolumn{4}{|c|}{ OTHER MACRO AND INSTITUTIONAL CHARACTERISTICS } \\
\hline Financial Openness & Chinn-Ito Index of financial openness & Chinn and Ito (2008) & Annual \\
\hline FX volatility & 30-day variance of the daily exchange rate against USD & Haver & $D \rightarrow M$ \\
\hline Institutional quality & ICRG composite score & ICRG & Annual \\
\hline Policy rate & Central bank policy rate & Haver & $D \rightarrow M$ \\
\hline$i-i^{*}$ & Central bank policy rate less US federal funds rate & Haver & $\mathrm{D} \rightarrow \mathrm{M}$ \\
\hline Exchange rate regime & $\begin{array}{l}\text { Dummy equal to one if Ilzetzki et al. (2019) score is in the } \\
\text { four least-free-floating designation }\end{array}$ & Ilzetzki, Reinhart, and Rogoff (2019) & Monthly \\
\hline
\end{tabular}

Notes: Table reports additional details, sources, and frequency for variables used in first-stage regressions for the policy-shocks estimation in equations (1) and (2) and discussed in Section 4.1. 


\section{Appendix Table B \\ Variables for Baseline Regressions}

\begin{tabular}{|c|c|c|c|}
\hline Variable & Description & Source & Frequency \\
\hline \multicolumn{4}{|l|}{ MP MEASURES } \\
\hline Broad Intensity Index & Equally-weighted average of LTV, CCyB and index of foreign exchange measures & iMaPP, BIS, ESRB & Monthly \\
\hline Narrow Intensity Index & First principal component of LTV and CCyB & BIS, ESRP & Monthly \\
\hline Time-relative Index & $\begin{array}{l}\text { Dummy equal to one if the cumulative aggregate index summing all macroprudential } \\
\text { measures in the cross-section is greater than one }\end{array}$ & iMaPP & Monthly \\
\hline Country-relative Index & $\begin{array}{l}\text { Dummy equal to one if the cumulative aggregate index summing all macroprudential } \\
\text { measures in the cross-section is above the sample median each quarter }\end{array}$ & iMaPP & Monthly \\
\hline LTV & 100 less the loan-to-value ratio (calculated as a $z$-score when used in the index) & iMaPP & Monthly \\
\hline CCyB & Countercyclical capital buffer (calculated as a z-score when used in the index) & BIS, ESRP & $\mathrm{Q} \rightarrow \mathrm{M}$ \\
\hline FX Measures & $\begin{array}{l}\text { Cumulative aggregate changes in any macroprudential measures related to foreign currency } \\
\text { exposures, transactions or liquidity (calculated as a z-score when used in the index) }\end{array}$ & iMaPP & Monthly \\
\hline Demand Measures & $\begin{array}{l}\text { Cumulative index aggregating measures aimed at demand for bank loans, including debt- } \\
\text { service-to-income (DSTI) and loan-to-value limits (LTV); results report country-relative } \\
\text { treatment }\end{array}$ & iMaPP & Monthly \\
\hline Supply Measures & $\begin{array}{l}\text { Cumulative index aggregating measures aimed at supply of loans, including reserve } \\
\text { requirements, liquidity requirements, capital requirements, conservation buffers, the } \\
\text { leverage ratio, capital surcharges for systemically important financial institutions, } \\
\text { countercyclical capital buffers, limits on credit growth, loan loss provisions, and loan } \\
\text { restrictions; results report country-relative treatment }\end{array}$ & iMaPP & Monthly \\
\hline \multicolumn{4}{|c|}{ GLOBAL/PUSH VARIABLES } \\
\hline AE Monetary Stance (t-1) & $\begin{array}{l}\text { GDP-weighted average of Krippner SRTSM shadow rate estimates for US, UK, Japan and Euro } \\
\text { area. See https://www.ljkmfa.com/ for more detail on Krippner's shadow rates. }\end{array}$ & Haver & Monthly \\
\hline AE IP Growth (t-1) & GDP-weighted average of industrial production growth for US, UK, Japan and Euro area & Haver & Monthly \\
\hline \multicolumn{4}{|c|}{ DOMESTIC/PULL VARIABLES } \\
\hline Exchange Rate (t-1) & Bilateral exchange rate with the US dollar & Haver & $D \rightarrow W$ \\
\hline$i-i^{*}(t-1)$ & Central bank policy rate less US federal funds rate & Haver & $D \rightarrow W$ \\
\hline Real Growth $(t-1)$ & Quarterly real GDP growth & Haver & Quarterly \\
\hline FX Volatility & 30-day variance of the daily exchange rate against USD & Haver & $D \rightarrow W$ \\
\hline Financial Openness & Chinn-Ito Index, see http://web.pdx.edu/ ito/Chinn-Ito_website.htm & Chinn and Ito (2008) & Annual \\
\hline Institutional Quality & $\begin{array}{l}\text { ICRG composite score, see https://www.prsgroup.com/explore-our-products/international- } \\
\text { country-risk-guide/ }\end{array}$ & ICRG & Annual \\
\hline
\end{tabular}

Notes: Table reports additional details, sources, and frequency for variables used to estimate the baseline analysis in equation (2) used throughout the paper and discussed in Section 3.1 and 3.4. The $t-1$ indicates the variable is lagged by one quarter in the regression analysis. $D \rightarrow W$ indicates data is converted from daily to weekly frequency, and $Q \rightarrow M$ indicates the data is converted from quarterly to monthly. The CCyB is converted to monthly frequency to be consistent with the other macroprudential measures. 


\section{Appendix Table C \\ Country Coverage}

\begin{tabular}{|c|c|c|c|}
\hline \multicolumn{3}{|c|}{ Emerging and Developing Economies (EMDE) } & \multirow{2}{*}{$\begin{array}{c}\text { Advanced } \\
\text { Economies (AE) } \\
\text { Australia* }\end{array}$} \\
\hline Argentina & Lebanon & Uganda & \\
\hline Bahrain & Lithuania* & Ukraine* & Austria* \\
\hline Bangladesh & Malaysia* & United Arab Emirates* & Belgium* \\
\hline Brazil* & Mexico* & Vietnam & Canada* \\
\hline Bulgaria* & Morocco & Zambia & Denmark* \\
\hline Chile* & Nigeria* & & Finland* \\
\hline Colombia* & Oman & & France* \\
\hline Croatia* & Pakistan & & Germany* \\
\hline Czech Republic* & Peru* & & Greece* \\
\hline Dominican Republic & Philippines & & Ireland* \\
\hline Estonia* & Poland* & & |srael* \\
\hline Ghana & Romania* & & Italy* \\
\hline Hong Kong* & Russia* & & Korea* \\
\hline Hungary* & Saudi Arab & & Netherlands* \\
\hline India & Slovenia* & & New Zealand* \\
\hline Indonesia* & South Afric & & Norway* \\
\hline Kazakhstan & Sri Lanka & & Portugal* \\
\hline Kenya & Tanzania & & Spain* \\
\hline Kuwait* & Thailand & & Sweden \\
\hline Latvia* & Turkey* & & United Kingdom \\
\hline
\end{tabular}

Note: Table lists countries included in the dataset described in Section 3.4. The * denotes countries which appear in the baseline regressions using the Broad Intensity Index (our preferred measure of the MP Stance). 


\section{Appendix Table D \\ Summary Statistics}

\begin{tabular}{lccccc}
\hline & Mean & St. Dev. & Min. & Max. & $\#$ Obs. \\
\cline { 2 - 6 } Portfolio Flows & & & & & \\
Bond flows (\% of AUM) & 0.103 & 0.620 & -4.057 & 3.830 & 43,100 \\
Equity flows (\% of AUM) & 0.0242 & 0.563 & -5.401 & 5.350 & 47,483 \\
\hline & & & & & \\
Risk and Macroprudential Measures & & & & & \\
RORO & 0.0160 & 1.020 & -4.278 & 9.348 & 47,483 \\
Broad intensity index & 0.219 & 0.947 & -1.198 & 6.484 & 40,586 \\
Narrow intensity index & 0.250 & 1.124 & -1.296 & 4.069 & 40,586 \\
Time-relative dummy & 0.668 & 0.471 & 0 & 1 & 47,483 \\
Country-relative dummy & 0.476 & 0.499 & 0 & 1 & 47,483 \\
All FX Measures (AFX) & 0.151 & 1.329 & -3.029 & 8.689 & 47,483 \\
CCYB & 0.218 & 1.854 & -0.0947 & 16.24 & 47,483 \\
LTV & 0.240 & 1.281 & -0.934 & 9.627 & 40,586 \\
\hline & & & & & \\
Other Control Variables & & & & & \\
AE monetary stance (change) & -0.120 & 1.877 & -3.111 & 4.172 & 47,483 \\
AE IP growth & 0.000418 & 0.00801 & -0.0724 & 0.0172 & 47,483 \\
Real growth (domestic) & 0.0328 & 0.0342 & -0.151 & 0.251 & 47,483 \\
Financial openness & 1.069 & 1.444 & -1.920 & 2.334 & 47,483 \\
Institutional quality & 73.70 & 7.560 & 53.38 & 92.38 & 47,483 \\
i-i* (US interest rate differential) & 3.306 & 5.380 & -3.250 & 83.70 & 47,483 \\
Exchange rate (vs. US\$) & 599.9 & 2,798 & 0.265 & 23,628 & 47,483 \\
FX volatility & 2.643 & 16.84 & 0 & 885.7 & 47,483 \\
\hline
\end{tabular}

Note: Summary statistics for full sample of countries listed in Appendix Table C. See Appendix Table B for details on variable definitions, sources, and frequencies. 


\section{Appendix Table E \\ Sensitivity Tests}

Portfolio Flows and the Macroprudential Stance across the Global Financial Cycle

\begin{tabular}{|c|c|c|c|c|c|c|c|c|}
\hline \multirow[b]{2}{*}{ Unconditional Regressions } & \multicolumn{2}{|c|}{ Ex-COVID } & \multicolumn{2}{|c|}{ Pre-, Post-GFC } & \multicolumn{2}{|c|}{ Inc. Safe Havens } & \multicolumn{2}{|c|}{ VIX } \\
\hline & $\begin{array}{c}\text { Bonds } \\
\text { (1) }\end{array}$ & $\begin{array}{c}\text { Equity } \\
\text { (2) }\end{array}$ & $\begin{array}{c}\text { Bonds } \\
\text { (3) }\end{array}$ & $\begin{array}{c}\text { Equity } \\
\text { (4) }\end{array}$ & $\begin{array}{c}\text { Bonds } \\
\text { (5) }\end{array}$ & $\begin{array}{c}\text { Equity } \\
(6)\end{array}$ & $\begin{array}{l}\text { Bonds } \\
\text { (7) }\end{array}$ & $\begin{array}{c}\text { Equity } \\
(8)\end{array}$ \\
\hline MP Stance & $\begin{array}{l}-0.00108 \\
(0.00473)\end{array}$ & $\begin{array}{c}0.00242 \\
(0.00417)\end{array}$ & $\begin{array}{c}0.00151 \\
(0.00540)\end{array}$ & $\begin{array}{c}0.00223 \\
(0.00359)\end{array}$ & $\begin{array}{l}-0.000305 \\
(0.00503)\end{array}$ & $\begin{array}{l}0.000605 \\
(0.00355)\end{array}$ & $\begin{array}{l}-0.00183 \\
(0.00485)\end{array}$ & $\begin{array}{c}0.00195 \\
(0.00419)\end{array}$ \\
\hline Risk & $\begin{array}{r}-0.0720 * * * \\
(0.00302)\end{array}$ & $\begin{array}{c}-0.0939 * * * \\
(0.00264)\end{array}$ & $\begin{array}{c}-0.0920 * * * \\
(0.00426)\end{array}$ & $\begin{array}{c}-0.0842^{* * *} \\
(0.00300)\end{array}$ & $\begin{array}{c}-0.0942 * * * \\
(0.00424)\end{array}$ & $\begin{array}{c}-0.0816 * * * \\
(0.00287)\end{array}$ & $\begin{array}{c}-0.0438 * * * \\
(0.00263)\end{array}$ & $\begin{array}{c}-0.0401^{* * *} \\
(0.00228)\end{array}$ \\
\hline \multicolumn{9}{|c|}{ Regressions with interaction between risk and the macroprudential stance } \\
\hline MP Stance & $\begin{array}{l}-0.00130 \\
(0.00473)\end{array}$ & $\begin{array}{c}0.00223 \\
(0.00417)\end{array}$ & $\begin{array}{l}-0.00944 \\
(0.0143)\end{array}$ & $\begin{array}{c}0.00326 \\
(0.00456)\end{array}$ & $\begin{array}{l}-0.000250 \\
(0.00532)\end{array}$ & $\begin{array}{l}0.000646 \\
(0.00350)\end{array}$ & $\begin{array}{l}-0.00192 \\
(0.00485)\end{array}$ & $\begin{array}{c}0.00194 \\
(0.00419)\end{array}$ \\
\hline Risk & $\begin{array}{c}-0.0722^{* * *} \\
(0.00302)\end{array}$ & $\begin{array}{c}-0.0941 * * * \\
(0.00264)\end{array}$ & $\begin{array}{c}-0.0964^{* * *} \\
(0.00427)\end{array}$ & $\begin{array}{c}-0.0728^{* * *} \\
(0.00408)\end{array}$ & $\begin{array}{c}-0.0949 * * * \\
(0.00412)\end{array}$ & $\begin{array}{c}-0.0821 * * * \\
(0.00293)\end{array}$ & $\begin{array}{c}-0.0435^{* * *} \\
(0.00263)\end{array}$ & $\begin{array}{c}-0.0400^{* * *} \\
(0.00228)\end{array}$ \\
\hline $\begin{array}{l}\text { Interaction of MP stance } \\
\text { and risk }\end{array}$ & $\begin{array}{c}-0.0187 * * * \\
(0.00332)\end{array}$ & $\begin{array}{c}-0.0177 * * * \\
(0.00295)\end{array}$ & $\begin{array}{c}-0.0219 * * * \\
(0.00551)\end{array}$ & $\begin{array}{l}-0.0105 * * \\
(0.00415)\end{array}$ & $\begin{array}{c}-0.0196 * * * \\
(0.00439)\end{array}$ & $\begin{array}{c}-0.0127 * * * \\
(0.00281)\end{array}$ & $\begin{array}{c}-0.00796 * * * \\
(0.00256)\end{array}$ & $\begin{array}{l}-0.000691 \\
(0.00224)\end{array}$ \\
\hline $\begin{array}{l}\text { Interaction of pre-crisis dummy } \\
\text { and risk } \\
\text { Interaction of MP stance, risk, } \\
\text { and pre-crisis dummy }\end{array}$ & & & $\begin{array}{c}0.0350 * * * \\
(0.00797) \\
0.0433 * * * \\
(0.0135)\end{array}$ & $\begin{array}{c}-0.0909 * * * \\
(0.0118) \\
-0.0368 * * \\
(0.0138)\end{array}$ & & & & \\
\hline \multicolumn{9}{|l|}{ (Extreme risk-on) } \\
\hline Risk@ 0.5\% & $\begin{array}{c}0.0478 * * * \\
(0.00987)\end{array}$ & $\begin{array}{r}0.0486 * * * \\
(0.00874)\end{array}$ & $\begin{array}{c}0.0509 * * * \\
(0.0157)\end{array}$ & $\begin{array}{c}0.0309 * * * \\
(0.0114)\end{array}$ & $\begin{array}{c}0.0511 * * * \\
(0.0125)\end{array}$ & $\begin{array}{r}0.0338^{* * *} \\
(0.00814)\end{array}$ & $\begin{array}{l}0.0189 * * \\
(0.00826)\end{array}$ & $\begin{array}{c}0.00375 \\
(0.00719)\end{array}$ \\
\hline \multirow[t]{2}{*}{ Risk@1\% } & $0.0375^{* * *}$ & $0.0388 * * *$ & $0.0393^{* * *}$ & $0.0251^{* * *}$ & $0.0403^{* * *}$ & $0.0269 * * *$ & $0.0146 * *$ & 0.00337 \\
\hline & $(0.00831)$ & $(0.00736)$ & $(0.0135)$ & $(0.00934)$ & $(0.0104)$ & $(0.00674)$ & $(0.00717)$ & $(0.00623)$ \\
\hline Risk@ @\% & $\begin{array}{l}0.0235^{* * * *} \\
(0.00643)\end{array}$ & $\begin{array}{c}0.0256^{* * *} \\
(0.00568)\end{array}$ & $\begin{array}{c}0.0235^{* *} \\
(0.0109)\end{array}$ & $\begin{array}{l}0.0172 * * \\
(0.00680)\end{array}$ & $\begin{array}{c}0.0255^{* * *} \\
(0.00788)\end{array}$ & $\begin{array}{l}0.0173 * * \\
(0.00509)\end{array}$ & $\begin{array}{c}0.00862 \\
(0.00590)\end{array}$ & $\begin{array}{c}0.00285 \\
(0.00512)\end{array}$ \\
\hline Risk@ 10\% & $\begin{array}{c}0.0153^{* * *} \\
(0.00555)\end{array}$ & $\begin{array}{c}0.0179 * * * \\
(0.00490)\end{array}$ & $\begin{array}{c}0.0142 \\
(0.00952)\end{array}$ & $\begin{array}{l}0.0126^{* *} \\
(0.00558)\end{array}$ & $\begin{array}{c}0.0174 * * * \\
(0.00664)\end{array}$ & $\begin{array}{c}0.0121 * * * \\
(0.00432)\end{array}$ & $\begin{array}{c}0.00513 \\
(0.00534)\end{array}$ & $\begin{array}{c}0.00255 \\
(0.00462)\end{array}$ \\
\hline Risk@ 25\% & $\begin{array}{c}0.00688 \\
(0.00493)\end{array}$ & $\begin{array}{c}0.00996 * * \\
(0.00435)\end{array}$ & $\begin{array}{c}0.00466 \\
(0.00839)\end{array}$ & $\begin{array}{l}0.00786 * \\
(0.00474)\end{array}$ & $\begin{array}{c}0.00836 \\
(0.00566)\end{array}$ & $\begin{array}{l}0.00621^{*} \\
(0.00376)\end{array}$ & $\begin{array}{c}0.00155 \\
(0.00497)\end{array}$ & $\begin{array}{c}0.00224 \\
(0.00430)\end{array}$ \\
\hline Risk@median & $\begin{array}{l}0.000495 \\
(0.00473)\end{array}$ & $\begin{array}{c}0.00393 \\
(0.00417)\end{array}$ & $\begin{array}{l}-0.00256 \\
(0.00777)\end{array}$ & $\begin{array}{c}0.00427 \\
(0.00454)\end{array}$ & $\begin{array}{c}0.00169 \\
(0.00533)\end{array}$ & $\begin{array}{c}0.00190 \\
(0.00359)\end{array}$ & $\begin{array}{l}-0.00116 \\
(0.00486)\end{array}$ & $\begin{array}{c}0.00201 \\
(0.00420)\end{array}$ \\
\hline Risk@ $95 \%$ & $\begin{array}{l}-0.00812^{*} \\
(0.00489)\end{array}$ & $\begin{array}{l}-0.00420 \\
(0.00431)\end{array}$ & $\begin{array}{c}-0.0123^{*} \\
(0.00735)\end{array}$ & $\begin{array}{r}-0.000577 \\
(0.00493)\end{array}$ & $\begin{array}{c}-0.00723 \\
(0.00553)\end{array}$ & $\begin{array}{l}-0.00387 \\
(0.00377)\end{array}$ & $\begin{array}{c}-0.00482 \\
(0.00495)\end{array}$ & $\begin{array}{c}0.00169 \\
(0.00427)\end{array}$ \\
\hline Risk@ 90\% & $\begin{array}{c}-0.0206^{* * *} \\
(0.00586)\end{array}$ & $\begin{array}{c}-0.0160 * * * \\
(0.00518)\end{array}$ & $\begin{array}{c}-0.0265^{* * *} \\
(0.00776)\end{array}$ & $\begin{array}{c}-0.00762 \\
(0.00654)\end{array}$ & $\begin{array}{c}-0.0202^{* * *} \\
(0.00698)\end{array}$ & $\begin{array}{c}-0.0122 * * * \\
(0.00471)\end{array}$ & $\begin{array}{c}-0.0101^{*} \\
(0.00554)\end{array}$ & $\begin{array}{c}0.00123 \\
(0.00480)\end{array}$ \\
\hline Risk@ 95\% & $\begin{array}{c}-0.0293^{* * *} \\
(0.00688)\end{array}$ & $\begin{array}{c}-0.0242^{* * *} \\
(0.00609)\end{array}$ & $\begin{array}{c}-0.0363 * * * \\
(0.00866)\end{array}$ & $\begin{array}{c}-0.0125 \\
(0.00803)\end{array}$ & $\begin{array}{c}-0.0287^{* * *} \\
(0.00851)\end{array}$ & $\begin{array}{c}-0.0177^{* * *} \\
(0.00571)\end{array}$ & $\begin{array}{c}-0.0138^{* *} \\
(0.00620)\end{array}$ & $\begin{array}{l}0.000909 \\
(0.00538)\end{array}$ \\
\hline \multirow[t]{2}{*}{ Risk@ 99\% } & $-0.0666 * * *$ & $-0.0594 * * *$ & $-0.0785 * * *$ & $-0.0335 * *$ & $-0.0685 * * *$ & $-0.0435 * * *$ & $-0.0297 * * *$ & -0.000466 \\
\hline & $(0.0125)$ & $(0.0111)$ & $(0.0154)$ & $(0.0156)$ & $(0.0175)$ & $(0.0109)$ & $(0.0102)$ & $(0.00888)$ \\
\hline Risk @ 99.5\% & $-0.0894 * * *$ & $-0.0809 * * *$ & $-0.104 * * *$ & $-0.0463^{* *}$ & $-0.0923 * * *$ & $-0.0589 * * *$ & $-0.0394 * * *$ & -0.00130 \\
\hline (Extreme risk-off) & $(0.0163)$ & $(0.0145)$ & $(0.0203)$ & $(0.0204)$ & $(0.0209)$ & $(0.0140)$ & $(0.0130)$ & $(0.0114)$ \\
\hline
\end{tabular}

Notes: Table replicates the results from Tables 3 and 6 for portfolio bond and equity flows, except performs the sensitivity test listed at the top of the column. Each regression measures the MP stance using the Broad Intensity Index (our preferred measure). Columns 1 and 2 exclude the COVID window, defined as from Feb. 15, 2020 through the end of the sample. Columns 3 and 4 include a triple interaction with a dummy variable equal to one before the Global Financial Crisis (GFC), defined as starting with the collapse of Lehman Brothers. In these columns, the marginal effects are for the triple interaction between the MP Stance, Risk, and the pre-crisis dummy at each level of risk, thereby capturing any difference in this marginal effect for the later period relative to the pre-crisis window. Columns 5 and 6 include the safe haven countries (U.S., Japan, Switzerland), which are excluded from the sample in the baseline analysis. Columns 7 and 8 use the VIX instead of the RORO measure of Risk. See Table 3 for other details. All specifications include country and time fixed effects. Robust standard errors clustered by country are reported in parentheses. ${ }^{*}, * *$, and $* * *$ denote significance at the $10 \%, 5 \%$ and $1 \%$ levels, respectively. 


\section{Appendix Table F}

\section{Full Regression Results: Quarterly International Capital Flows}

\begin{tabular}{|c|c|c|c|c|c|c|c|c|}
\hline \multirow{2}{*}{$\begin{array}{r}\text { Intl Capital Flow } \\
\text { Controls }\end{array}$} & \multicolumn{2}{|c|}{ Debt } & \multicolumn{2}{|c|}{ Equity } & \multicolumn{2}{|c|}{ Bank } & \multicolumn{2}{|c|}{ Total } \\
\hline & $\begin{array}{c}\text { Macro } \\
\text { (1) }\end{array}$ & $\begin{array}{c}\text { Finance } \\
\text { (2) }\end{array}$ & $\begin{array}{c}\text { Macro } \\
\text { (3) }\end{array}$ & $\begin{array}{c}\text { Finance } \\
\text { (4) }\end{array}$ & $\begin{array}{c}\text { Macro } \\
(5)\end{array}$ & $\begin{array}{c}\text { Finance } \\
(6)\end{array}$ & $\begin{array}{c}\text { Macro } \\
\text { (7) }\end{array}$ & $\begin{array}{c}\text { Finance } \\
\text { (8) }\end{array}$ \\
\hline MP Stance & $\begin{array}{l}-0.012 \\
(0.135)\end{array}$ & $\begin{array}{l}-0.023 \\
(0.128)\end{array}$ & $\begin{array}{l}-0.037 \\
(0.158)\end{array}$ & $\begin{array}{l}-0.077 \\
(0.169)\end{array}$ & $\begin{array}{l}-0.015 \\
(0.092)\end{array}$ & $\begin{array}{l}-0.012 \\
(0.095)\end{array}$ & $\begin{array}{l}-0.040 \\
(0.042)\end{array}$ & $\begin{array}{l}-0.076 \\
(0.114)\end{array}$ \\
\hline Risk & $\begin{array}{c}0.449 \\
(0.306)\end{array}$ & $\begin{array}{c}0.644 * * * \\
(0.233)\end{array}$ & $\begin{array}{c}0.519 \\
(0.461)\end{array}$ & $\begin{array}{c}0.467 \\
(0.477)\end{array}$ & $\begin{array}{c}-0.513 * * \\
(0.252)\end{array}$ & $\begin{array}{c}-0.562 * * \\
(0.259)\end{array}$ & $\begin{array}{l}-0.056 \\
(0.119)\end{array}$ & $\begin{array}{l}-0.071 \\
(0.138)\end{array}$ \\
\hline $\begin{array}{r}\text { Interaction of } M P \\
\text { stance and risk }\end{array}$ & $\begin{array}{l}-0.294 \\
(0.189)\end{array}$ & $\begin{array}{l}-0.285 \\
(0.180)\end{array}$ & $\begin{array}{l}-0.430 \\
(0.374)\end{array}$ & $\begin{array}{l}-0.493 \\
(0.388)\end{array}$ & $\begin{array}{c}0.068 \\
(0.176) \\
\end{array}$ & $\begin{array}{c}0.087 \\
(0.187) \\
\end{array}$ & $\begin{array}{c}0.079 \\
(0.076)\end{array}$ & $\begin{array}{l}-0.012 \\
(0.130) \\
\end{array}$ \\
\hline Push/Global Variable & & & & & & & & \\
\hline $\begin{array}{l}\text { AE monetary stance } \\
\text { (change) }\end{array}$ & $\begin{array}{l}-0.150 \\
(0.241)\end{array}$ & $\begin{array}{l}-0.218 \\
(0.257)\end{array}$ & $\begin{array}{c}0.184 \\
(0.259)\end{array}$ & $\begin{array}{c}0.183 \\
(0.265)\end{array}$ & $\begin{array}{c}0.155 \\
(0.227)\end{array}$ & $\begin{array}{c}0.116 \\
(0.245)\end{array}$ & $\begin{array}{l}-0.096 * \\
(0.055)\end{array}$ & $\begin{array}{c}0.044 \\
(0.112)\end{array}$ \\
\hline $\begin{array}{l}\text { Global growth } \\
(A E I P)\end{array}$ & $\begin{array}{l}-11.508 \\
(21.632) \\
\end{array}$ & $\begin{array}{c}-2.536 \\
(19.026) \\
\end{array}$ & $\begin{array}{c}-1.059 \\
(22.579) \\
\end{array}$ & $\begin{array}{c}0.719 \\
(23.316) \\
\end{array}$ & $\begin{array}{l}-36.139 * \\
(18.741) \\
\end{array}$ & $\begin{array}{l}-36.982 * \\
(20.086) \\
\end{array}$ & $\begin{array}{c}7.602 \\
(7.890) \\
\end{array}$ & $\begin{array}{l}10.573 \\
(9.580) \\
\end{array}$ \\
\hline Pull/Domestic Variab & & & & & & & & \\
\hline $\begin{array}{l}\text { Domestic } \\
\text { growth }\end{array}$ & $\begin{array}{l}-0.017 \\
(0.034)\end{array}$ & $\begin{array}{l}-0.028 \\
(0.034)\end{array}$ & $\begin{array}{l}-0.019 \\
(0.026)\end{array}$ & $\begin{array}{l}-0.005 \\
(0.028)\end{array}$ & $\begin{array}{c}0.047 \\
(0.030)\end{array}$ & $\begin{array}{c}0.048 \\
(0.032)\end{array}$ & $\begin{array}{c}0.011 \\
(0.015)\end{array}$ & $\begin{array}{c}0.022 \\
(0.025)\end{array}$ \\
\hline $\begin{array}{l}\text { Financial } \\
\text { openness }\end{array}$ & $\begin{array}{l}0.363^{*} \\
(0.195)\end{array}$ & $\begin{array}{c}0.270 \\
(0.188)\end{array}$ & $\begin{array}{l}-0.164 \\
(0.302)\end{array}$ & $\begin{array}{l}-0.095 \\
(0.301)\end{array}$ & $\begin{array}{l}-0.090 \\
(0.195)\end{array}$ & $\begin{array}{l}-0.176 \\
(0.194)\end{array}$ & $\begin{array}{c}0.057 \\
(0.038)\end{array}$ & $\begin{array}{c}0.073 \\
(0.088)\end{array}$ \\
\hline $\begin{array}{l}\text { Institutional } \\
\text { quality }\end{array}$ & $\begin{array}{c}0.001 \\
(0.024)\end{array}$ & $\begin{array}{c}0.011 \\
(0.029)\end{array}$ & $\begin{array}{c}-0.011 \\
(0.037)\end{array}$ & $\begin{array}{l}-0.002 \\
(0.042)\end{array}$ & $\begin{array}{c}0.057 \\
(0.035)\end{array}$ & $\begin{array}{c}0.052 \\
(0.033)\end{array}$ & $\begin{array}{l}-0.010 \\
(0.018)\end{array}$ & $\begin{array}{l}-0.003 \\
(0.022)\end{array}$ \\
\hline $\begin{array}{c}\text { US interest rate } \\
\text { differential }\end{array}$ & & $\begin{array}{l}-0.033 \\
(0.046)\end{array}$ & & $\begin{array}{c}0.072 \\
(0.072)\end{array}$ & & $\begin{array}{l}-0.022 \\
(0.060)\end{array}$ & & $\begin{array}{l}-0.012 \\
(0.026)\end{array}$ \\
\hline Exchange rate & & -0.000 & & $0.000 * *$ & & 0.000 & & -0.000 \\
\hline vs. USȘ & & $(0.000)$ & & $(0.000)$ & & $(0.000)$ & & $(0.000)$ \\
\hline FX volatility & & $\begin{array}{c}0.009 \\
(0.010)\end{array}$ & & $\begin{array}{c}0.004 \\
(0.004)\end{array}$ & & $\begin{array}{c}-0.014 \\
(0.015)\end{array}$ & & $\begin{array}{c}0.001 \\
(0.001)\end{array}$ \\
\hline Constant & $\begin{array}{c}-0.573 \\
(1.767)\end{array}$ & $\begin{array}{c}-1.131 \\
(2.181)\end{array}$ & $\begin{array}{c}1.090 \\
(2.854)\end{array}$ & $\begin{array}{c}-0.022 \\
(3.324)\end{array}$ & $\begin{array}{c}-4.416^{*} \\
(2.550)\end{array}$ & $\begin{array}{c}-3.888 \\
(2.476)\end{array}$ & $\begin{array}{c}0.662 \\
(1.342)\end{array}$ & $\begin{array}{c}0.054 \\
(1.654) \\
\end{array}$ \\
\hline Observations & 2,096 & 2,031 & 2,096 & 2,031 & 2,096 & 2,031 & 2,096 & 2,031 \\
\hline \# Countries & 38 & 38 & 38 & 38 & 38 & 38 & 38 & 38 \\
\hline$R$-squared & 0.006 & 0.008 & 0.002 & 0.004 & 0.005 & 0.006 & 0.005 & 0.005 \\
\hline
\end{tabular}

Notes: Table reports the full regression results behind the subset of results in Table 8 for the international capital flows listed at the top (instead of the portfolio investor flows from the EPFR data used in most of this paper). International capital flows are the percent change in quarterly flows based on data from Forbes and Warnock (2020) and MP Stance is measured using the Broad Intensity Index. In the row at the top for Controls, "Macro" indicates the regression includes standard macro controls in capital flow regressions: AE monetary stance, global growth, domestic growth, financial openness and institutional quality and "Finance" indicates the controls also include the US interest rate differential, the US\$ exchange rate and FX volatility (as in Table 2). Each equation estimated with fixed effects and robust standard errors, clustered by country. All Pull/Domestic variables are lagged by one quarter. Each equation estimated with fixed effects 


\section{Figure 1: Measuring the Macroprudential Stance}

\section{CCyB and Aggregate Stance: Means and Medians}

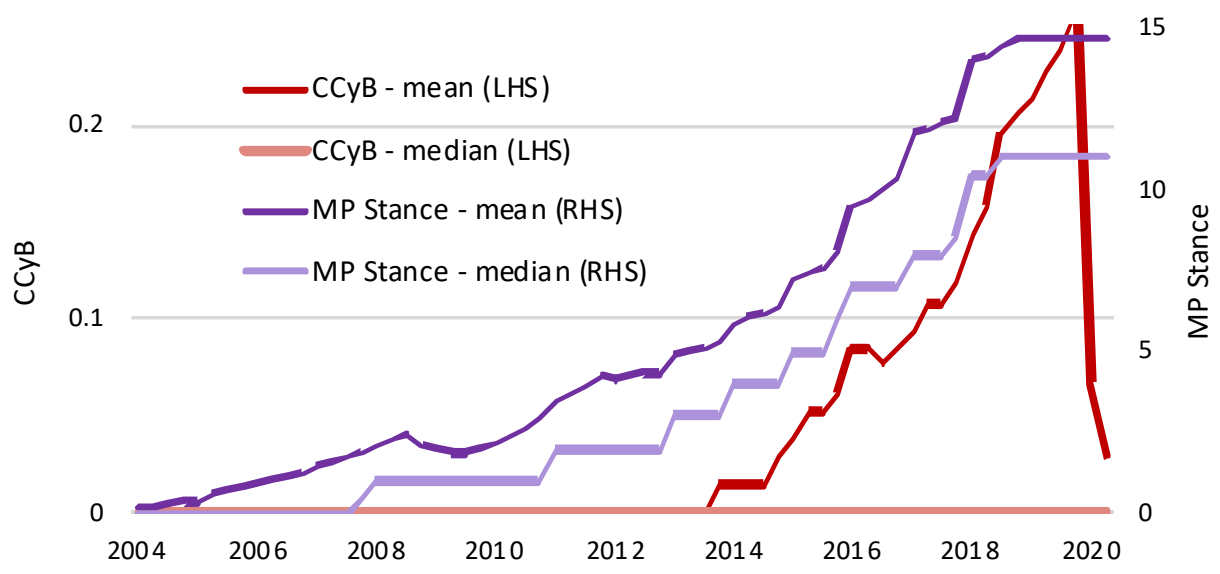

\section{Macroprudential Stance Indices and Relative Dummies}

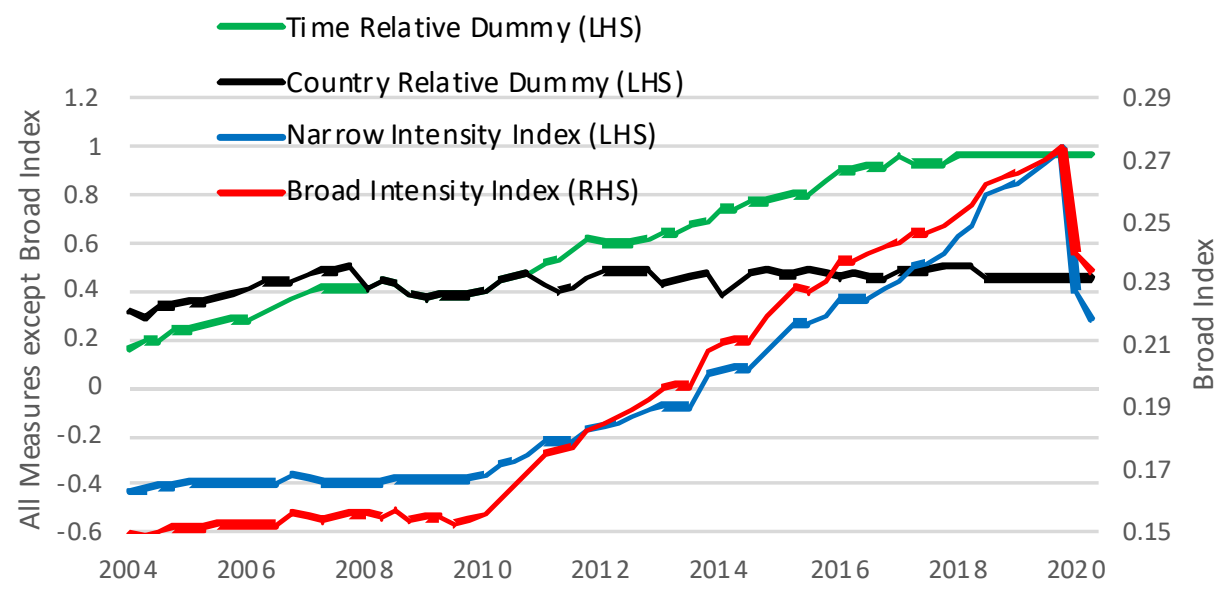

Notes: $C C y B$ is the countercyclical capital buffer. MP Stance is the sum of changes in all macroprudential measures, cumulated each quarter starting in 2000. The Broad Intensity Index is an equally-weighted index of normalized values of the CCYB, LTV ratio and FX stance, with the FX stance calculated as the cumulated sum of changes in FXrelated macroprudential regulations since 2000. The Narrow Intensity Index is the principal component of the CCyB and LTV ratio. The Country Relative Dummy is a dummy equal to one for countries with a tighter MP Stance than the sample median each quarter. The Time Relative Dummy is a dummy equal to one for countries that have an MP Stance of more than one tightening as of the given quarter (so that most of the variation in the sample is over time). All data is smoothed to quarterly frequency.

Source: CCYB data is from the BIS and ESRB, both datasets accessed as of 11/2020. The data used to calculate the MP Stance, including for the LTV and FX Stance, are from Alam et al. (2018) with data updated through 2018. 
Figure 2

RORO Measure of Risk-on/Risk-off

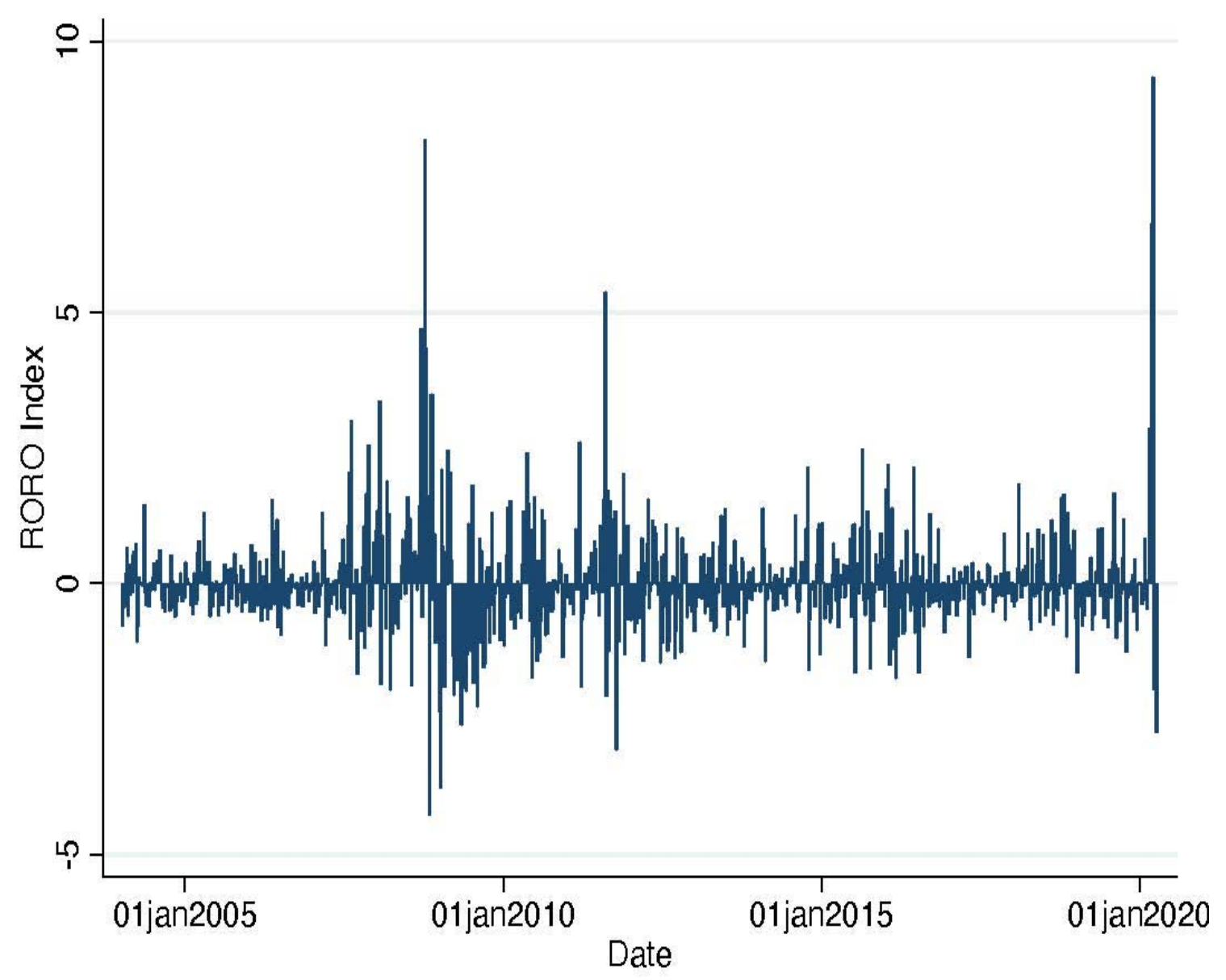

Notes: The risk-on/risk-off (RORO) index is calculated following the methodology in Chari et al. (2020). This index captures the realized variation in global investor risk appetite using the first principal component of a multi-faceted set of daily changes in several standardized asset market variables. See Section 3.2 for details on individual components. 
Figure 3: Measuring the Macroprudential Stance with Policy Shocks

Estimated Policy Shocks: Sample Means for Four Macroprudential Measures

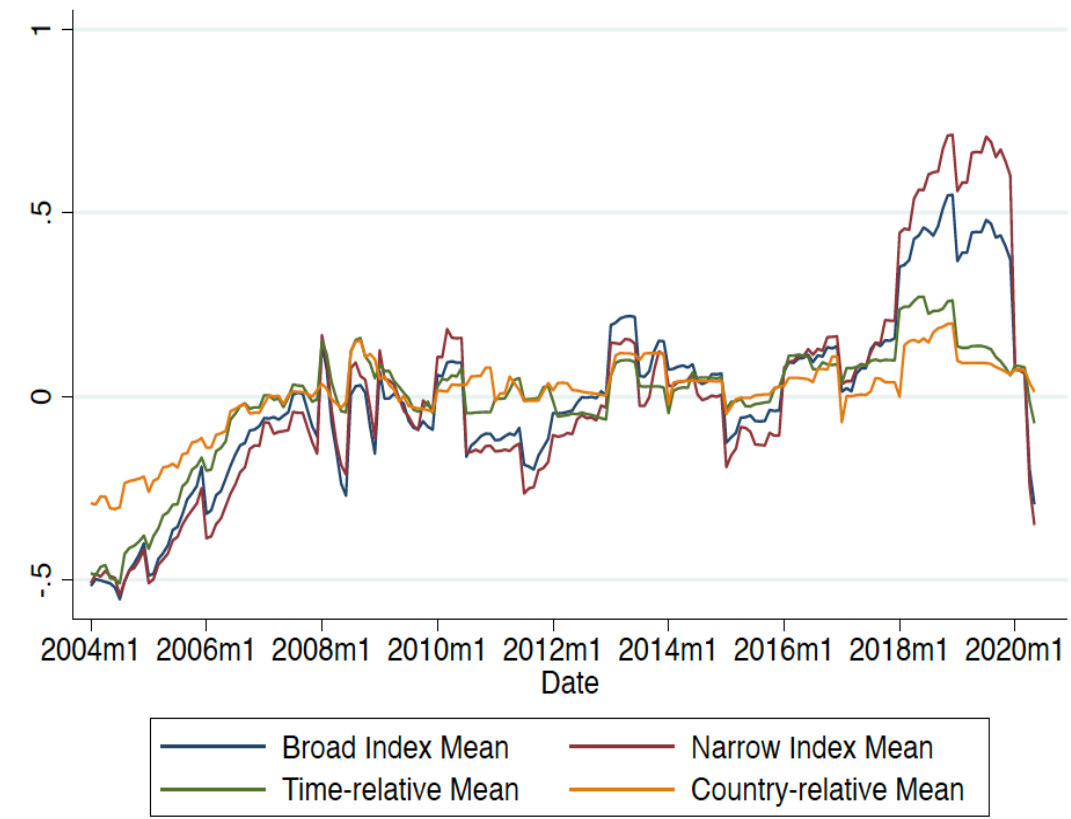

Broad Intensity Index: Additional Details

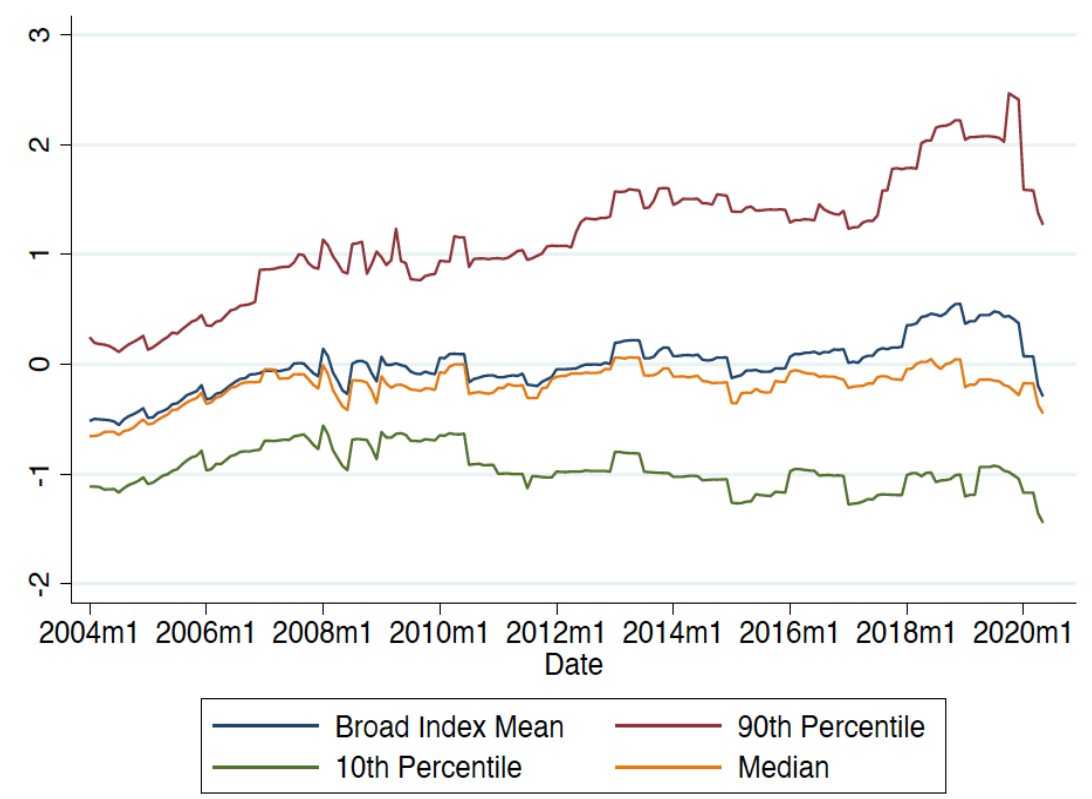

Notes: The macroprudential "shocks" are the residuals from first-stage regressions of the macroprudential stance on a large set of variables that could affect the implementation of macroprudential regulation. The Broad (Intensity) Index is an equally-weighted index of normalized values of the CCYB, LTV ratio and FX stance, with the FX stance calculated as the cumulated sum of changes in FX-related macroprudential regulations since 2000. The Narrow (Intensity) Index is the principal component of the CCYB and LTV ratios. The Country Relative measure is a dummy equal to one for countries with a tighter MP Stance than the sample median each quarter. The Time Relative measure is a dummy equal to one for countries that have an MP Stance of more than one tightening as Source: See Section 3.1 for details on the macroprudential measures and section 3.4 for details on the variables to estimate the policy shocks. See Appendix Table B underlying source data. 
Figure 4

Marginal Effects of of a Tighter Macroprudential Stance across the Risk Distribution

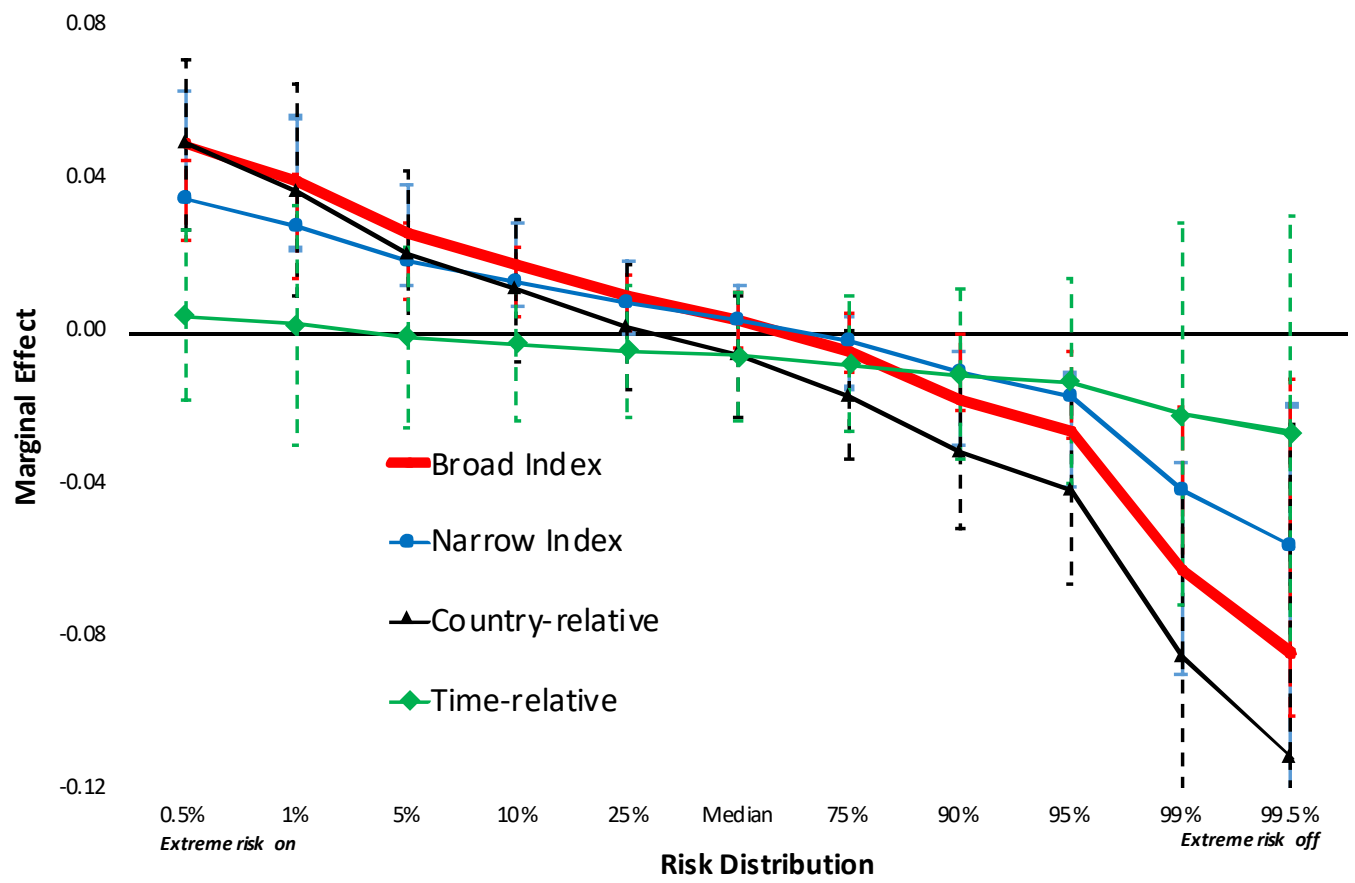

Notes: Figure shows a graphical representation of the results in Table 3 on the marginal effects of a lexrinte increase in theMP Stance when interacted withRisk at different points in theisk distribution. In each specificationRisk is measured using the RORO index, and theP Stance is measured using the estimated policy shock of one of the four macroprudential measures developed in Section 3.1. All specifications include country and time fixed effects and the control variables in Appendix Table B. Error bars correspond to $10 \%$ confidence intervals. 